\title{
The Effect of Pallet Top Deck Stiffness on the Compression Strength of Asymmetrically Supported Corrugated Boxes
}

\author{
Chandler Quesenberry
}

Thesis submitted to the faculty of the Virginia Polytechnic Institute and State University in partial fulfillment of the requirements for the degree of

Master of Science

In

Forest Products

\author{
Laszlo Horvath, Committee Chair \\ John Bouldin \\ Marshall White
}

December $11^{\text {th }}, 2019$

Blacksburg, VA

Keywords: corrugated box, box compression strength, pallet, pallet stiffness, unit load interactions 
The Effect of Pallet Top Deck Stiffness on the Compression Strength of Asymmetrically

Supported Corrugated Boxes

Chandler Blake Quesenberry

\section{ACADEMIC ABSTRACT}

During unitized shipment, the components of unit loads are interacting with each other. During floor stacking of unit loads, the load on the top of the pallet causes the top deck of the pallet to bend which creates an uneven top deck surface resulting in uneven, or asymmetrical support of the corrugated boxes. This asymmetrical support could significantly affect the strength of the corrugated boxes, and it depends on the top deck stiffness of the pallet. This study is aimed at investigating how the variations of pallet top deck stiffness and the resulting asymmetric support, affects corrugated box compression strength.

Pallet top deck stiffness was determined to have a significant effect on box compression strength. There was a $27-37 \%$ increase in box compression strength for boxes supported by high stiffness pallets in comparison to low stiffness pallets. The fact that boxes were weaker on low stiffness pallets could be explained by the uneven pressure distribution between the pallet deck and bottom layer of boxes. Pressure data showed that a higher percentage of total pressure was located under the box sidewalls that were supported on the outside stringers of low stiffness pallets in comparison to high stiffness pallets. This was disproportionately loading one side of the box.

Utilizing the effects of pallet top deck stiffness on box compression performance, a unit load cost analysis is presented showing that a stiffer pallet can be used to carry boxes with less board material; hence, it can reduce the total unit load packaging cost. 
The Effect of Pallet Top Deck Stiffness on the Compression Strength of Asymmetrically

Supported Corrugated Boxes

Chandler Blake Quesenberry

\section{GENERAL AUDIENCE ABSTRACT}

Packaged products are primarily shipped as unit loads that consist of packaged products restrained to a platform, commonly a pallet. Paying particular attention to the design of the unit loads' components is necessary to safely ship products while still maintaining low packaging costs and sustainability initiatives.

Stacking unit loads is a common practice to effectively use warehouse space, but warehouse stacking causes large amounts of weight for packaging to support. Pallets are not completely rigid and will deform because of this weight. The purpose of the study was to investigate the effect of pallet stiffness on the compression strength of corrugated boxes.

Compression tests were completed on boxes supported by pallet designs having different deck stiffnesses. The top deck stiffness of a pallet was determined to have up to a $37 \%$ effect on the strength of corrugated boxes. Pressure data recorded between the bottom layer of boxes and the top deck of the pallet showed a larger percentage of pressure was located towards the outside edges of the unit load for boxes carried by a flexible pallet. Effectively, one side of the box was stressed more than the other causing package failure.

Utilizing the effects of pallet top deck stiffness on box compression performance, a unit load cost analysis is presented showing that a stiffer pallet can be used to carry boxes with less board material; hence, it can reduce the total unit load packaging cost. 


\section{ACKNOWLEDGEMENTS}

The research was financially supported by the Industrial Affiliate Membership of the Center for Packaging and Unit Load at Virginia Tech. The corrugated material was donated by the Roanoke, VA facility of the Packaging Corporation of America. 
This thesis is dedicated to my soon to be wife Allison Hurst who has been patient and supportive throughout my academic career. Also, it is dedicated to my entire family who has taught me to be driven. 


\section{Chapter 1 Introduction}

\section{TABLE OF CONTENTS}

1.1 Introduction to pallet stiffness .................................................................................... 1

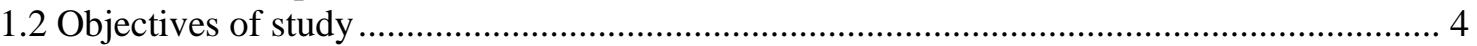

Chapter 2 Literature Review

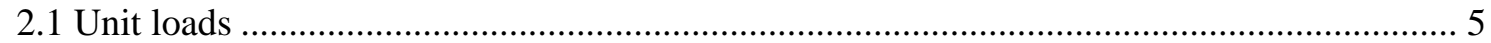

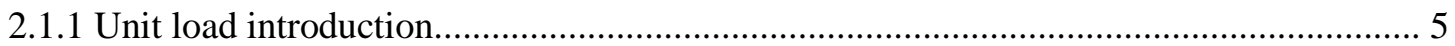

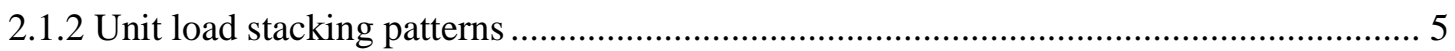

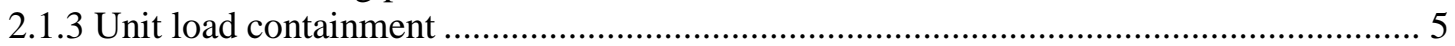

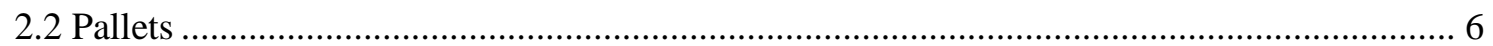

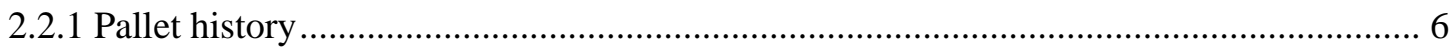

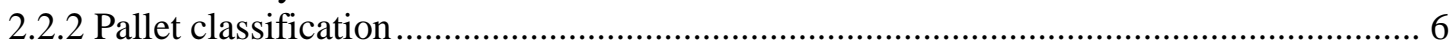

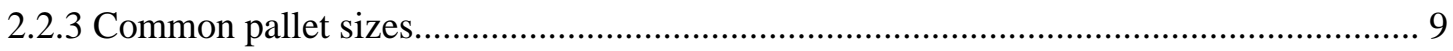

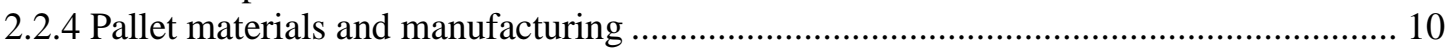

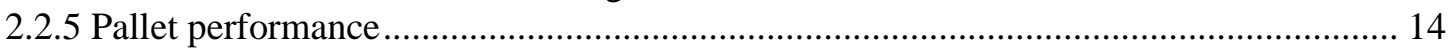

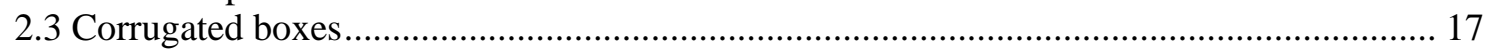

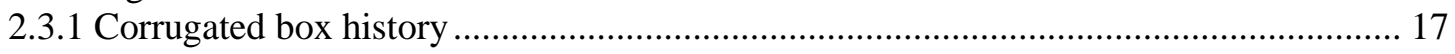

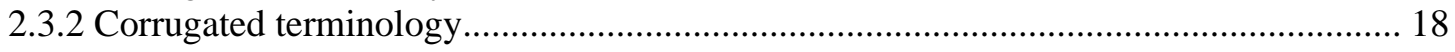

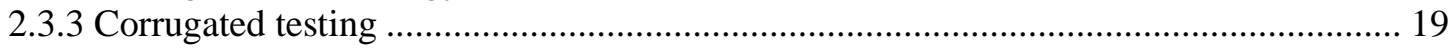

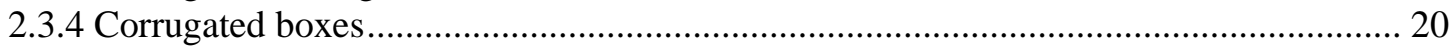

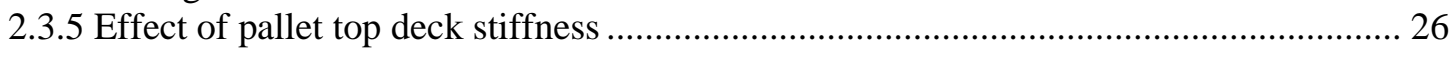

Chapter 3 Materials and Methods

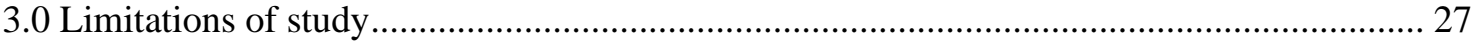

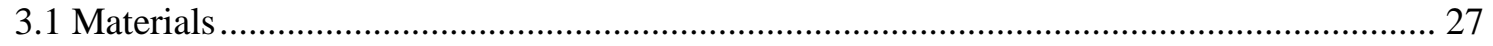

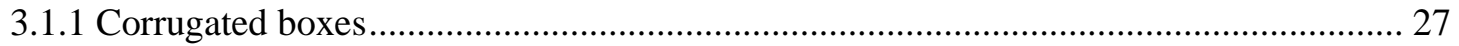

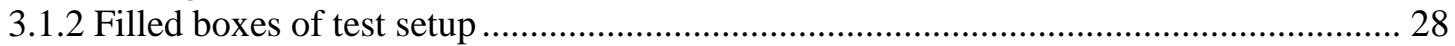

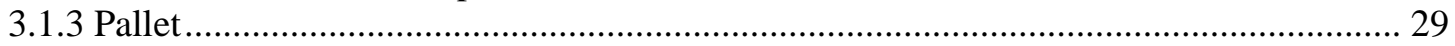

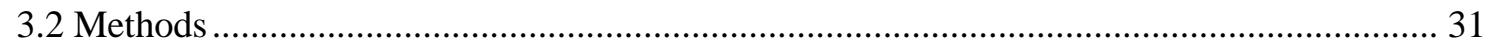

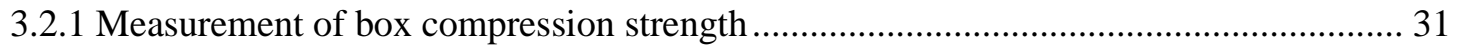

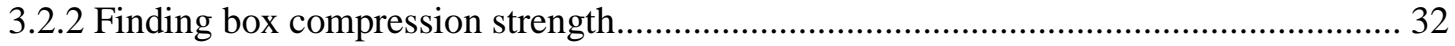

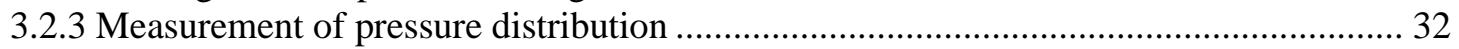

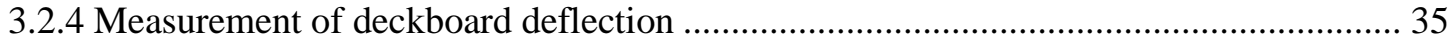

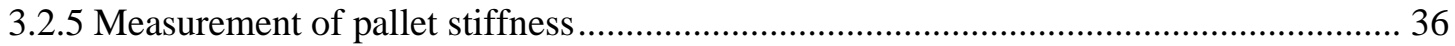

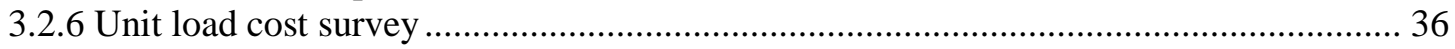

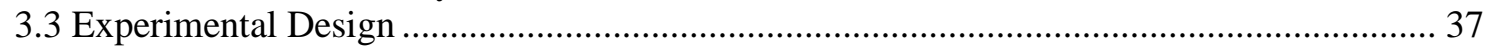

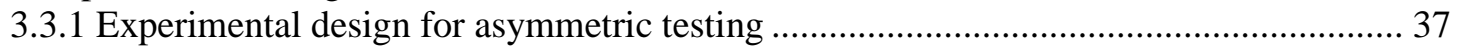

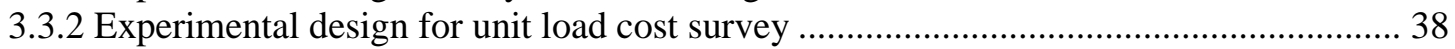

\section{Chapter 4 Results and Discussion}

4.1 The effect of top deck pallet stiffness on box compression strength................................. 39

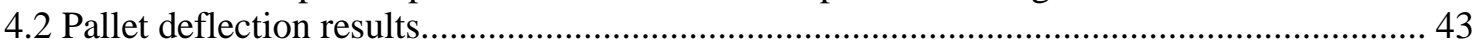

4.3 Pressure measurement results between pallet top deck and C-flute boxes.......................... 44

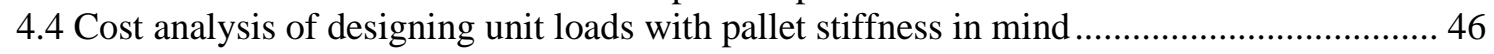

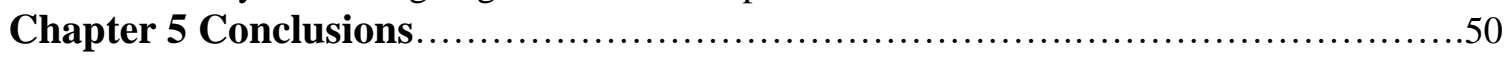

Chapter 6 Recommendations for Future Research ..............................52

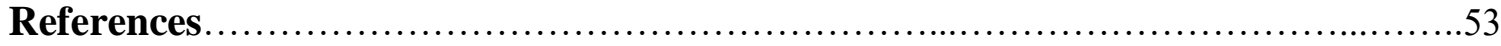

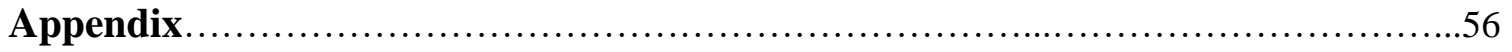




\section{List of Figures}

Figure 1 Illustration of symmetric vs. asymmetrically supported boxes. Figure 1 (A), all box corners are similarly supported. Figure 1 (B), box corners are supported differently. 2 Figure 2 Illustration of asymmetrically loaded boxes in common unit load arrangements.

Figure 3 Note: Reprinted from Baker (2016). Possible box locations on a pallet............. 3

Figure 4 Stringer vs. Block class pallets (Image generated using The Pallet Design System $\left.{ }^{\circledR}\right)$

Figure 5 Stringer placement: Flush, single wing, double wing (Image generated using

The Pallet Design System $\left.{ }^{\circledR}\right)$.......................................................................................... 8

Figure 6 Reprinted. Common species of wood by region (Park 2015)......................... 11

Figure 7 Reprinted. Rubber stoppers to increase surface friction (ANSI MH1, 2016) ... 12

Figure 8 Supply chain support conditions and pallet reactions. .................................... 15

Figure 9 Top deck deflection of a floor stacked pallet. " $w "=$ loading, " $L "=$ span and " $\delta "$

$=$ deflection.

Figure 10 Structure of a single face corrugated board............................................... 17

Figure 11 Single and double wall example............................................................. 18

Figure 12 Direction of loading during the Edge Crush Test (ECT) ................................ 19

Figure 13 Direction of loading during Flat Crush Test (FTC)…………....................... 20

Figure 14 Reprinted. Four-point bending test (TAPPI T820)...................................... 20

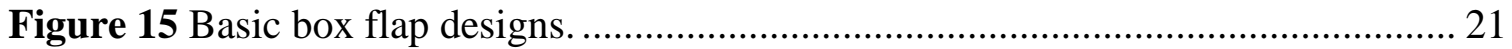

Figure 16 Box compressive test direction of loading. ............................................ 21

Figure 17 Illustration of an overhanging box........................................................ 24

Figure 18 Note. Reprinted from Baker 2016. Box locations A and C are symmetrically

loaded while location B is asymmetrically loaded. ……………………………….... 25

Figure 19 Illustration of symmetric and asymmetrically supported boxes on a flexible

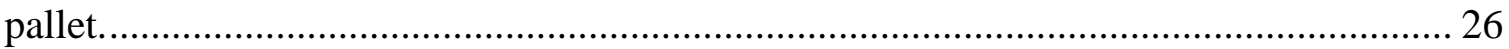

Figure 20 Illustration of asymmetrically loaded boxes in common unit load

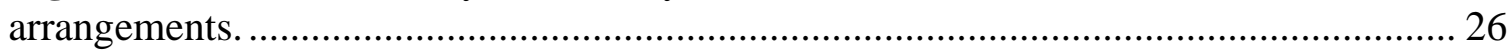

Figure 21 Experimental setup for box compression testing......................................... 28

Figure 22 Graphical representation of the loading and the method of box weight consolidation.

Figure 23 Depiction of 48 in. $x 40$ in. GMA Pallet (image generated using The Pallet

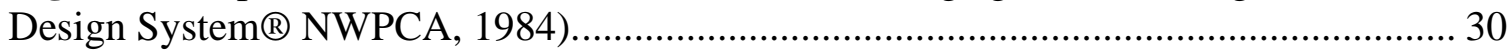

Figure 24 Overall and component sizes of the 28 in. $\mathrm{x} 20$ in. pallet sections.................. 31

Figure 25 Length sidewall buckling of box (A), load vs. deflection curve of compression test (B).

Figure 26 In the top left image, $1.5 \mathrm{in}$. zones were created that included the length sidewalls of the corrugated box. Individual pressures found in a zone (top right image) were summed and divided by the total mat pressure. The percentage of total compressive pressure in a zone (bottom image) was compared between low and high stiffness pallets.

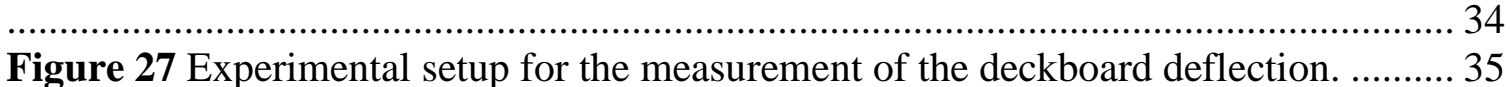

Figure 28 Deflection measurement locations................................................................. 36

Figure 29 Experimental setup for measuring pallet stiffness.......................................... 36 
Figure 30 Observed compression strengths of all replicates from four box types in

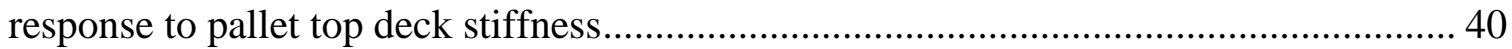

Figure 31 Observed compression strengths separated by flute size in response to pallet top deck stiffness.

Figure 32 Average box compression strength of asymmetrically supported boxes supported on pallets with different top deck stiffnesses .......................................... 41

Figure 33 Low stiffness pallet deflection at box failure (left), medium-high stiffness pallet deflection at box failure (right)....

Figure 34 Locations of box sidewalls and resulting load transfer (LS - Left Stringer, MSMidspan, RS - Right Stringer).

Figure 35 Pressure distribution for the small size C-flute corrugated boxes on pallets

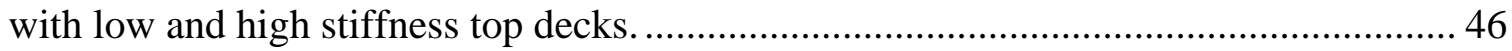
Figure 36 Pressure distribution for the large size C-flute corrugated boxes on pallets with low and high stiffness top decks.

\section{List of Tables}

Table 1 ISO 6780 Recognized regional pallet sizes. 9

Table 22016 newly produced pallet market share by size (Gerber) .............................. 9

Table 3 Corrugated flute sizes.............................................................................. 18

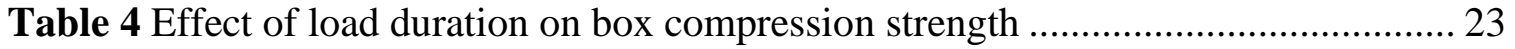

Table 5 Average performance characteristics of corrugated board used. ...................... 28

Table 6 Summary table of actual weights in the loaded top boxes................................ 29

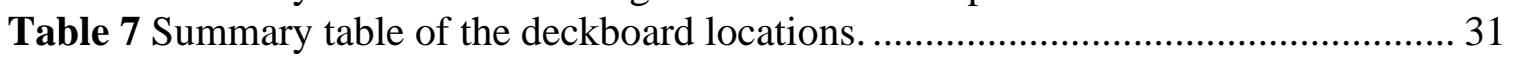

Table 8 Experimental design of project. .................................................................. 37

Table 9 Average box compression strength of asymmetrically supported corrugated boxes supported on pallets with different top deck stiffnesses.................................... 39

Table 10 Average compression strength of all box types when supported on pallets with

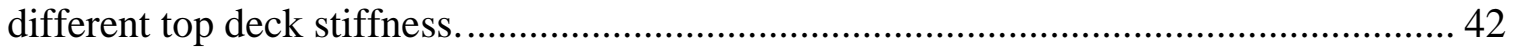

Table 11 Average bending performance of pallet sections....................................... 43

Table 12 Results of average total pressure above the pallet stringers and the midspan of

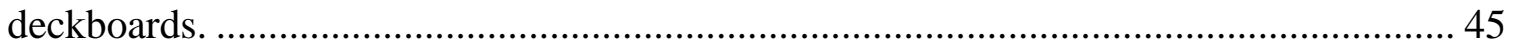

Table 13 Average quoted costs for unit load components .......................................... 47

Table 14 Average unit load costs of multiple unit load designs. .................................. 48

Table 15 ANOVA results for the effect of pallet top deck stiffness on box compression

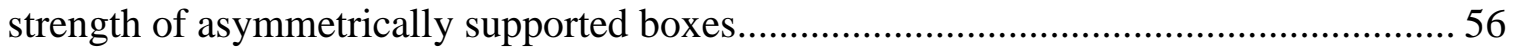

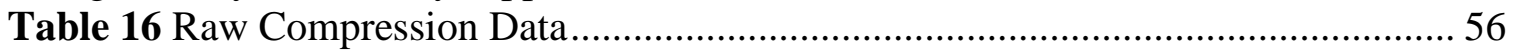

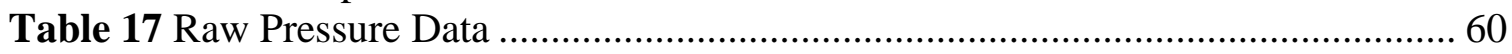

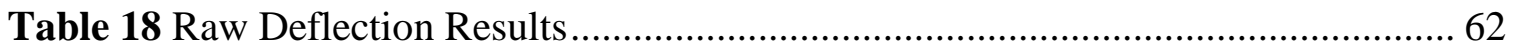




\section{Chapter 1 - Introduction}

\subsection{Introduction to pallet stiffness}

Most packaged goods are transported in the form of a unit load. A unit load consists of restrained units; either a single item, multiple items, or a bulk material (White \& Hamner, 2005) which allows for safe warehousing, transporting, and handling of products using a pallet or slipsheet. An estimated 508 million new wooden pallets were produced in 2016 (Gerber, 2018).

American National Standards Institute's (ANSI) material handling committee defines a pallet as "a portable, horizontal, rigid, composite platform used as a base for assembling, storing, stacking, handling, and transporting goods as a unit load" (ANSI MH1, 2016). Pallets, by this definition, are assumed to be a rigid platform. Inherently, in the design and use of pallets, bending will occur, resulting in a deformable platform rather than a rigid platform.

The amount of bending experienced by the pallet components, or pallet deflection, can be controlled during the design of the pallet. For example, using thicker top deckboards will result in a stiffer pallet deck. Further, altering the species of lumber, or how many stringers are in the design, can have a similar effect. Changing these aspects of the pallet design changes the mechanical behavior of the pallet, but it also affects the purchase price. The pallet's price is the most important factor when selecting a pallet design for Modern Materials Handling subscribers (McCrea, 2017). Using thinner pallet components reduce the initial pallet price because less material is used. Yet, the stiffness of the pallet design is dependent on these component thicknesses. A variety of pallet top deck stiffnesses are available ranging from a thin, flexible top deck ( 0.375 in. deckboards) to a thick, rigid top deck ( 0.75 in. deckboards). Since pallets carry packaged products, the performance of these packages could be affected by the different levels of pallet stiffnesses similar to how corrugated boxes are affected by other unit load factors.

Corrugated boxes are commonly stacked during warehousing and transportation; therefore, the compression strength of a box is important. Boxes should provide enough vertical compression strength to support the stacking weight that the box might encounter, otherwise package failure will occur. Many studies have investigated how box compression strength is affected by pallets. Pallet factors such as the vertical alignment of boxes in a stack (Kellicut, 1963; Ievans, 1975; Singh, Singh, \& Saha, 2011a), what pallet stacking pattern is used (Kellicut, 1963; Ievans, 1975), the deckboard gaps in a pallet, and overhanging box corners (Ievans, 1975; Monaghan \& Marcondes, 1992; DiSalvo, 1999; Baker, 2016) have all been studied. Yet, there has 
been a limited number of studies investigating the effect of pallet stiffness on box compression strength.

Baker, and later Phanthanousy, concluded that box compression strength is not affected by top deckboard stiffness when there are deckboard gaps in a pallet design (Baker, 2016; Phanthanousy, 2017). Conversely, pallet stiffness for solid top deck pallets affects box compression strength (Baker, 2016). Both Baker and Phanthanousy's experiments were completed using symmetrically supported boxes. Box symmetry refers to how the corners of a box are supported. Symmetrical support is when all four corners of the box are supported in a similar manner. Asymmetric box support means at least one of the four corners is supported differently from the others. Figure 1 (B) shows an asymmetrically supported box where two of the box corners are over the deflecting span of the top deckboard, while the other two corners are supported by the pallet's stringer where minimal deflection will occur. This creates a surface with unequal supports beneath the box corners.

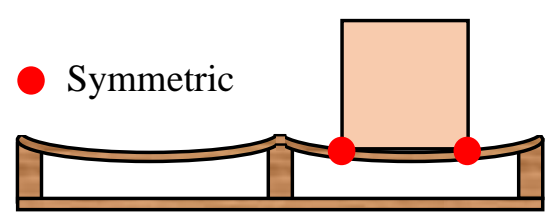

A

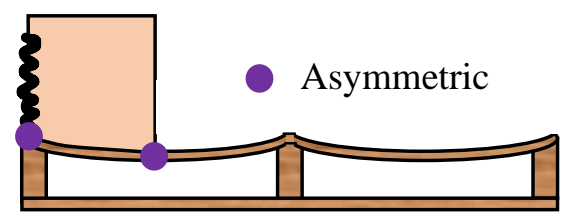

B

Figure 1 Illustration of symmetric vs. asymmetrically supported boxes. Figure 1 (A), all box corners are similarly supported. Figure 1 (B), box corners are supported differently.

Corrugated boxes are supported symmetrically and asymmetrically in a unit load because boxes are placed everywhere on a pallet to effectively use the top deck area. The relevance of the asymmetric location in common unit load configurations can be seen in Figure 2.
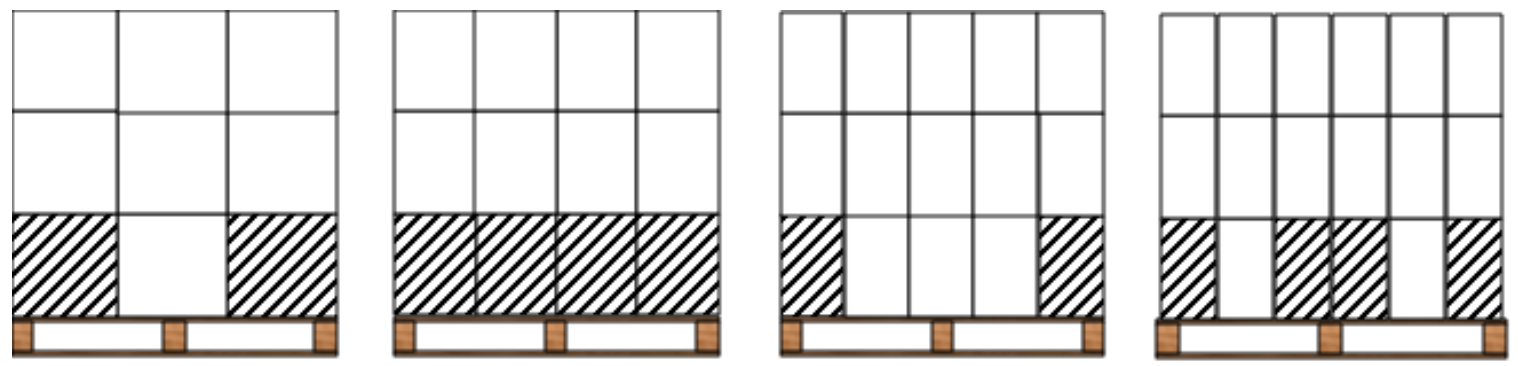

Figure 2 Illustration of asymmetrically loaded boxes in common unit load arrangements. 
An additional study was conducted by Baker to see if box location on a pallet had an effect on box compression strength (Baker, 2016) (Figure 3). Three locations were investigated (two symmetric and one asymmetric). It was found that an asymmetrically loaded box (Figure 3 B), box corners with different support conditions, was $15 \%$ weaker than boxes in other locations (Figure $3 \mathrm{~A}, \mathrm{~B}$ ) on a low stiffness pallet with no deckboard gaps. This difference in compression strength can be attributed to how a box is stressed on a low stiffness pallet. There are higher box stress concentrations located in boxes near the ends of pallet deckboards (Yoo, 2011). These pallets create a surface with uneven stresses for boxes and ultimately stress one side of the box more than the other.

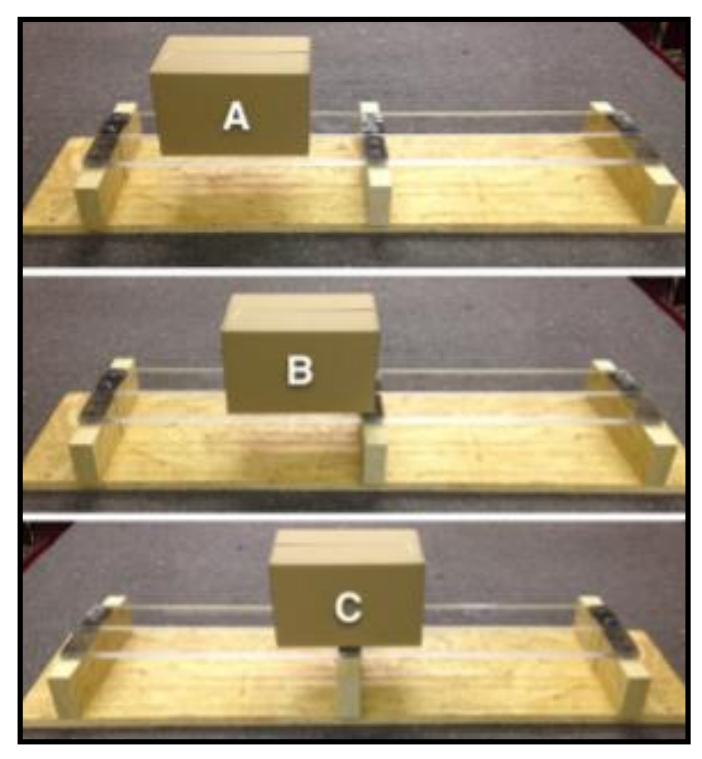

Figure 3 Note: Reprinted from Baker (2016). Possible box locations on a pallet.

Corrugated boxes are designed to support maximum compression. Maximum compression is on the bottom layer of a unit load due to the higher compressive forces from stacking (Frank, 2014). Furthermore, the asymmetric position is the weakest location within the bottom layer on a flexible pallet (Baker, 2016), but there are a lack of studies investigating how the level of top deck stiffness affects box compression strength in this location. An array of pallet designs are available; they use different structures, component sizes, and species of lumber which all affect the level of top deck stiffness. Better understanding about how different top deck stiffnesses affect box performance will be useful in determining an efficient box design. Therefore, the goal of this study was to investigate the effect of pallet top deck stiffness on the box compression strength of asymmetrically supported boxes. 


\subsection{Objectives of study}

The objectives of the project are as follows:

- Investigate the effect of pallet top deck stiffness on the compression strength of asymmetrically supported corrugated boxes.

- Evaluate the change in unit load packaging cost as a function of various top deck thicknesses. 


\section{Chapter 2 - Literature Review}

\subsection{Unit Loads}

\subsubsection{Unit load introduction}

A unit load refers to multiple packaging components acting as one unit which allows for safe warehousing, transporting and handling of products between locations. A unit load consists of restrained units: either a single item, multiple items or a bulk material (White and Hamner, 2005). Boxes, barrels or other containers that encompass products are restrained to a pallet or restrained to other containers on a pallet and form a singular unit. This is the most common method of moving packaged goods in the U.S. where $80 \%$ of packaged goods are shipped on pallets (Raballand and Aldaz-Carroll, 2007).

\subsubsection{Unit load stacking patterns}

The layout of boxes or packages within a unit load are referred to as stacking patterns. Software such as CAPE Pack, TOPS or BestLoad ${ }^{\mathrm{TM}}$ can produce stacking patterns for a specific pallet to efficiently use the pallet area. Column stacking, interlocking and pinwheel layouts are popular patterns. Column stacking vertically aligns boxes and layers while an interlocking pattern rotates adjacent layers 90 or 180 degrees. Interlocking packages provides more unit load stability while column stacking provides more vertical compression strength (Laundrie, 1986). Unit load stability is essential to ensure that the unit load survives distribution events such as truck braking, railcar coupling or forklift handling while compression strength is needed for warehouse and truck stacking.

\subsubsection{Unit load containment}

Along with interlocking stacks, additional methods are used to prevent movement of products in distribution. Antiskid treatments are designed to increase friction between packages to restrict movement (Laundrie, 1986). High shear and low tension adhesives serve this purpose. An alternative method to increase friction is placing a pallet sized corrugated sheet (often referred to as a tier sheet or anti slip sheet) between unit load layers. A tier sheet is often treated to have high surface friction. Also, strapping a unit load with steel or plastic straps, provide compressive forces that causes the individual layers and columns within a unit load to act similar to a single unit. Another solution to containing unit loads is using plastic film; Linear Low-density polyethylene (LLDPE) is often used (Laundrie, 1986; Coles, McDowell and Kirwan, 2003). 
Plastic film can be applied to a unit load two different ways: using a shrink hood, stretch hood or stretch wrapping. Using a shrink hood involves a unit load size hood that covers the entire unit load. Then, heat is applied by a hand tool or hood to shrink the plastic to compress the packages and pallet (Laundrie, 1986). Finally, stretch wrapping a unit load with plastic film involves stretching the film and applying the film under tension forces. This can be done manually or by machine (Singh, Cernokus, Saha, \& Roy, 2014). Both methods provide compressive forces to restrict movement of products.

\subsection{Pallets}

\subsubsection{Pallet history}

The material handling committee of the American National Standards Institute (ANSI) defines a pallet as "a portable, horizontal, rigid, composite platform used as a base for assembling, storing, stacking, handling, and transporting goods as a unit load" (ANSI MH1, 2016). A pallet provides a cheap, efficient solution to ship a multitude of products at once. World War II provided an influential point in pallet history where efficiency in logistics became a necessity to meet the war demand for food and supplies (Twede, Selke, Kamdem, \& Shires, 2015). After the war, pallets became a logistical solution for civilian uses to help businesses reduce shipping costs. Now, pallets are even more popular. In 2016 alone, there were 508 million newly produced wooden pallets in addition to 341 million recycled and remanufactured pallets within the U.S. (Gerber, 2018).

\subsubsection{Pallet classification}

Pallets can be classified by their end usage, type, style, class and bottom deck construction to differentiate between pallet designs (ANSI MH1, 2016).

\section{Classification of Pallets: Classes}

Wooden pallets are classified as either a stringer class or block class pallet based on their components (Figure 4). Both classes contain deckboards either placed on the top and/or bottom of a pallet. A deckboard is an element of a pallet deck perpendicular to stringers or stringer boards that interfaces with products (ANSI MH1, 2016). A stringer is the wooden beam between top and bottom deckboards. Stringers are commonly manufactured from actual 3.5in. x 1.5in. (nominal $2 \times 4 s$ ) beams and are cut to the needed length of a pallet. The stringer height determines the spacing between the deckboards and restricts pallet openings to that height (ANSI MH1, 2016). Consequently, pallet openings are commonly 3.5 in. due to the height of the stringer. 
In a block class pallet, there are usually nine blocks that are tied together by stringer boards. Stringer boards are located between blocks and deckboards within block pallets (Figure 4) and tie the two components together (ANSI MH1, 2016). Major pallet pooling companies such as CHEP (Commonwealth Handling Equipment Pool) or PECO (Pallet Exchange Company) mostly use block pallets due to their durable design.

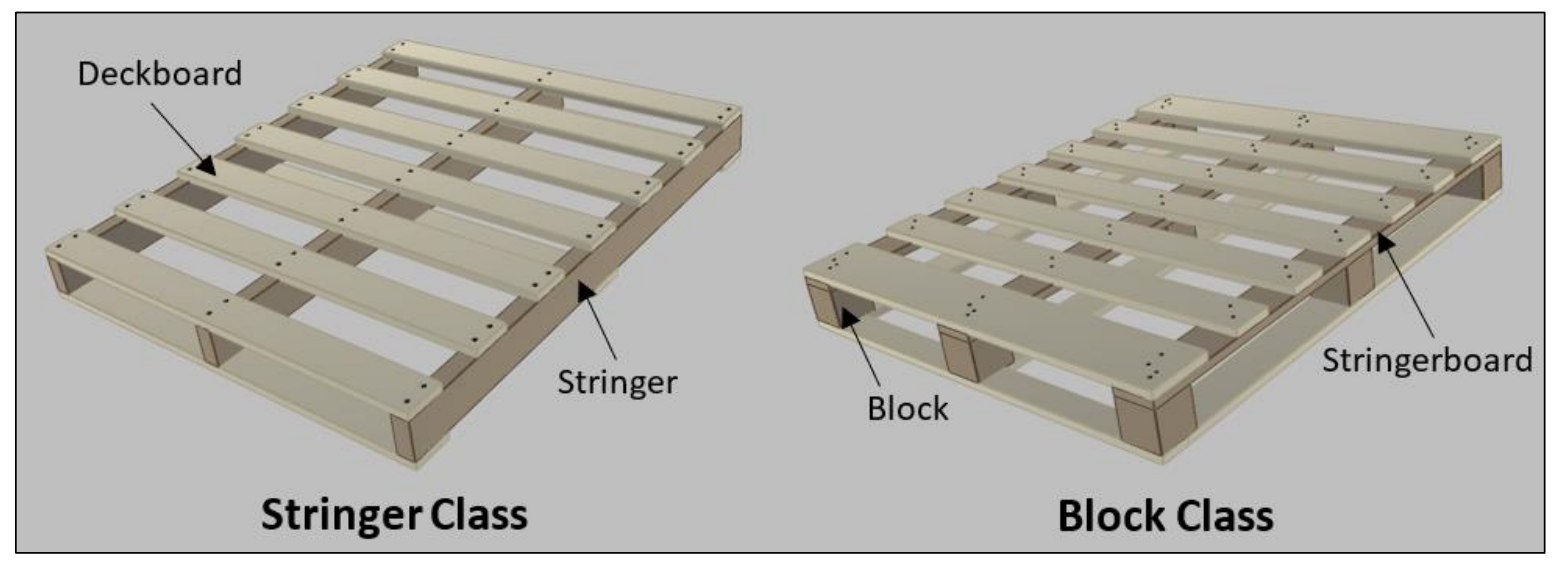

Figure 4 Stringer vs. Block class pallets (Image generated using The Pallet Design System $\left.{ }^{\circledR}\right)$

\section{Classification of Pallets: Styles}

There are three pallet styles: Single-face, reversible double-face and non-reversible double-face (NWPCA, 2014). Classifying the style depends on the surfaces of the pallet. Deckboards only forming one surface is a single-face pallet. Deckboards located on the top and bottom of the pallet classifies the pallet as a double-face pallet (Forest Service, 1971). A doubleface pallet is reversible when the top and bottom of the pallet cannot be distinguished, and product can be stored and handled on both surfaces. In contrast, a non-reversible double-face pallet, as seen in Figure 4, has many top deckboards that can interface with products on one face and less bottom deckboards on the opposite face.

\section{Classification of Pallets: Types}

Pallets can further be classified as a 2-way, partial 4-way or full 4-way design. This classification is based on the number of sides available for entry by forklift and pallet jacks (Forest Service, 1971). A solid stringer beam would prevent access from the side of the pallet; therefore, it is classified as a 2-way pallet. A partial 4-way pallet has notches cut out of the stringer. The notches only allow forktine access to the length side of the pallet and bars entry from pallet jacks due to pallet jacks having thicker tines. 
A block pallet has full 4-way access for both pallet jacks and forklifts. This full accessibility is made possible by having blocks instead of stringers, so there is no obstruction for entry.

\section{Classification of Pallets: Bottom Deck Construction}

Pallets with bottom deckboards that are parallel with the pallet length only or width only are classified as having a unidirectional base. While a perimeter-based pallet has bottom deckboards in both the length and width directions. The third bottom deck construction is similar to perimeter based but has the addition of connector boards that form a cross shape in the middle of the pallet. This bottom deck construction is classified as a cruciform base. Finally, a pallet can be classified as having overlapping bottom deckboards when bottom stringerboards are in between blocks and bottom deckboards (NWPCA, 2014).

\section{Classification of Pallets: Top Deck Construction}

A pallet can also be classified from the outer stringer placement. If the stringers are flush (Figure 5) with the end of top and bottom deckboards, then the pallet is classified as flush (Forest Service, 1971). When the outer stringers are located inward from the end of the pallet deckboards, then the pallet is winged. A single wing pallet has top non-flush deckboards and a double wing pallet has top and bottom non-flush deckboards.

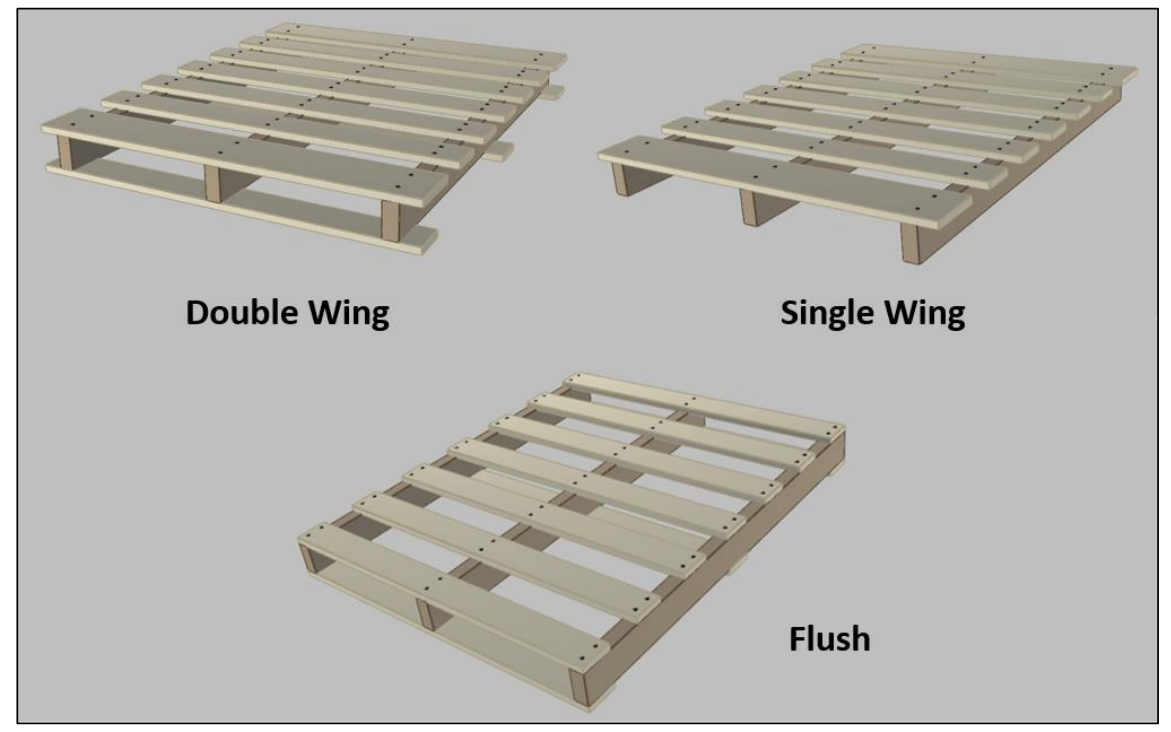

Figure 5 Stringer placement: Flush, single wing, double wing (Image generated using The Pallet Design System ${ }^{\circledR}$ )

\section{Classification of Pallets: Usage}


Pallets can further be classified based on their intended usages. There are two use categories for pallets: reusable and single-use. American National Standards Institute's Material Handling committee defines a reusable pallet as being "intended for more than one unit load", while a single-use pallet "is intended to be loaded once for one unit trip" (ANSI MH1, 2016).

\subsubsection{Common pallet sizes}

A pallet's overall length is determined by the length of the stringer or stringer board and the perpendicular direction becomes the width (NWPCA, 2014). For example, a pallet with a 48" stringer beam will have a pallet length of 48 ". Varying industries and different material handling infrastructures make it difficult to develop a standardized one-size fits all pallet. Instead, certain pallet sizes better fit geographic areas (Table 1) than others do. International Organization for Standardization (ISO) 6780 - Flat pallets for intercontinental materials handling lists six common pallet sizes used by different regions across the world.

Table 1 ISO 6780 Recognized regional pallet sizes

\begin{tabular}{c|c|c}
\hline Dimensions (mm) & Dimensions (in.) & Region \\
\hline $1219 \times 1016$ & $48 \times 40$ & North America \\
$1200 \times 1000$ & $47.24 \times 39.37$ & Europe, Asia \\
$1165 \times 1165$ & $45.90 \times 45.90$ & Australia \\
$1067 \times 1067$ & $42 \times 42$ & North America, Europe, Asia \\
$1100 \times 1100$ & $43.30 \times 43.30$ & Asia \\
$1200 \times 800$ & $47.24 \times 31.50$ & Europe
\end{tabular}

In addition to accommodating a region's infrastructure, pallet sizes are standardized to a specific industry based on a common product's specifications. For example, a 48 in. x 48 in. pallet is used by the chemical industry (Gerber, 2018) since that size pallet is an efficient fit for chemical drums. The grocery industry uses a 48 in. $x 40$ in. sized pallet which is the most common sized pallet manufactured in the U.S. (Gerber, 2018). This pallet size had a $35 \%$ share of the annual wooden pallet production as of 2016 (Table 2).

Table 22016 newly produced pallet market share by size (Gerber)

\begin{tabular}{c|c|c}
\hline Use & Pallet size (in.) & Share of annual production (\%) \\
\hline Grocery & $48 \times 40$ & 35 \\
Drums & $48 \times 48$ & 6 \\
Chemical & $42 \times 42$ & 5 \\
Automotive & $48 \times 45$ & 5 \\
Military & $40 \times 48$ & 4 \\
Chemical, Beverage & $48 \times 42$ & 3 \\
Other sizes & Various & 42
\end{tabular}




\subsubsection{Pallet materials and manufacturing}

\section{Wood Pallets}

Wood is the dominant material in the pallet market with $93 \%$ of companies using wooden pallets in 2017 (McCrea, 2017). Wooden pallets are popular because they are relatively inexpensive and are easily customized. (Leblanc and Richardson, 2003). A pallet can easily be manufactured to a specific need. For example, the location, thickness, and number of deckboards of a pallet can be adjusted during manufacturing. Pallet customization is useful to better fit the packages they carry. Also, wood is commonly used because it has strong static and dynamic loadbearing properties for the price (Leblanc and Richardson, 2003). At the end of a pallet's use, it can be recycled (Leblanc and Richardson, 2003) where a recycler can collect the pallets and repair a broken component and sell it again for more uses.

Even though wood is very practical to use as a material, it has drawbacks. Wood is an orthotropic material which means it has varying mechanical properties in different directions. Constructing a pallet out of a wood results in variability between seemingly identical pallets. Also, wood pallets can allow mold growth and can splinter, making it unsuitable for use in many food and pharmaceutical applications.

Wooden pallets are constructed from either softwood or hardwood lumber. There are different species of trees within the classes of softwoods and hardwoods. Depending on the geographic region, different species are available. Since wood pallets are a low-cost product, lumber is usually only purchased regionally from suppliers. Therefore, pallet manufacturers are constricted by what species are available in the region (Figure 6). Pallet performance will further differ between which species is selected because strength and stiffness properties vary between species (Kretschmann, 2010). 


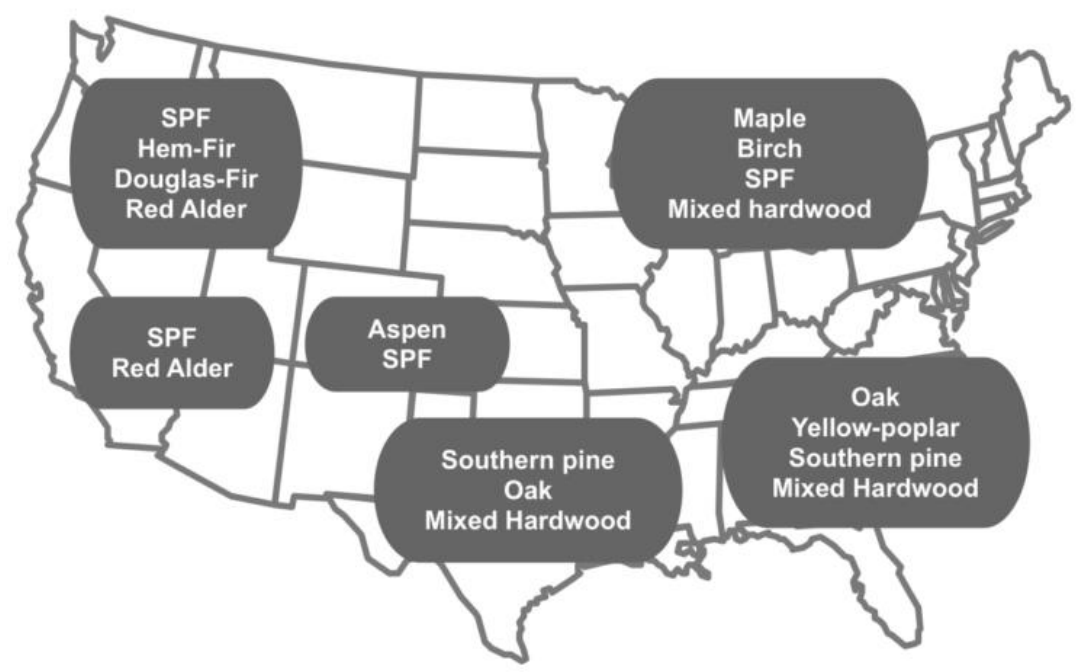

Figure 6 Reprinted. Common species of wood by region (Park 2015)

Strength is also dependent on the moisture content of the wood. Moisture content is the percentage of the weight of water by the weight of ovendry wood (Forest Products Laboratory, 2010). Shrinkage or swelling of wood occurs when water leaves or enters the wood; dimensions are never truly fixed for green wood, or wood that has not been dried. A hardwood pallet is particularly prone to mold growth due to the use of green lumber. If mold is a concern, a softwood pallet should be used. Softwood lumber is often purchased kiln-dried, which is the process of conditioning the wood in a large oven for a period of time until the moisture content falls below $20 \%$.

The pallet industry constructs wooden pallets from the lowest grade of lumber available because that is the least expensive lumber. Lower grades refer to lumber being cut from the weakest part of the tree or lumber with numerous knots, checks or splitting. The National Wooden Pallet and Container Association (NWPCA) provides a minimum lumber quality requirement for the lumber used in pallet manufacturing. It limits the amount knots, splits or decay that can be found in a pallet component (NWPCA, 2014).

The wooden pallet manufacturing process is similar throughout suppliers. Carrano et al stated that pallet manufactures followed the same general steps in manufacturing a new wooden pallet. The manufacturer cuts and dimensions components, kiln dries the components, assembles the components and then heat treats the pallet (Carrano, Thorn and Woltang, 2014).

Pallet manufacturing can be broken down by the amount of automation used in the assembly process. A pallet is either manually, semi-automatically, or automatically assembled. 
Prior to the mid 1950's, pallet manufacturing was limited to manually nailing pallet components together on a table until pneumatic hammers and pallet assembly machines were introduced (Leblanc and Richardson, 2003). Due to the high demand for pallets, the industry developed a machine that automatically feeds and places components for nailing (Leblanc and Richardson, 2003). To assemble a wooden pallet, it was found that it takes around two minutes per pallet for a manual process with one operator, one and one-half minutes per pallet with a semi-automatic machine and between one-half to one minutes per pallet for a fully automatic assembly machine (Carrano, Thorn and Woltang, 2014).

\section{Plastic Pallets}

Plastic is typically a more uniform material than wood. In 2017, $45 \%$ of companies surveyed by Modern Materials Handling used plastic pallets (McCrea, 2017). Plastic pallets can either be manufactured from recycled material, virgin material or a combination of both. Virgin material has not been used or processed prior to manufacturing (ANSI MH1, 2016). Having higher virgin content will increase the cost of a pallet. Yet, having more recycled plastic will decrease the strength and durability of the pallet. Also, surface friction is a concern for plastic pallet users due to plastic's smooth surface where packages might slide in distribution. Pallet manufacturers mitigate friction concerns by placing rubber pucks or coatings on the top deck (Figure 7) to prevent sliding of boxes (ANSI MH1, 2016).

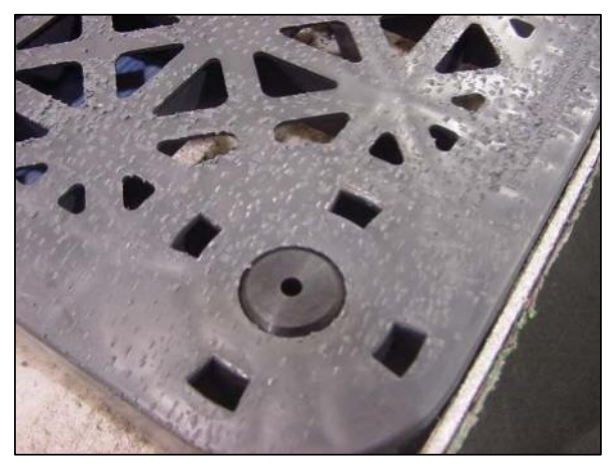

Figure 7 Reprinted. Rubber stoppers to increase surface friction (ANSI MH1, 2016)

Plastic pallets may have higher durability than wooden pallets and offer a long service life. A plastic pallet can be sanitized (Leblanc and Richardson, 2003), so it is a popular material for the food and healthcare industry. Thermoforming or compression molding a pallet can create a nestable design, where there are no bottom decks and the top deck has hollow blocks, so pallets can fit into each other for stacking (ANSI MH1, 2016). Having a nestable pallet allows a company to benefit by reducing storage space of pallets. 
Polyethylene and polypropylene are the most common plastics used for making pallets. High-density polyethylene should be selected if strength, durability and manufacturability is needed. While polypropylene offers rigidity, and chemical/temperature resistance (Leblanc and Richardson, 2003).

\section{Metal Pallets}

Metal pallets have existed since the 1930's and are commonly found in the pharmaceutical, military and automotive industry (Leblanc and Richardson, 2003). They are manufactured to simple designs similar to wood pallets. Steel and aluminum are the common metals used for pallets. Although aluminum has a higher initial purchase price, it doesn't corrode so it can be recycled over and over. Metal pallet advantages are durability, load bearing strength, consistency in material and resistance to contamination (ANSI MH1, 2016).

\section{Paper-based Pallets}

Corrugated and paper-based materials are more isotropic than wood. A pallet can be constructed from corrugated/paper board. Commonly, the top deck surface is one solid, flat surface and this is accomplished by using multiple walled corrugated or a honeycomb sheet. A honeycomb sheet uses Kraft sheets oriented into hexagonal shapes to provide rigidity (ANSI MH1, 2016). Molding fiber-based material into a pallet structure is another option for forming a paper-based pallet.

Compared to wood pallets, paper-based pallets arrive in uniform weights and sizes with little variation. Corrugated and honeycomb pallets are a lightweight option compared to other materials and are a common material selection for airfreight (Leblanc and Richardson, 2003). If a paper-based pallet is used in a humid environment, then it becomes susceptible to water damage and the performance becomes an issue.

\section{Composite Wood Pallets}

There are four main types of composite pallet designs: plywood stringer, molded oriented strand board, plywood block, and plywood block with a unidirectional bottom. Oriented strand board is sometimes used as a substitute for the previously mentioned designs using plywood. Engineered wood pallets like these are very compatible with automated handling systems because the pallet retains its size and shape throughout usage (Leblanc and Richardson, 2003). In contrast to dimension lumber wooden pallets, there are no phytosanitary concerns because the components are heated and laminated together during manufacturing. It is a common material used in 
international shipping because it is exempt from phytosanitary regulations. (Leblanc and Richardson, 2003).

\subsubsection{Pallet performance}

The most important performance characteristics of a pallet are strength, stiffness and durability of the pallet (NWPCA, 2014). During distribution, the strength of a pallet must withstand the amount of weight of the products that is placed on it. The stiffness, or resistance to bending of a pallet, is important to ensure that the shape of the pallet structure remains the same so that material handling efficiency is not reduced. Durability of a pallet refers to how long a pallet lasts during use.

ISO 8611 and ASTM D1185 are laboratory testing standards used to determine the performance of pallets (ISO, 2011; ASTM, 2009). Also, two software programs are another way to determine pallet performance. Pallet Design System (PDSTM) developed in 1984, BestPallet $^{\mathrm{TM}}$ developed in 2011, and BestLoad ${ }^{\mathrm{TM}}$ developed in 2012, offer users the ability to design pallets and predict strength based on years of empirical pallet research (NWPCA, 1984; White and Company, 2011). The programs take support conditions, load types and wood properties into consideration and outputs load carrying capacities for pallets.

\section{Pallet Strength}

A pallet's strength (ISO, 2011) is the maximum amount of weight it supports before the pallet breaks or exceeds a specified deflection limit set by a standard. The strength is not a safe working or design load a pallet can support. A pallet's nominal load (ISO, 2011) is the adjusted load value with a safety factor included; this value is the maximum load that should be placed on the pallet.

Pallets have varying load carrying capacities dependent on the support conditions. Floor stacking, racking, forklifting, double stacking and conveyor supporting conditions are all common throughout supply chains and stress pallets differently (Figure 8). For example, a pallet will typically have a higher load carrying capacity when it is floor stacked than when it is in a rack system. Standards ISO 8611, ASTM D1185, and AIAG RC-9 describe tests to simulate these stresses using compression testing (ASTM, 2009; ISO, 2011; AIAG, 2015). 


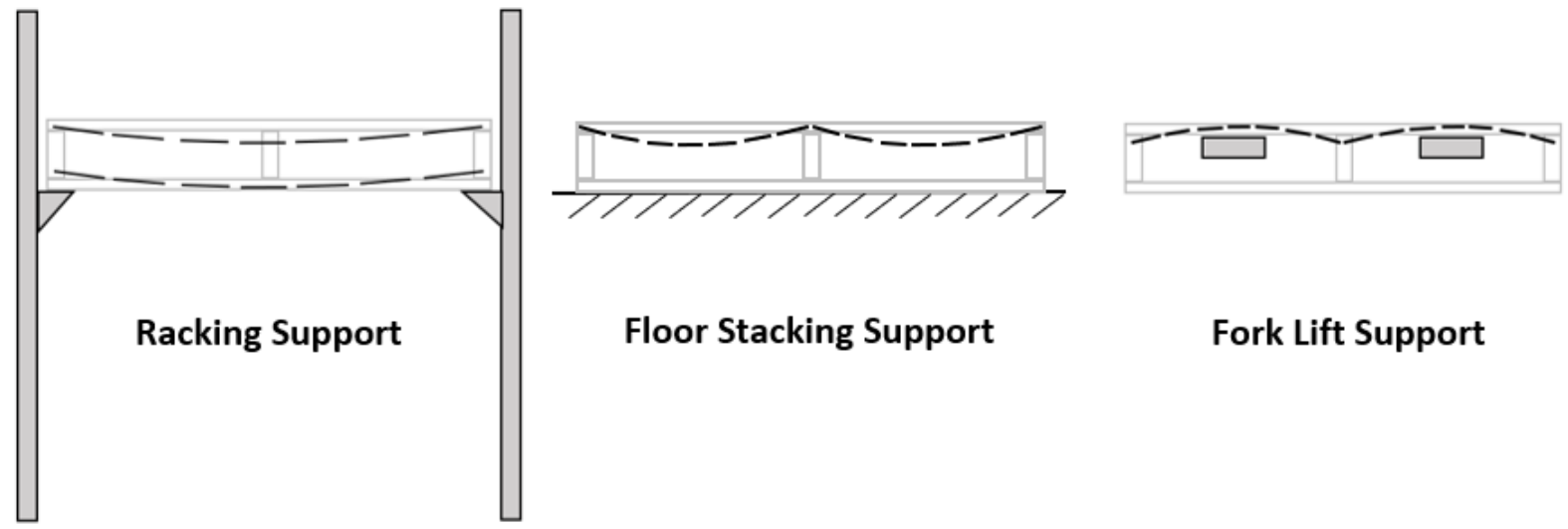

Figure 8 Supply chain support conditions and pallet reactions.

\section{Pallet Stiffness}

The pallet testing standards ASTM D1185 and ISO 8611 limit the amount of pallet deflection during testing and deem a pallet failed once the limit is met (NWPCA, 2014). The mechanical forces and stresses acting on a pallet can be summed up by the beam theory used in engineering. Stringers and deckboards transfer and distribute load as beams (Heebrink, 1959). Figure 9 demonstrates how a deckboard, considered a beam, would bend if the unit load was stored on a warehouse floor assuming there is uniform loading.

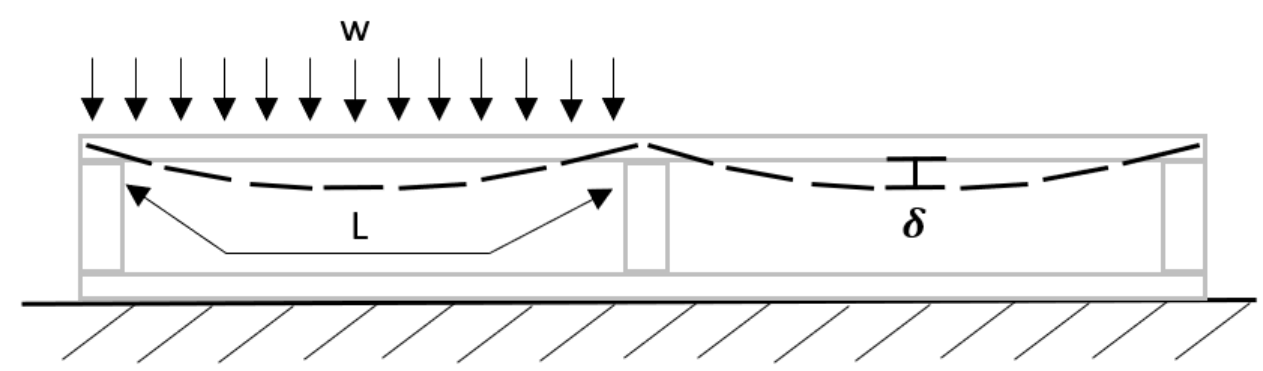

Figure 9 Top deck deflection of a floor stacked pallet. " $w "=$ loading, "L" = span and " $\delta "=$ deflection.

The bending of a pallet or pallet components is measured as deflection. Deflection is the vertical distance the beam moved due to loading. A stiffer beam will have a higher bending resistance or moment of inertia. Moment of Inertia is characterized in Equation 1 for a beam with a rectangular cross section (Rammer, 2010) Since deckboards act as beams, changing a 
deckboard's thickness (h) will have the largest effect on the bending stiffness of the beam; the effect is three-fold compared to changing the width of the beam.

$$
\boldsymbol{I}=\frac{\boldsymbol{b \boldsymbol { h } ^ { \mathbf { 3 } }}}{\mathbf{1 2}} \quad \begin{aligned}
& \text { I }=\text { Moment of Inertia }\left(\text { in. } .^{4}\right) \\
& b=\text { Width of beam (in.) } \\
& h=\text { Thickness of beam (in.) }
\end{aligned}
$$

Equation 1 Moment of Inertia

Since wooden pallets are easily customized, there is an array of possible pallet top deck stiffnesses. Therefore, not all pallets will react the same to similar loading. For example, more bending will occur with thin deckboards compared to thick deckboards because the moment of inertia increases. The relationship between deckboard thickness and deflection, along with other design considerations, can be see seen in Equation 2. Simplifying pallet deckboards to simply supported beams, the factors influencing beam deflection are the number/width/placement of stringers (span), shape of the deckboard (Moment of Inertia), the specific stiffness of the species used (Modulus of Elasticity) and the product weight.

$$
\begin{aligned}
& w=\text { applied weight }(l b) \\
& \text { Deflection }=\frac{\mathbf{5} \boldsymbol{w} \boldsymbol{l}^{\mathbf{3}}}{\mathbf{3 8 4 E I}} \quad \begin{array}{l}
l=\operatorname{lpan}(\text { in. }) \\
I=\text { Modulus of elasticity }\left(\text { lb/in. } .^{2}\right)
\end{array}
\end{aligned}
$$

Equation 2 Deflection of a simply supported beam with a uniformly distributed load

\section{Load Bridging}

Pallet bending is common during the distribution of unit loads. Boxes vertically stacked interact with each other during pallet bending, resulting in redistribution of stresses called load bridging (Montoya, 2017). Better pallet performance can be achieved by using the concept of load bridging. For example, a pallet with thin deckboards and stiff packaging deflects less than a pallet with thin deckboards and flexible packaging (Fagan, 1982) because the stiffer packaging redistributes the stress towards the pallet stringers (Yoo, 2011). Initially all loads were assumed to apply uniform stresses to a pallet, but that is not reality. Stresses are distributed differently depending on the load type and stiffness of the pallet. Table 3 cites studies that investigated the effect of load bridging. (Fagan, 1982; Collie, 1984; Yoo, 2011; Park, 2015; Montoya, 2017). 
Table 3 Factors that influence load bridging

\begin{tabular}{l|c}
\hline \multicolumn{1}{c|}{ Author } & Factor influencing load bridging \\
\hline Fagan (1982) & Stacking Pattern \\
Collie (1984) & Packaging and Pallet Stiffness \\
Yoo (2011) & Packaging and Pallet Stiffness \\
Park (2015) & Containment Force \\
Park (2015) & Number of Layers \\
Park (2015) & Package Size \\
Montoya (2018) & Interlocked Stacking
\end{tabular}

Load bridging significantly decreases when stiffer pallets are used (Fagan, 1982; Collie, 1984), meaning there is more even stress distribution of the products. Yoo found that there are higher stresses redistributed towards the supports of a low stiffness pallet (Yoo, 2011) which support the carried products unevenly. Supporting products unevenly in a unit load could influence the performance of the designed packaging, which is most commonly corrugated boxes.

\subsection{Corrugated Boxes}

\subsubsection{Corrugated box history}

The early version of the corrugated board (Figure 10) was a paper-based material that is a combination of a flat paper, called a liner, adhered to an arched-shaped paper called a medium. The first corrugated board patent was issued in 1856 (Fibre Box Association, 2015) but it wasn't until 1894 when the first double face design appeared. The double faced corrugated board was constructed into a shipping box in New York City by Robert Thompson and Henry Norris. Shortly after, the corrugated box industry gained popularity as it became a substitute for wooden boxes for rail transportation. In the 1920's, corrugated boxes became the most widely used shipping container (Twede, Selke, Kamdem, \& Shires, 2015). Nearly a century later in 2016, over 31 million tons of corrugated board was consumed (Fibre Box Association, 2016) and paper and paperboard packaging represented $36 \%$ of overall packaging material consumption by weight. (Teck Kim, Min and Won Kim, 2013).
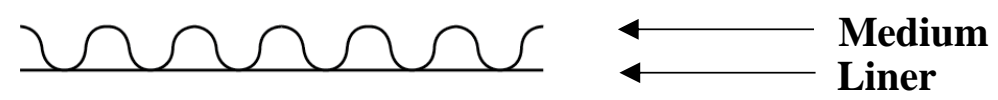

Figure 10 Structure of a single face corrugated board. 


\subsubsection{Corrugated terminology}

Single, double and triple wall corrugated board are the most common found in industry. The amount of liners and mediums in the structure of the corrugated board determines the designation of single, double and triple wall. A single and double wall example can be found in Figure 11. A single wall will have one corrugated medium while double and triple wall will have two and three corrugated mediums respectively. The mediums are located in between two liners.
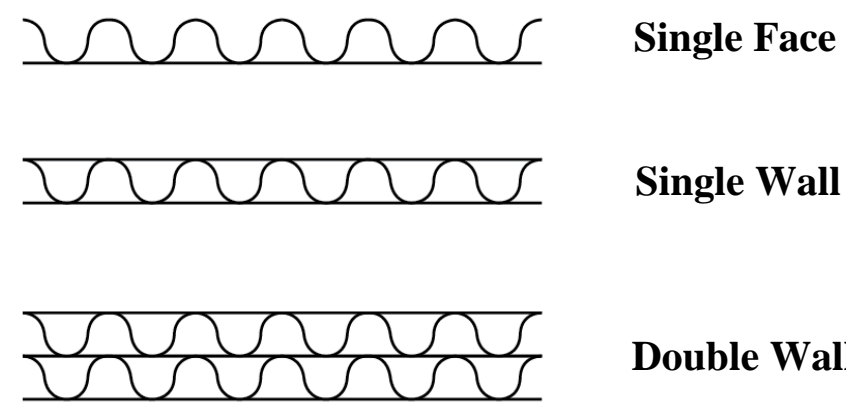

\section{Double Wall}

Figure 11 Single and double wall example.

The arch shapes of the medium are also referred to as flutes and specifying the flute size is the common way of selecting a standardized board. Flute size corresponds with how thick a board is and can also be referred to as board caliper. A, B, C, E and F are common flute sizes where A flute was the first flute size available (Kaushal, Sirohiya and Rathore, 2015). Alphabetic order of names is the order of creation, but not the order of thickness (Twede, Selke, Kamdem, \& Shires, 2015). Thickest flute size to thinnest flute size is as follows: A, C, B, E and F. The larger the flute size, the fewer arches of the medium there are. A flute will have around 36 flutes per foot while F flute will have approximately 128 flutes per foot (Kaushal, Sirohiya and Rathore, 2015). For clarification of flute size and naming see Table 3.

Table 3 Corrugated flute sizes

\begin{tabular}{c|c}
\hline Flute Name & Flute Thickness (in.) \\
\hline A & $6 / 32$ \\
C & $5 / 32$ \\
B & $4 / 32$ \\
E & $2 / 32$
\end{tabular}

Note. Adapted from (Kaushal, Sirohiya and Rathore, 2015)

Liners and mediums are available with different densities. The amount of fiber weight per area is termed the basis weight and the typical unit for basis weight is pounds per thousand square 
feet (Park, 2015). Basis weight of 42 is the most common grade (Fibre Box Association, 2015). To fully specify a corrugated board, the board grade needs to be defined. For example, a 42/33A/42 board grade will have liners with a 42-basis weight and medium with a 33-basis weight and the board will have a thickness of A flute.

\subsubsection{Corrugated testing}

\section{Edgewise Compressive Strength (Edge Crush Test)}

McKee et al. found that the edgewise compressive strength (ECT) of corrugated board is one of the most important factors affecting a container's compression strength (McKee, Gander and Wachuta, 1961). A few standardized tests were developed to measure the ECT where all tests require flutes to be oriented vertically (Figure 12). Short column TAPPI T811 (TAPPI, 2012b), neck down TAPPI T838 (TAPPI, 2012c) or the clamping method TAPPI T839 (TAPPI, 2012d) are edge crush tests with TAPPI T811 being the most common test.

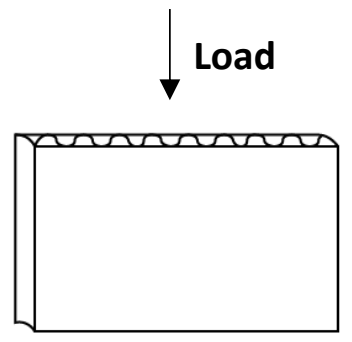

Figure 12 Direction of loading during the Edge Crush Test (ECT).

\section{Flat Crush Test (FCT)}

Flat crush testing measures corrugated board's flute rigidity. Flute rigidity is an indication of the quality of flutes within the board such as how well formed they are from manufacture. For example, fluting could be leaning or even partially crushed (TAPPI, 1997). To conduct a flat crush test, a sample is placed flat on a liner face and two parallel platens are used where one lowers until the side walls of the sample collapse and the maximum load is recorded (Figure 13). 


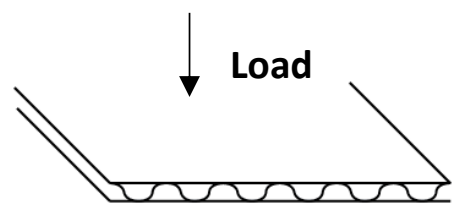

Figure 13 Direction of loading during Flat Crush Test (FTC).

\section{Flexural Strength Test}

Flexural stiffness is the ability to resist bending (TAPPI, 1985) and is a contributing factor to box compression strength (McKee, Gander, \& Wachuta, 1961; Frank, 2014). TAPPI T820 contains a description of a four-point beam bending test where equal load is applied to each end of a sample and deflection is measured (Figure 14).

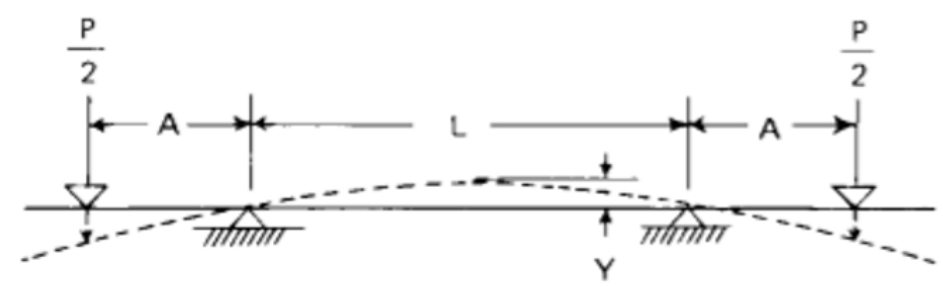

Figure 14 Reprinted. Four-point bending test (TAPPI T820).

\section{Burst Strength}

TAPPI T810, sometimes called the Mullen Burst Tests, measures the burst strength of paperboard and linerboard. A sample is placed in a clamping apparatus that exposes the center of the specimen where a diaphragm is used to burst the corrugated sheet. Burst strength is commonly used to define different grades of corrugated (TAPPI, 2009).

\subsubsection{Corrugated boxes}

\section{Corrugated Box Specifications}

The light weight of corrugated board is one of the reasons why corrugated boxes are the most widely used material for a shipping container (Twede, Selke, Kamdem, \& Shires, 2015). Corrugated boxes are commonly composed of side panels, top and/or bottom minor and major flaps. (Figure 15). The most commonly used shipper box is the Regular Slotted Container (RSC) (McKee, Gander, \& Wachuta, 1961; Campbell, 2010; Fibre Box Association, 2015; Frank, 2014; Twede, Selke, Kamdem, \& Shires, 2015) which has top and bottom flaps that fold and meet in the 
middle of the box. Other common designs include Half Slotted Containers (HSC) that only have a bottom set of flaps that fold and meet in the middle or Full Overlap Slotted Container (FOL) that has flaps that fully extend to the opposite edge of the box and the flaps overlap.

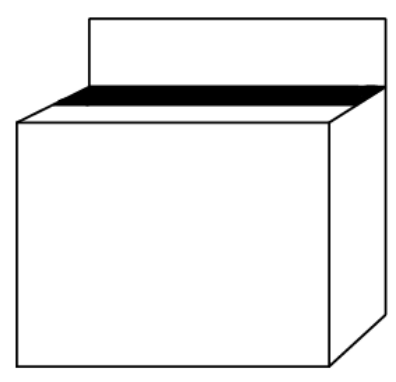

Regular Slotted Container

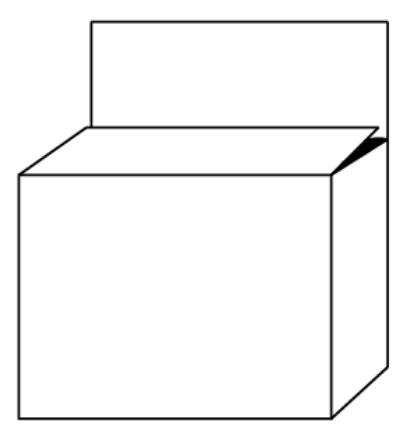

Full Overlap Slotted Container

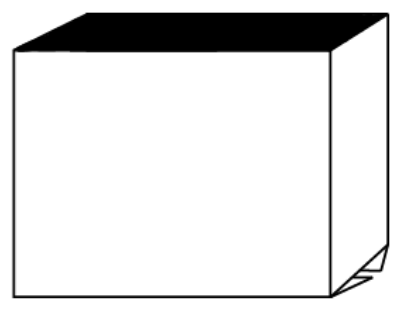

Half Slotted Container

Figure 15 Basic box flap designs.

Standard box styles have a four letter identification code developed by FEFCO (The European Federation of Corrugated Board Manufacturers) to exactly specify what international design was used. For example, a regular slotted container's code is \#0201 (Twede, Selke, Kamdem, \& Shires, 2015).

\section{Box Compression Strength}

ASTM D642 and TAPPI T804 are standardized laboratory test methods to measure the vertical compression strength of corrugated boxes. During the test, two parallel platens are used where one platen is stationary while the opposing platen is compressing at a fixed rate of 0.5 inches/minute (TAPPI, 2012a; ASTM, 2015) until the test specimen fails (Figure 16). The peak load before failure is the compression strength.

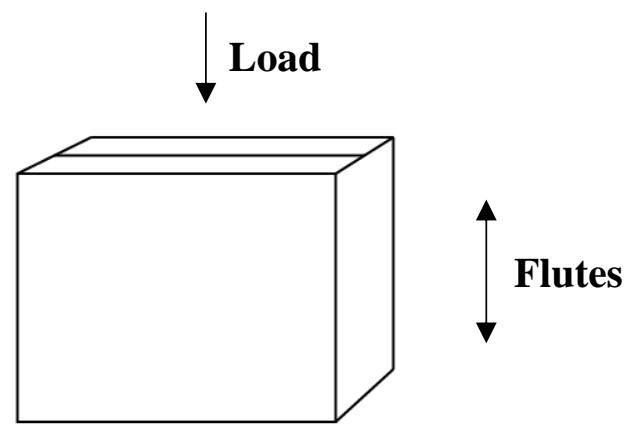

Figure 16 Box compressive test direction of loading. 
In 1963, the simplified McKee equation (Equation 3) was developed to estimate a box's compression strength and has become the most popular prediction method (Frank, 2014). The initial equation assumed a box was made up of four panels that would buckle and fail, and based on this panel theory, an empirical equation was derived to fit to the results of compression tests on a small population of boxes (Frank, 2014). The equation is only applicable for RSC type corrugated boxes that are not short in box depth. Box height has to be tall enough for the sidewall to buckle before the board fails by short column crushing (Baker, 2016). Also, the equation assumes that the plates (sidewalls) are square (Frank, 2014) and as the length/width ratio (aspect ratio)of the box significantly changes then the accuracy of the prediction could be affected (Baker, 2016). The McKee equation can predict within $+/-15 \%$ accuracy for $95 \%$ of data (Baker, 2016).

$$
\text { Box Compression Strength }=5.87 \times \text { ECT } x(\text { Caliper } x \text { Perimeter })^{\frac{1}{2}}
$$

Equation 3 Simplified McKee Equation.

The main factors affecting a box's compression strength are the edge crush test value (ECT), box perimeter, and caliper of the board (McKee, Gander and Wachuta, 1961). Another governing material property is the bending resistance of the corrugated board - otherwise known as the flexural stiffness (Frank, 2014). When loaded vertically, the side walls tend to bow out and the board's resistance to bowing is the flexural stiffness. A way to increase flexural stiffness is to increase board grade and caliper. McKee et al included the flexural stiffness effect by specifying board caliper in the Simplified McKee Equation.

\section{Stacking Strength}

Stacking strength of a box provides a safe top load value by including a safety factor that accounts for known and unknown distribution conditions that affect a box's compression strength. The stacking strength will be much lower than the compression strength of the box. It is a more practical value for use, than box compression strength, since it incorporates the effects of humidity, load duration, corrugated box specifications (Frank, 2014) and pallet and unit load interactions that affect box strength.

\section{Factors Affecting Box Compression Strength}

There will most likely be moisture changes in the distribution of products. As relative humidity in the air changes, the fibers within corrugated boxes absorb and release moisture (Frank, 2014). The strength of fibers decreases when the moisture content of the board increases. 
Therefore, controlling the moisture exposure is critical to box compression strength. The higher the humidity, the lower the compression strength (Kellicut \& Landt, 1958; Whitsitt \& McKee, 1972; Navaranjan, Dickson, Paltakari, \& Ilmonen, 2013). For example, a relative humidity change from $50 \%$ to $90 \%$ in a warehouse will result in more than a $50 \%$ loss of compression strength (Whitsitt and McKee, 1972).

In addition to humidity, load duration affects the performance of corrugated boxes. Duration of load is the amount of time a box is under compressive stress, usually found in stacking and warehousing products. Longer warehousing time requires a box with a higher compression strength (Frank, 2014; Whitsitt \& McKee, 1972). An early study showed (Table 4) that for a box to survive under load for a month, only loads up to $58 \%$ of its box compression strength can be placed on the top of the box (Kellicutt and Landt, 1958).

Table 4 Effect of load duration on box compression strength

\begin{tabular}{c|c|c|c}
\hline $\begin{array}{c}\text { Static Compressive strength } \\
\text { of comparable box (lb) }\end{array}$ & $\begin{array}{c}\text { Actual dead load } \\
\text { on box (lb) }\end{array}$ & $\begin{array}{c}\text { Ratio of dead load to static } \\
\text { compressive strength (\%) }\end{array}$ & $\begin{array}{c}\text { Time to } \\
\text { failure (min) }\end{array}$ \\
\hline 702 & 664 & 95 & 1.3 \\
699 & 610 & 87 & 7.3 \\
696 & 544 & 78 & 399 \\
696 & 403 & 58 & 35.6 (days)
\end{tabular}

Note. Reprinted from Whitsitt and McKee 1972

Overhanging boxes (Figure 17) is a common way to increase the space utilization of a pallet. Yet, this practice will further reduce the compression strength of corrugated boxes. Corners provide $2 / 3$ to $3 / 4$ of the box compression strength (Maltenfort, 1988) and they become unsupported when a box is overhanging a pallet, leaving the box without a critical component for its strength. In a 1975 study, Ievans found a 36\% loss of compression strength and later in 1999, DiSalvo found a 30\% reduction of compression strength due to overhang (Ievans, 1975; DiSalvo, 1999). Monaghan and Marcondes completed a similar experiment and concluded that as the amount of overhang increases, box compression strength decreases (Monaghan and Marcondes, 1992). 


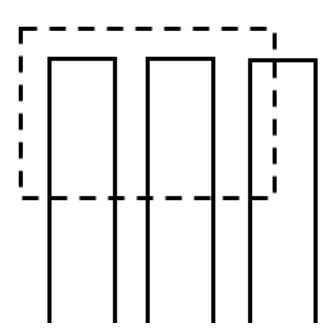

Figure 17 Illustration of an overhanging box.

When unitized, a box is most likely spanning the unsupported area between deckboards known as pallet gaps. There is variation between previous studies of what the exact effect of pallet gaps on compression strength are, but in general as the pallet gap gets larger, box compression strength reduces(Ievans, 1975; Monaghan \& Marcondes, 1992; DiSalvo, 1999). Baker discovered that larger boxes are less susceptible to pallet gaps than smaller boxes and pallet gaps located closer to box corners are more detrimental to box compression strength (Baker, 2016).

Interlocking boxes within a unit load is a solution for better stability performance compared to column stacking (Fibre Box Association, 2015) but this pallet pattern misaligns the corners. Compared to column stacking in a unit load, interlocking compromises the compression strength of a box between 39-45\% (Kellicut, 1963; Ievans, 1975). This is due to the load not directly transferring from corner to corner, rather from corner to sidewall. Column stacked boxes within a unit load need to be well aligned. It was found that when stacking 3 boxes with a half inch misalignment of width and length panels resulted in 27-29\% loss in box compression strength (Ievans, 1975; Singh, Singh, \& Saha, 2011a), while Kellicutt found misaligning one panel of the center box of a stack of 3 resulted in a 35\% reduction of strength (Kellicut, 1963). This is comparable to the effect of pallet overhang where there are unsupported box corners.

In 2011, a study concluded that unitized boxes on a CHEP® style pallet had higher compression strength than boxes supported on a GMA style pallet (Singh, Singh, \& Saha, 2011b). These results could have been a result of a combination of a stiffness difference between top decks and deckboard gap differences between the pallet designs. Also in 2011, Yoo discovered differences in box compression stress distributions of pallets with different stiffness. A less stiff pallet had higher stress concentrations near the ends of deckboards (Yoo, 2011), creating a surface with uneven support conditions. Baker, and later Phanthanousy, related the difference in stress concentrations to box compression strength (Baker, 2016; Phanthanousy, 2016). It was concluded that the compression strength of boxes does not change because of pallet top deck 
stiffness when the pallet design has gaps. Yet, for pallets with a solid top deck, Baker found a $26 \%$ difference in compression strength from a rigid surface to the lowest stiffness surface used. These tests were conducted when box corners were supported symmetrically. The boxes were centered between stringers on the top deck (Location A of Figure 18).

Baker further investigated the idea of box location on a pallet. In distribution, boxes are found everywhere on the pallet's top deck to efficiently use the total pallet area, boxes are not just centered over the forktine entry holes. He realized that there were varying support conditions for boxes dependent on the location of the box on the pallet top deck. On a flexible surface with no pallet gaps, an asymmetrically loaded box is the weakest location on the pallet, where it was $15.3 \%$ weaker in compression strength compared to the other locations (Baker, 2016).

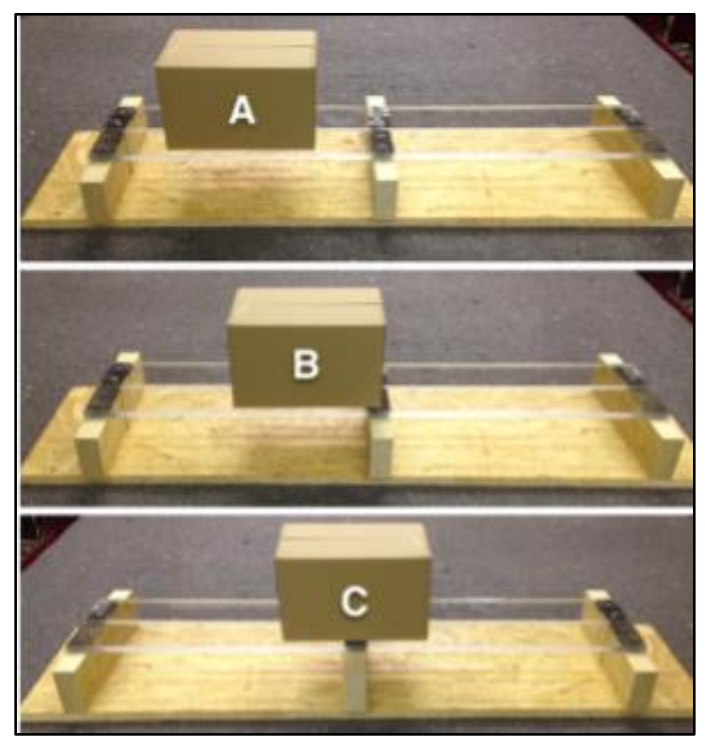

Figure 18 Note. Reprinted from Baker 2016. Box locations A and C are symmetrically loaded while location B is asymmetrically loaded.

Symmetrical loading is where all four corners of a box are supported in a similar manner. Asymmetric box loading means at least one of the four corners is supported differently from the rest. For example, location B in Figure $\mathbf{1 8}$ is asymmetrically supported because two corners are over the deflecting span of the top deck while the other two corners are supported by the stringer where minimal deflection will occur (Figure 19). Unequal support conditions are present. 

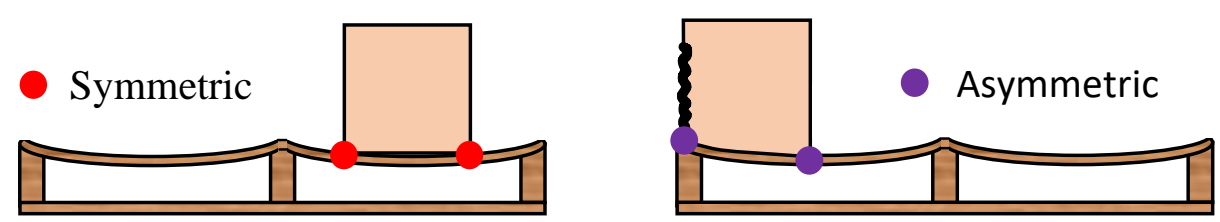

Figure 19 Illustration of symmetric and asymmetrically supported boxes on a flexible pallet.

The bottom box in a stack always carries more load than the box above it. Therefore, all of the boxes not on the bottom layer are overdesigned (Frank, 2014). Further, the boxes not in the asymmetric position of a flexible pallet are overdesigned too. The asymmetric location is the weakest possible box location within the unit load and it is extremely common (Figure 20).
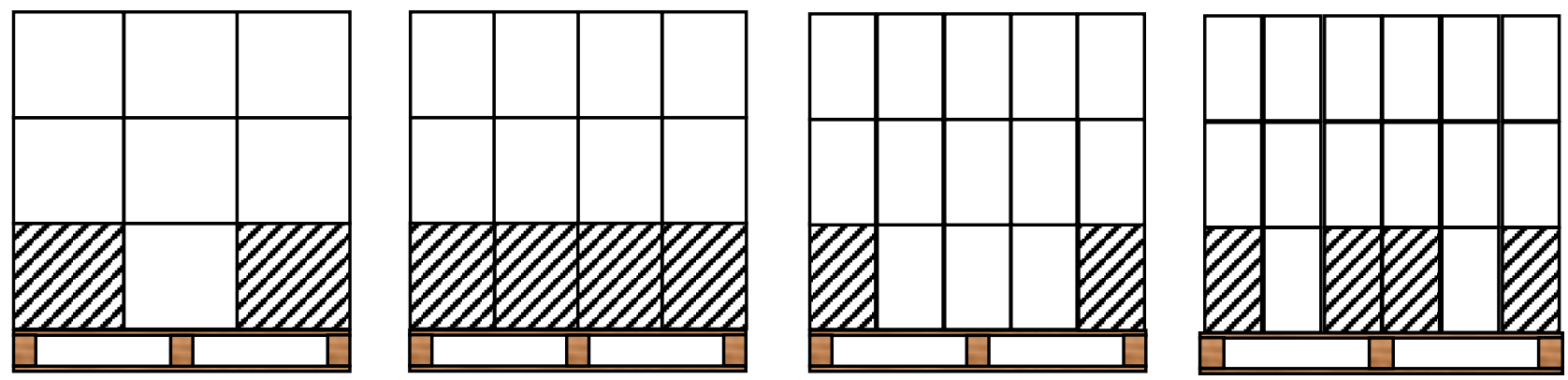

Figure 20 Illustration of asymmetrically loaded boxes in common unit load arrangements.

\subsubsection{Effect of pallet top deck stiffness}

Stacking strength of a box is determined by the previous researched factors, but pallet stiffness is unaccounted for in common safety factors. Deckboard thickness, similar to pallet gaps, is adjustable in pallet manufacturing resulting in many possible pallet stiffnesses. In addition, pallets are made from different materials. Further, wooden pallets may be constructed from different species resulting in even more variation of stiffnesses. Yet, the effect of pallet top deck stiffness on box compression strength is mostly unknown. 


\section{Chapter 3 - Materials and Methods}

An experiment was designed to investigate the effect of pallet top deck stiffness on the strength of corrugated boxes. Four levels of top deck stiffnesses, two sizes of boxes, and two types of corrugated flutes were used.

\subsection{Limitations of study}

- Tests were completed on partial size unit loads.

- Tests were completed only on GMA style stringer pallets.

- Industry cuts 7/16 in. and 11/16 in. deckboard thicknesses for softwood pallets which differs slightly from the thicknesses that were tested.

- In order to fix pallet joint stiffness, screws, instead of nails, were used to connect deckboards and stringers.

- Bottom deck stiffness of the top pallet in the test setup was not measured and could have contributed to the results.

- The pricing quotes received could vary from other actual pallet and box costs based on species availability, manufacturing capabilities, order quantity, and also market fluctuations at any given point in time.

\subsection{Materials}

\subsubsection{Corrugated boxes}

Two sizes of Regular Slotted Container (RSC) style corrugated boxes that varied in length were investigated. The size of the box was selected to completely cover the top surface of a 48 in. x 40 in. pallet. The resulting external box dimensions were 16 in. x 9.75 in. $x 10$ in. (small) and 24 in. $x 9.75$ in. $x 10$ in. (large).

The boxes were manufactured on a Gerber Innovations DT9066 computerized cutting table (Gerber Innovations, Tolland, Connecticut) using flat corrugated stock produced by Packaging Corporation of America in Roanoke, Virginia. The corrugated stock was nominal 32 lb/in. ECT (edge crush test) value B-flute and C-flute corrugated board. Edgewise crush testing using the clamping method in TAPPI 810 (TAPPI, 2012), bending stiffness testing TAPPI T836 (TAPPI, 2009b), box compression strength ASTM D462 (ASTM, 2015), and burst strength testing TAPPI T810 (TAPPI, 2009a) were all conducted to evaluate the performance of the corrugated board (Table 5). 
Table 5 Average performance characteristics of corrugated board used.

\begin{tabular}{c|c|c|c}
\hline Performance Test & B-flute & C-flute & Repetitions \\
\hline Edgewise Compressive Test (lb/in.) & $35.97(2.7)$ & $29.06(2.3)$ & 10 \\
\hline Bending Stiffness - Machine Direction (lb/in.) & $46.6(6.4)$ & $91.6(12.8)$ & 10 \\
Bending Stiffness - Cross Direction (lb/in.) & $34.6(22)$ & $49.7(6.7)$ & 10 \\
\hline Burst Strength - Outside Liner (lb/in. $\left.{ }^{2}\right)$ & $174(5.2)$ & $160.3(6)$ & 10 \\
Burst Strength - Inside Liner (lb/in. $\left.{ }^{2}\right)$ & $165(5)$ & $157.8(12.3)$ & 10 \\
\hline Box Compression Strength - Small Box (lb) & $398(6)$ & $452(11)$ & 10 \\
Box Compression Strength - Large Box (lb) & $368(3)$ & $463(6)$ & 10 \\
\hline Box Stiffness - Small Box (lb/in.) & $2360(10)$ & $1836(12)$ & 10 \\
Box Stiffness - Large Box (lb/in.) & $2738(14)$ & $2310(10)$ & 10
\end{tabular}

*Numbers in parenthesis are coefficient of variation expressed as percentages

The boxes were stored flat and preconditioned to $50 \%$ relative humidity and $73^{\circ} \mathrm{F}$ for 72 hours based on the recommendations of ASTM D4332 (ASTM, 2014). The boxes were erected using a jig to ensure 90 -degree corners. The manufactured joint was closed by two $\sim 1$ in. drops of ethyl-vinyl acetate adhesive (3M, Inc.), and the top and bottom of the boxes were closed using 1.88 in. packaging tape (Staples, Inc.).

\subsubsection{Filled boxes of test setup}

The test setup was designed to force compression failure to the bottom box in the stack because in practice, the product weight in the corrugated boxes produce a higher compressive force on the bottom box of the stack. Therefore, performing compression tests with filled/weighted top boxes predominately forces failure to the bottom box (Frank, Gilgenbach, \& Maltenfort, 2010) where it would most likely occur in distribution. The bottom boxes of the setup, Figure 21, were left empty.

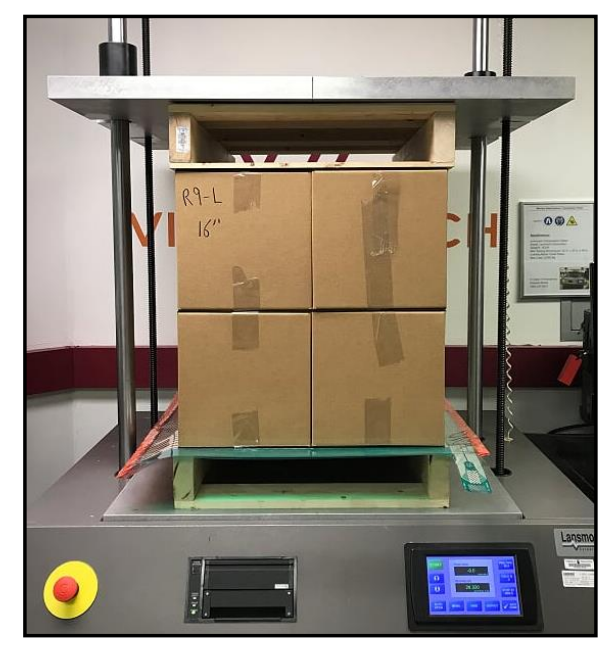

Figure 21 Experimental setup for box compression testing. 
For the loaded corrugated boxes, a load spreader made of 0.75 in. thick Birch plywood was placed on the bottom of the box and metal weights were used as the load. The maximum allowable weight (MAW) in each corrugated box was calculated based on the simplified McKee equation, with a safety factor of 3 , four layers of boxes on the pallet, and double stacked pallets in a warehouse (Equation 4). The weight in the top loaded boxes was determined by consolidating the weight of three boxes on the top of the bottom pallet into one and rounding it based on practical considerations. The methods of consolidating weight and loading boxes are presented in Figure 22. The actual weights added into the top boxes are listed in Table 6.

Table 6 Summary table of actual weights in the loaded top boxes.

\begin{tabular}{|c|c|c|c|}
\hline & Flute Size & Small Box & Large Box \\
\hline & B & $60 \mathrm{lb}$ & $75 \mathrm{lb}$ \\
\hline & $\mathrm{C}$ & $75 \mathrm{lb}$ & $85 \mathrm{lb}$ \\
\hline & \multicolumn{3}{|c|}{$5.87 *$ ECT $* \sqrt{(\text { Perimeter } * \text { Caliper })}$} \\
\hline
\end{tabular}

Equation 4 Determining the maximum allowable weight in the top loaded box.

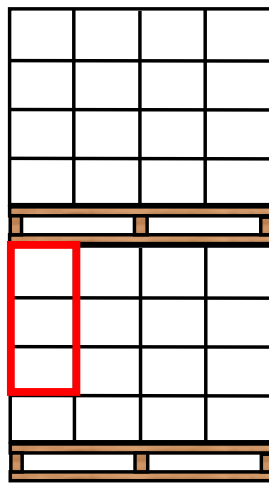

Distribution Scenario

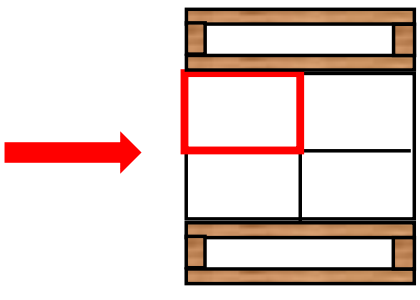

Test Setup

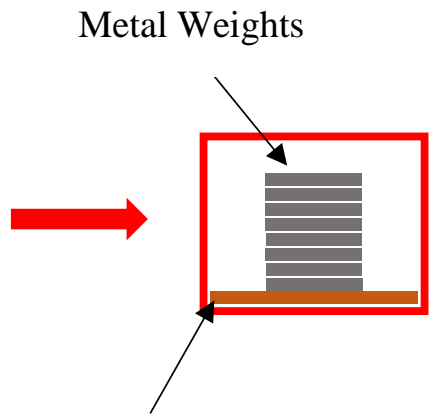

Load Spreader

Top Box

Figure 22 Graphical representation of the loading and the method of box weight consolidation.

\subsubsection{Pallet}

A 28 in. x 20 in. stringer class, non-reversible, flush, two-way, quarter size wooden pallet section was used. These pallet sections represent a quarter section of a full sized 48 in. $\mathrm{x} 40$ in. 
GMA $^{\mathrm{TM}}$ (Grocery Manufacturers Association) pallet with seven equally spaced top deckboards and five bottom deckboards (Figure 23).

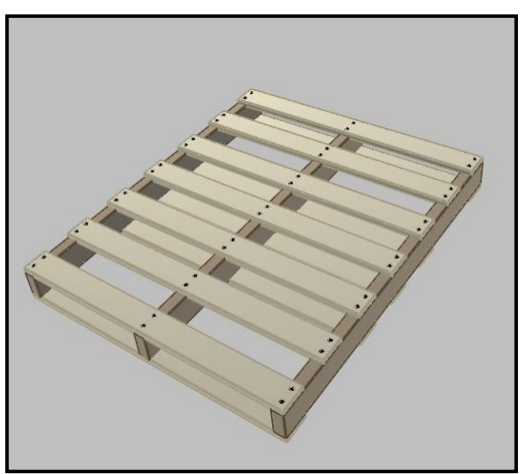

Figure 23 Depiction of 48 in. $x 40$ in. GMA Pallet (image generated using The Pallet Design System ${ }^{\circledR}$ NWPCA, 1984).

Eight pallet sections were constructed from \#2 kiln-dried SPF lumber purchased from Home Depot, in Christiansburg, VA. The stringers of the pallet sections were 1.5 in. wide, 3.5 in. tall, and $28 \mathrm{in.} \mathrm{long.} \mathrm{The} \mathrm{top} \mathrm{and} \mathrm{bottom} \mathrm{deckboards} \mathrm{were} 3.5 \mathrm{in}$. and $20 \mathrm{in}$. long and spaced 3.91 in. apart. The thickness of the top and bottom deckboards were varied to simulate four pallet stiffnesses: low (0.375 in.), medium (0.5 in.), medium-high (0.625 in.), and high (0.75 in.). Different thicknesses were obtained by planing the deckboards from nominal 2 in. $\mathrm{x} 4$ in. lumber stock. The deckboards were attached to the stringers using two 1.25 in. long construction screws per deckboard joint. The location of the top and bottom deckboard sections are presented in Table 7 and seen in Figure 24. 


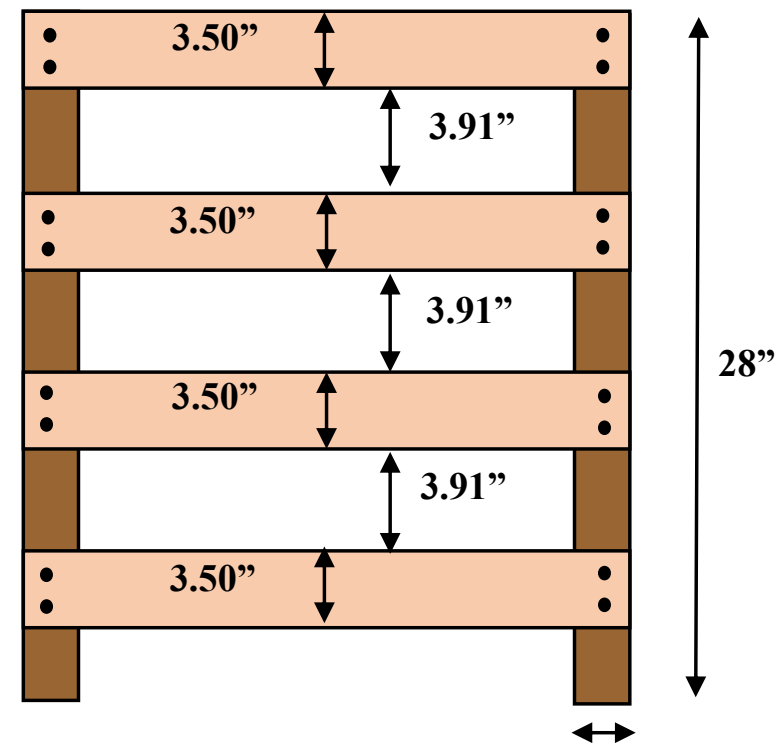

$1.5 \%$

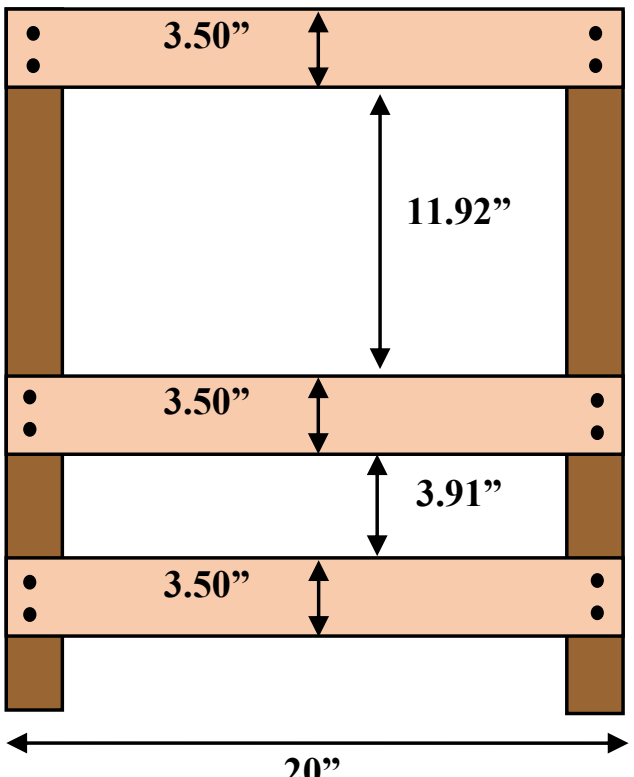

20"

Figure 24 Overall and component sizes of the 28 in. x 20 in. pallet sections.

Table 7 Summary table of the deckboard locations.

\begin{tabular}{c|c}
\hline Top deckboard number & $\begin{array}{c}\text { Deckboard location in reference to } \\
\text { front of pallet (in.) }\end{array}$ \\
\hline 1 & 0 \\
2 & 7.41 \\
3 & 14.82 \\
4 & 22.23 \\
\hline Bottom deckboard number & $\begin{array}{c}\text { Deckboard location in reference to } \\
\text { front of pallet (in.) }\end{array}$ \\
\hline 1 & 0 \\
2 & 14.82 \\
3 & 22.23
\end{tabular}

\subsection{Methods}

\subsubsection{Measurement of box compression strength}

Compression strength for asymmetrically loaded boxes was recorded using a Lansmont Squeezer fixed platen compression tester (Lansmont Corp, Monterey, California) equipped with a $5,000 \mathrm{lb}$ load cell. The simulated pallet was centered on the bottom platen. A TekScan 5400N (Tekscan, South Boston, Massachusetts) pressure mat contained in a plastic sleeve was placed on the top of the pallet. A layer of empty corrugated boxes was then loaded on the top of the pressure mat followed by a layer of loaded corrugated boxes. An identical pallet was placed on the top of the boxes to simulate the load distribution during double stacking. Before testing, the weight of the unit load and test setup was zeroed in order to record only the force applied by the 
compression tester. The simulated unit load was compressed following the guidelines of ASTM D642 using a compression rate of 0.5 in./ minute until visual box failure was observed (ASTM, 2015). Visual box failure was defined as the buckling of the entire boxes' sidewall, and at that point, the peak in the load versus the deformation curve was recorded.

\subsubsection{Finding Box Compression Strength}
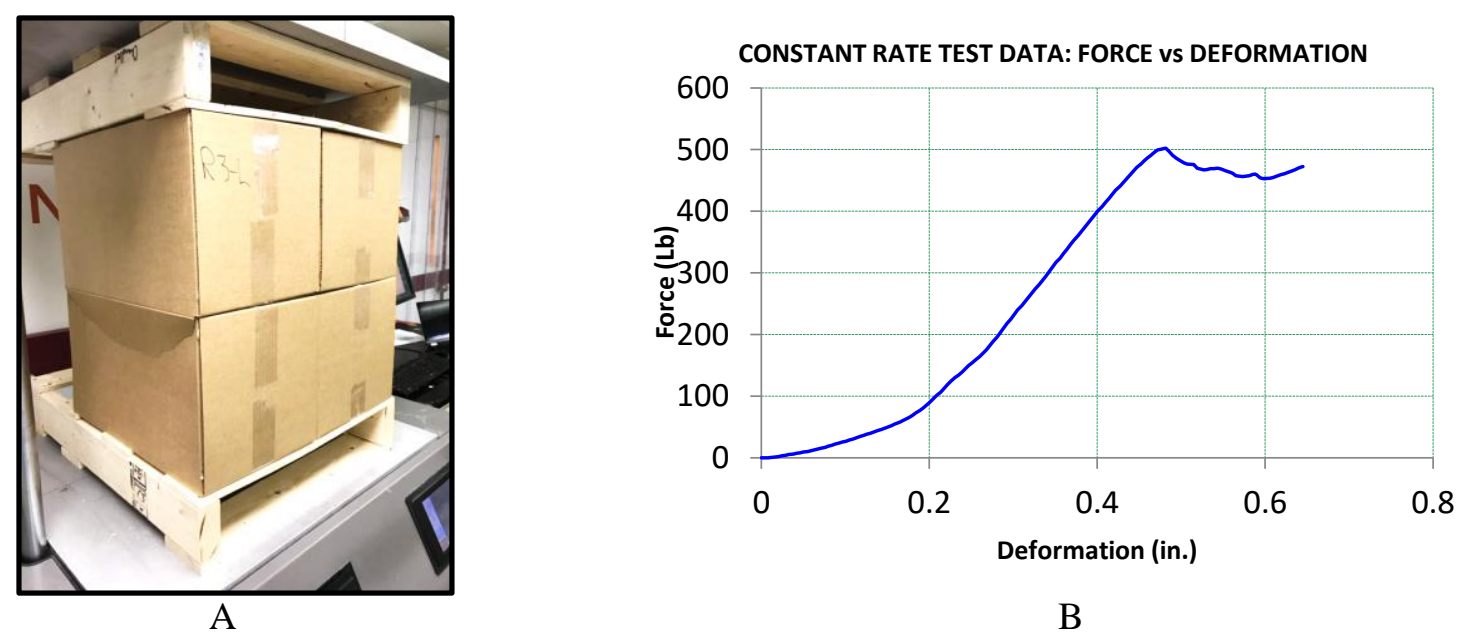

B

Figure 25 Length sidewall buckling of box (A), load vs. deflection curve of compression test (B).

To determine the box compression strength, maximum load values were recorded (Figure 25 B) at the visual failure (Figure 25 A) of the box. This value was then divided by two because there were two columns of boxes compressed during testing, and then the weight from the second layer of loaded top boxes was added.

\subsubsection{Measurement of pressure distribution}

The pressure between the top pallet surface and C-flute corrugated boxes was measured using a Tekscan $5400 \mathrm{~N}$ pressure mat. The size of the pressure mat was $41.7 \mathrm{in}$. $x 25.2 \mathrm{in}$. and it contained 1,768 individual sensels. The size of a sensel is $0.394 \mathrm{in.} \times 0.394 \mathrm{in}$. and they are located $0.669 \mathrm{in}$. apart from each other. The pressure range of the mat is 4-94 psi. The pressure mat was placed into a 0.02 in. thick protective sleeve made of Polyethylene Terephthalate (PET). Tekscan I-Scan software was used to record pressure distributions at the pallet and box interface.

In order to compare the pressure distribution at the interface between the pallets and boxes for the different levels of pallet stiffnesses tested, the measurement was recorded under the same load for each box size. This load was $415 \mathrm{lb}$ and $430 \mathrm{lb}$ for small and large boxes 
respectively. These weights were selected because they were at the point just below box failure on the load vs. deflection curve for the boxes compressed on the lowest stiffness pallet.

The results were analyzed into zones: a 1.5 in. zone above each pallet stringer, where minimal deckboard deflection occurred, and an additional $1.5 \mathrm{in}$. zone midway between the stringers where maximum top deck deflection occurred. This method of analysis was chosen because the zones included all of the boxes' corners in the setup, and the majority of compression force is supported by box corners (Frank, 2014). Once the readings were grouped, readings from the pressure sensels within each group were summed. Then, the sum within the zone was divided by the total pressure experienced by the mat resulting in the amount of pressure found in each zone of the pallet/box interface. The percentage of pressure at the midspan zone was further divided by two because two sidewalls (one from each box) were applying pressure in that zone. An average of ten observations at each zone were reported for a pallet stiffness, box size combination. The analysis method is summarized in Figure 26. 

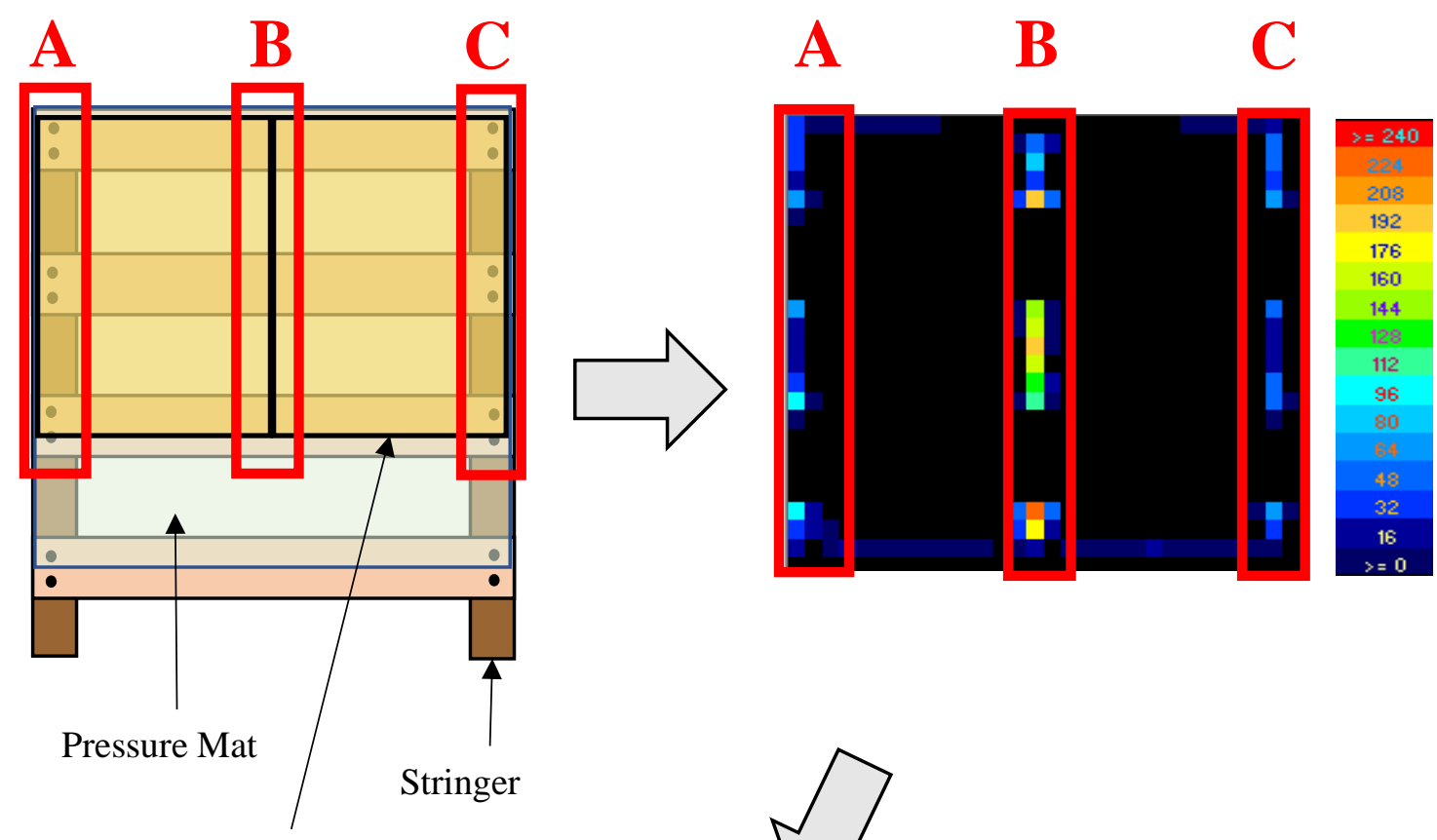

Corrugated Box

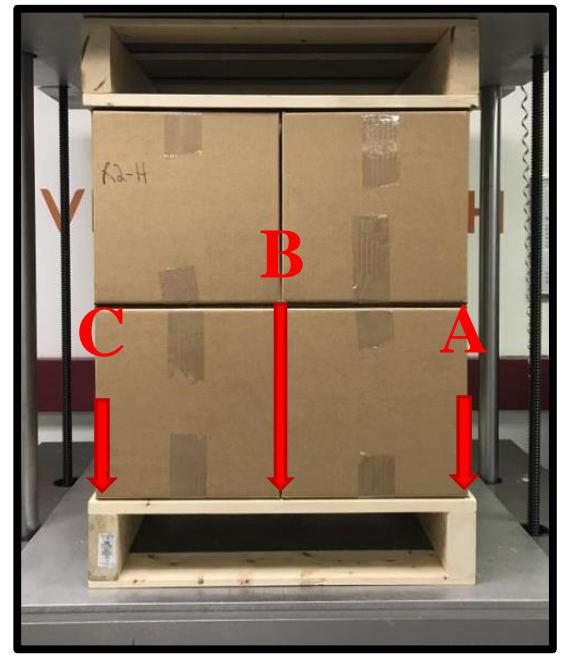

Figure 26 In the top left image, $1.5 \mathrm{in}$. zones were created that included the length sidewalls of the corrugated box. Individual pressures found in a zone (top right image) were summed and divided by the total mat pressure. The percentage of total compressive pressure in a zone (bottom image) was compared between low and high stiffness pallets. 


\subsubsection{Measurement of deckboard deflection}

String potentiometers were used to measure the top deck deflection for a portion of the experiment to connect differences in pallet top deck deflection to different pressure concentrations between the pallet and box interface. Deflection of all four pallet stiffness levels were compared at $160 \mathrm{lb}$, which was the weight of the filled top boxes in addition to the top pallet. Only the deflection of the deckboard that experienced the greatest deflection was recorded.

The test setup was elevated in order to record deflection (Figure $27 \mathbf{A}$ ). The pallet stringers were fully supported by two 2 in. $\mathrm{x} 2$ in. $\mathrm{x} 32$ in. steel bars. The steel bars rested on 6 in. tall I-beams with 4 in. wide flanges. Four string potentiometers (UniMeasure P510-5-S3) with a 5 in. range and a tolerance of $\pm 0.00075 \mathrm{in}$. were used. The string potentiometers were affixed to a 1.5 in. thick plywood base plate along with the I-beams. String potentiometers were connected to a National Instruments ${ }^{\mathrm{TM}}$ (Austin, Texas) digital data collection system and National Instruments LabVIEW ${ }^{\text {TM }}$ software version 17.0 was used to capture deflection data.

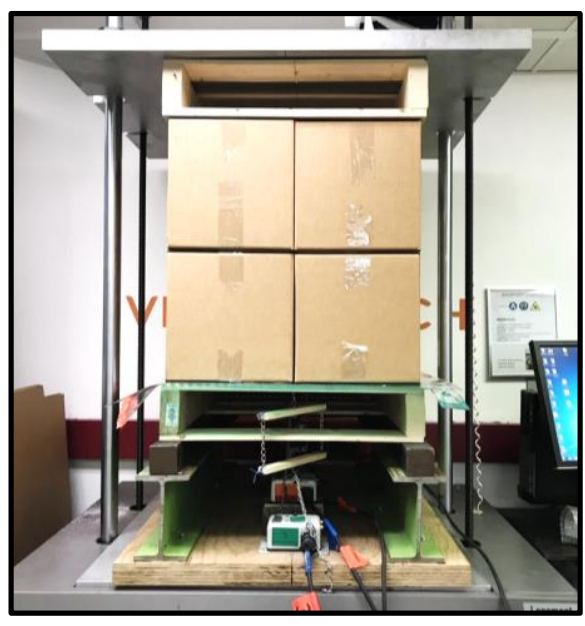

A

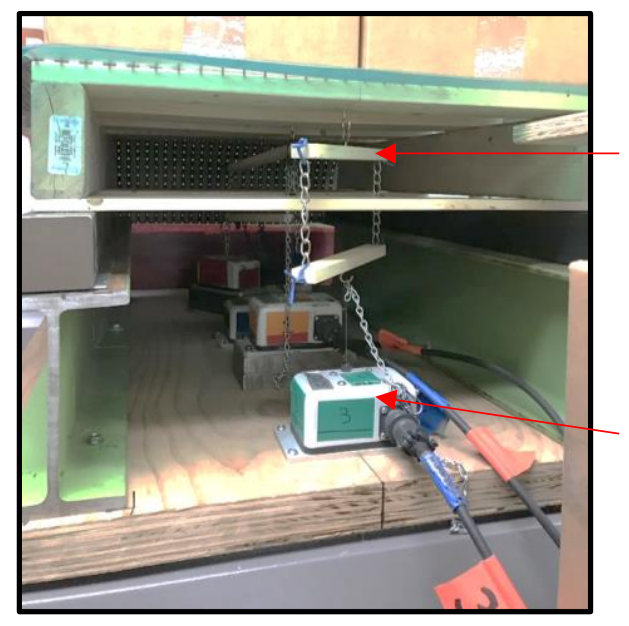

B
Connecting

Device

String

Potentiometer

Figure 27 Experimental setup for the measurement of the deckboard deflection.

The deflections of the first three top deckboards and the third bottom deckboard were measured. The measurement locations (Figure 28) were at the center of each deckboard span, 10 in. from the deckboard end. Since the lead top deckboard and the third top deckboard were directly above corresponding bottom deckboards, a connecting device was developed and used (Figure 27 B) to work around the bottom deckboard and capture only the deflection of the top deckboards. 

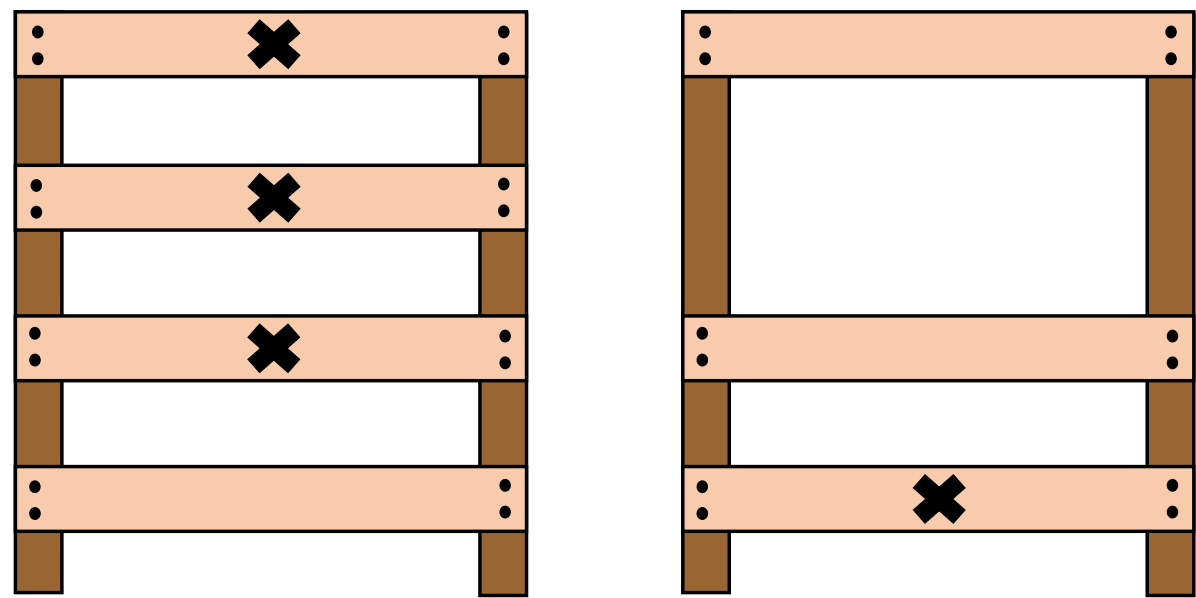

Figure 28 Deflection measurement locations

\subsubsection{Measurement of pallet stiffness}

The composite stiffness of the pallet top deck was measured by a 3-point bending test using a Lansmont Squeezer fixed platen compression tester equipped with a 5,000 lb load cell compressing at a rate of $0.5 \mathrm{in} . /$ minute. A steel cylinder with a 2 in. diameter connected to a 2 in. wide steel plate was used to apply load to the top deck in the middle of the deckboard span (Figure 29). Pallet stiffness was recorded after every four compression tests for each pallet section to investigate stiffness changes from continual loading.

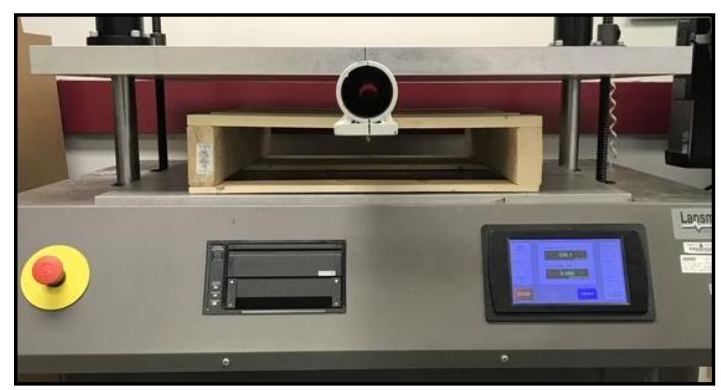

Figure 29 Experimental setup for measuring pallet stiffness.

\subsubsection{Unit load cost survey}

Three pallet suppliers and three box suppliers were surveyed to discover an estimated average total unit load cost. Pallet suppliers were asked for a quote, including volume discounts for 1 million pallets per year; the quote was for three non-reversable, two-way, stringer class wooden pallets with 12 deckboards made of SPF. The pallet designs differed only in deckboard thickness (0.375 in., 0.625 in., and 0.75 in.). Box suppliers were also asked for a quote, including 
volume discounts for 48 million boxes per year; the quote was for four Regular Slotted Container (RSC) style corrugated box designs with external dimensions of 16 in. x 9.75 in. $x 10$ in. The quoted box designs were to be made with both B-flute and C-flute corrugated boards with nominal $32 \mathrm{lb} / \mathrm{in}$. and $40 \mathrm{lb} / \mathrm{in}$. ECT grade.

\subsection{Experimental Design}

\subsubsection{Experimental design for asymmetric testing}

During the study, two box sizes, two corrugated board types, and four deckboard thicknesses were investigated to determine the effect of pallet stiffness on box compression strength. Ten replicate tests were conducted for each variable. The experimental design is presented in Table 8.

Table 8 Experimental design of project.

\begin{tabular}{c|c|c|c|c}
\hline \multirow{2}{*}{$\begin{array}{c}\text { Deckboard } \\
\text { Thickness }\end{array}$} & \multicolumn{4}{|c}{ Corrugated Box Types } \\
\cline { 2 - 5 } (in.) & \multicolumn{2}{|c}{ B - Flute } & \multicolumn{2}{c}{ C - Flute } \\
\cline { 2 - 5 } & Small Size & Large Size & Small Size & Large Size \\
\hline 0.375 & 10 & 10 & $10^{*}$ & 10 \\
0.500 & 10 & 10 & $10^{*}$ & 10 \\
0.625 & 10 & 10 & $10^{*}$ & 10 \\
0.750 & 10 & 10 & $10^{*}$ & 10
\end{tabular}

*Top deckboard deflection was recorded

The experiment was set up as a randomized complete block design with one treatment (pallet stiffness) and two blocking factors (box size and flute size). There were four levels of the treatment (pallet stiffness). All treatment and block combinations were replicated 10 times.

The data was analyzed in SAS JMP Pro 14® software (SAS Enterprises, Raleigh, NC). A one-way analysis of variance (ANOVA) with a significance level of 0.05 was conducted on the randomized complete block design to investigate if the pallet stiffness has an effect on box compression strength. Tukey's Honest Significant Difference (HSD) with a significance level of 0.05 was used as a multiple comparison test to find any significant differences between box compression strengths at different pallet stiffnesses. Equation $\mathbf{5}$ is the statistical model for the experiment.

$$
y_{i j k}=\mu+\alpha_{i}+\beta_{j}+\gamma_{k}+\varepsilon_{i j k}
$$

Equation 5 Model used for box compression strength

- $y_{i j k}=$ is the box compression strength given the pallet stiffness, box size and flute size

- $\quad \mu=$ grand mean response 
- $\quad \alpha_{i}=$ is the effect of the $i^{\text {th }}$ level of pallet stiffness treatment

- $\beta_{j}=$ effect of $j^{\text {th }}$ level of box type blocking factor

- $\quad \gamma_{k}=$ effect of $k^{\text {th }}$ level of flute type blocking factor

- $\varepsilon_{i j k}=$ unexplained random error

\subsubsection{Experimental design for unit load cost survey}

Three pallet suppliers and three box suppliers were surveyed to estimate an average total unit load cost. Four different corrugated board grades (nominal 32 lb/in. ECT B, 40 lb/in. ECT B, 32 lb/in. ECT C, 40 lb/in. ECT C) and three different pallet top deck thicknesses (0.375 in., 0.625 in., and 0.75 in.) were quoted from each box or pallet supplier. 


\section{Chapter 4 - Results and Discussion}

\subsection{The effect of top deck pallet stiffness on box compression strength}

Compression strength measurements for boxes compressed on varied deckboard thicknesses are presented in Table 9 and Figure 32. A One-way Analysis of Variance (ANOVA) test using a randomized complete block design (RCBD) concluded that pallet stiffness has a significant effect on box compression strength regardless of box size or flute type tested (p-value $<0.0001$ ) at a significance level of 0.05 . When the pallet top deck stiffness increased, the compression strength of corrugated boxes increased as well.

Table 9 Average box compression strength of asymmetrically supported corrugated boxes supported on pallets with different top deck stiffnesses.

\begin{tabular}{|c|c|c|c|c|}
\hline $\begin{array}{c}\text { Board } \\
\text { Type }\end{array}$ & Box Size & $\begin{array}{c}\text { Pallet } \\
\text { Stiffness }\end{array}$ & $\begin{array}{l}\text { Compression } \\
\text { Strength (lb) }\end{array}$ & Strength Increase \\
\hline \multirow{2}{*}{ B } & Small & $\begin{array}{c}\text { Low } \\
\text { Medium } \\
\text { Medium-High } \\
\text { High }\end{array}$ & $\begin{array}{c}263(9) \\
301(4) \\
307(12) \\
360(10)\end{array}$ & $\begin{array}{c}- \\
14 \% \\
17 \% \\
37 \% \\
\end{array}$ \\
\hline & Large & $\begin{array}{c}\text { Low } \\
\text { Medium } \\
\text { Medium-High } \\
\text { High }\end{array}$ & $\begin{array}{l}276(7) \\
314(2) \\
330(7) \\
360(3)\end{array}$ & $\begin{array}{c}- \\
14 \% \\
20 \% \\
30 \%\end{array}$ \\
\hline \multirow{2}{*}{$\mathrm{C}$} & Small & $\begin{array}{c}\text { Low } \\
\text { Medium } \\
\text { Medium-High } \\
\text { High }\end{array}$ & $\begin{array}{l}332(12) \\
395(17) \\
415(11) \\
450(14)\end{array}$ & $\begin{array}{c}- \\
19 \% \\
25 \% \\
36 \% \\
\end{array}$ \\
\hline & Large & $\begin{array}{c}\text { Low } \\
\text { Medium } \\
\text { Medium-High } \\
\text { High }\end{array}$ & $\begin{array}{l}340(8) \\
402(6) \\
415(8) \\
431(4)\end{array}$ & $\begin{array}{c}- \\
18 \% \\
22 \% \\
27 \%\end{array}$ \\
\hline
\end{tabular}




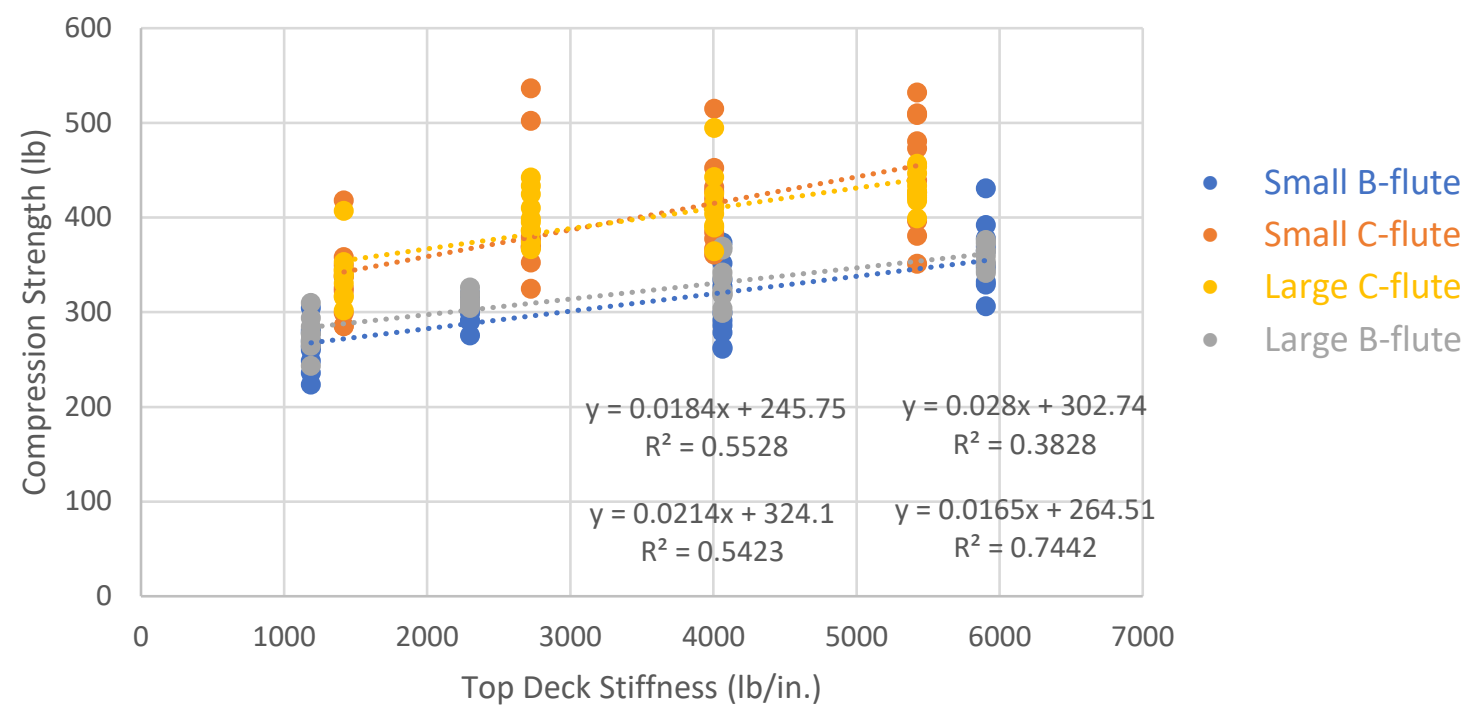

Figure 30 Observed compression strengths of all replicates from four box types in response to pallet top deck stiffness

Figure 30 represents box compression strength in response to a change in pallet top deck stiffness. A linear regression equation was produced to describe the relationship between pallet top deck stiffness and box compression strength for each of the box types tested. An increase of $100 \%$ in top deck stiffness results in a $5.87 \%, 6.19 \%, 6.96 \%$ and $8.47 \%$ increase in box compression performance for large $\mathrm{B}$, large $\mathrm{C}$, small $\mathrm{B}$ and small C-flute boxes respectively.

There was low variation among the responses to pallet stiffness between the different box sizes within a flute type. The two box sizes resulted in a similar compression strength and a similar spread of data. A trend can be observed in the data where there is a natural separation of box compression strength dependent on the flute type used. Therefore, an additional approach was taken to describe the relationship between box compression strength and pallet top deck stiffness.

In Figure 31, the results were only separated based on the flute type to better generalize the response of compression strength. Two linear regression equations, one for B-flute boxes and another for C-flute boxes, were produced to fit the data. Increasing the top deck stiffness by $100 \%$ results in a $6.38 \%$ and $7.31 \%$ increase in box compression performance for $\mathrm{B}$ and $\mathrm{C}$-flute boxes respectively. To strengthen these models, more box compression strength observations at different pallet top deck stiffnesses should be completed. 


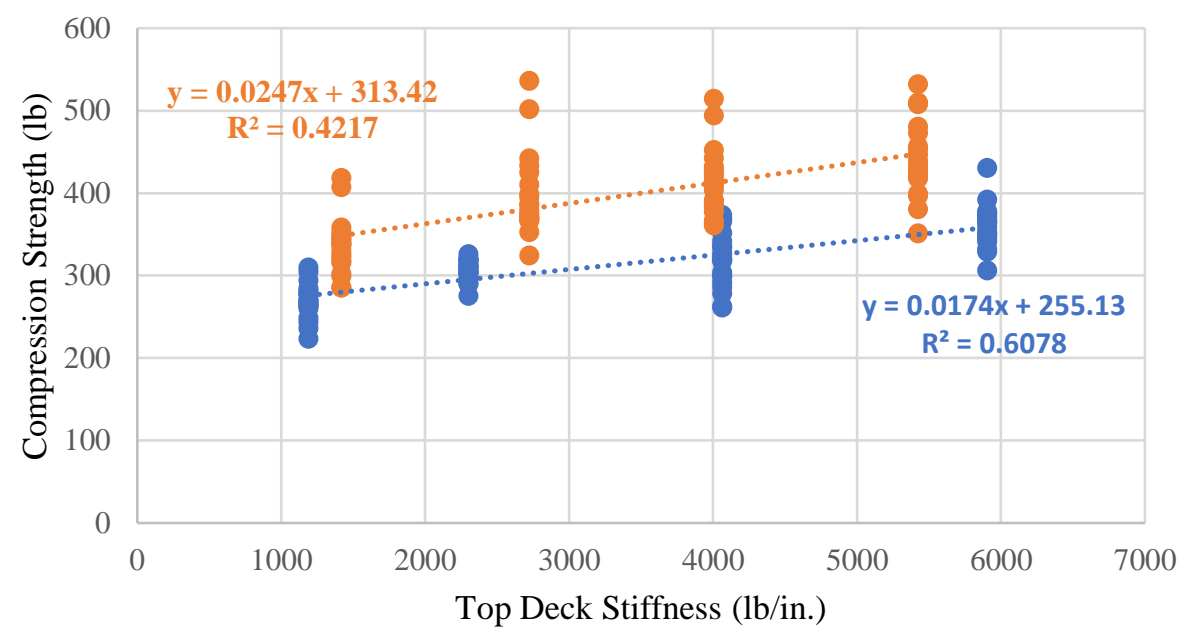

- B-flute C-flute ........ Linear (B-flute) $\ldots . . .$. ... Linear (C-flute)

Figure 31 Observed compression strengths separated by flute size in response to pallet top deck stiffness

$$
\square \text { Low } \square \text { Medium } \quad \text { Medium-High } \quad \square \text { High }
$$

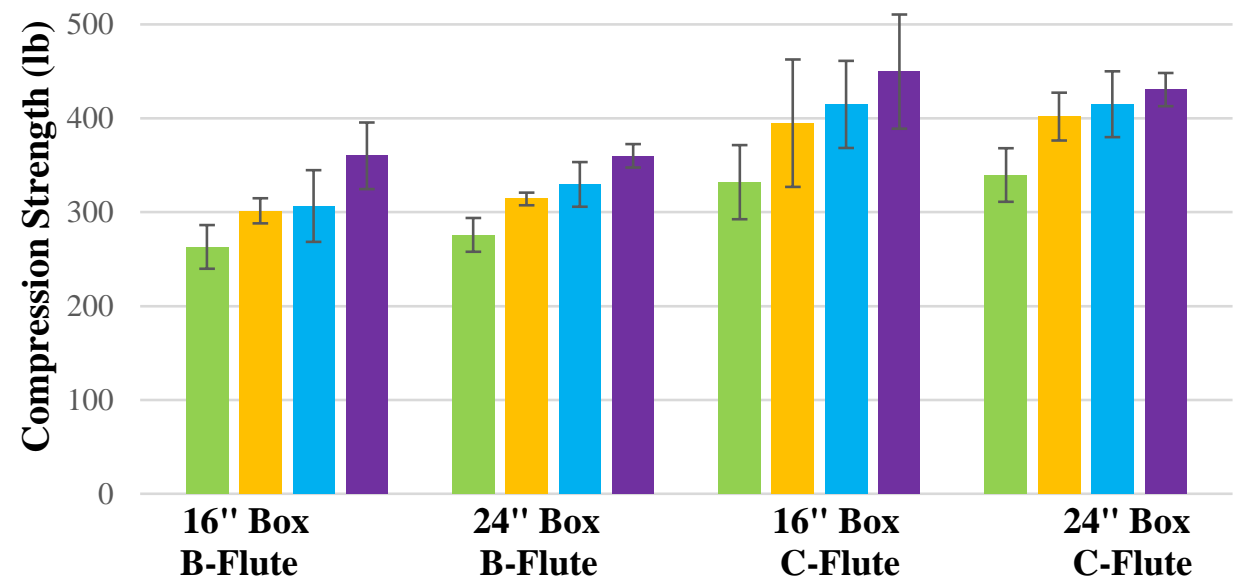

Figure 32 Average box compression strength of asymmetrically supported boxes supported on pallets with different top deck stiffnesses

For small-sized boxes tested, there was a $17 \%$ increase in strength for B-flute and a $20 \%$ increase for C-flute boxes when moving from low to medium-high pallet top deck stiffness. Comparing boxes on low to high stiffness pallets, there was a strength increase of $37 \%$ and $36 \%$ for B-flute and C-flute respectively. Similarly, the same trend was observed for the larger 
corrugated boxes; higher average box compression strength was observed when supported on a stiffer pallet.

The obtained results differed from the findings of Baker and Phanthanousy, who reported that the effect of pallet stiffness on box compression strength is not significant for pallet designs having deckboard gaps (Baker, 2016; Phanthanousy, 2017). The differences in the conclusions of these studies are most likely due to the way the box was supported on the pallet. In each previous experiment, the corrugated box tested for compression strength was placed on a pallet section between stringers where all box corners were supported similarly when the pallet section deflected. Meanwhile, in the present experiment an asymmetrical support condition was used; two corners of the box being tested were above the pallet stringers and the other two corners were located over the span between the stringers. In a different experiment, Baker also investigated the asymmetrical location for pallet designs with no deckboard gaps and reported there was an effect from pallet stiffness (Baker, 2016) which is consistent with the findings of the present study for a pallet containing deckboard gaps. The asymmetrical support and the resulting uneven pressure distribution to the side walls could have resulted in over stressing the box side walls that were supported by the stringers and could have caused a reduction in box compression strength for boxes that were supported on lower stiffness pallet top deckboards.

A summary of the multiple comparison tests of the compression strength responses at different levels of pallet top deck stiffnesses is presented in Table 10. The values represent an average compression strength of both box sizes and flute types when supported on pallets with different top deck stiffnesses.

Table 10 Average compression strength of all box types when supported on pallets with different top deck stiffness.

\begin{tabular}{c|c|c}
\hline $\begin{array}{c}\text { Pallet top deck } \\
\text { stiffness }\end{array}$ & $\begin{array}{c}\text { Average compression } \\
\text { strength (lb) }\end{array}$ & Tukey's HSD \\
\hline Low & $303(14)$ & $\mathrm{A}$ \\
Medium & $353(16)$ & $\mathrm{B}$ \\
Medium-High & $366(17)$ & $\mathrm{B}$ \\
High & $400(14)$ & $\mathrm{C}$
\end{tabular}

Note: Values in parentheses are coefficient of variation expressed as percentages for the average treatment effect. Compression strengths not connected by the same letter are statistically different determined by Tukey's HSD test at $\alpha=0.05$ significance level.

Overall, the average compression strength of the boxes supported on low and high stiffness pallets was significantly different from each other and also different from boxes 
supported on medium and medium-high pallets. The compression strength of the boxes supported on medium and medium-high stiffness pallets were statistically the same.

\subsection{Pallet deflection results}

The differences in compression strengths for identical boxes can be attributed to the level of bending in the pallet's top deck. Pallet deflection creates a surface of uneven pressure distribution between the pallet's top deck and the bottom layer of boxes (Yoo, 2011). A thicker deckboard, acting as a simply supported beam, deflects less than a thin deckboard under the same load (Rammer, 2010). The average deflections of the investigated pallets' segments loaded with small C-flute corrugated boxes are presented in Table 11. There were eight deflection measurements for pallets with medium and medium-high top deck stiffnesses instead of ten because there were invalid readings associated with the data recordings and zeroing string potentiometers. Tests weren't repeated because of material shortages.

The top deck stiffness testing had 10 observations for all levels of pallet stiffnesses because corrugated board material was not needed for this test's completion.

Table 11 Average bending performance of pallet sections.

\begin{tabular}{c|c|c|c|c}
\hline $\begin{array}{c}\text { Pallet top deck } \\
\text { stiffness }\end{array}$ & $\begin{array}{c}\text { Top } \\
\text { Deckboard } \\
\text { Thickness (in.) }\end{array}$ & $\begin{array}{c}\text { Measured stiffness } \\
\text { of pallet top deck } \\
\text { (lb/in.) }^{\text {a }}\end{array}$ & $\begin{array}{c}\text { Pallet top deck } \\
\text { deflection at 160 } \\
\text { lb top load (in.) }\end{array}$ & $\begin{array}{c}\text { Deflection at } \\
\text { box failure } \\
\text { (in.) }\end{array}$ \\
\hline Low & 0.375 & $1418(3), 1192(1)$ & $0.056(16)$ & $0.208(10)$ \\
Medium & 0.500 & $2723(1), 2305(1)$ & $0.045(7)$ & $0.183(12)$ \\
Medium-High & 0.625 & $4004(1), 4028(2)$ & $0.030(12)$ & $0.156(13)$ \\
High & 0.750 & $5422(1), 6007(1)$ & $0.027(6)$ & $0.122(17)$
\end{tabular}

Note: Values in parentheses are coefficient of variation expressed as percentages

${ }^{a}$ Measured stiffness values were an average of five readings taken from load vs. deflection curves of 3-point bending tests performed on the different pallets after testing. First value is stiffness of pallets used for $C$-flute testing and second value is stiffness of pallets used for B-flute testing.

When $160 \mathrm{lb}$ of top load was added, the deflection of the pallet increased as the deck stiffness of the pallet top deck decreased. Twice as much deflection was measured for the lowest stiffness pallets in comparison to the highest stiffness pallets. The deflection measurement at box failure showed a similar trend. Since the boxes failed at varied load levels depending on the pallet, it was hypothesized that the deflection of the top deck at box failure might be similar because the higher loads observed for box failures on stiffer decks could have deflected the deckboards the same amount in comparison to the lower box failure loads on less stiff pallets. However, it was observed that there was still more deflection for the low stiffness pallet at box failure. 
The greater pallet deflection observed for the lower stiffness pallets results in a pallet top deck surface that unevenly supported the box corners. This could have contributed to the reduction of box compression strength. Meanwhile, the high stiffness pallets resemble a surface closer to complete rigidity which created more even support for the corrugated boxes and most likely increased the compression strength of the boxes. An example of the difference in pallet top deck deflection is presented in Figure 33.

Low and high stiffness pallet decks behave differently under compression and support the boxes differently. The pallets' top deck stiffness impacts a box's response to compression. Baker reported that there is more box deformation at failure and a lower apparent box stiffness for boxes carried by a low stiffness pallet (Baker, 2016), which could also contribute to the reduction in box compression strength.
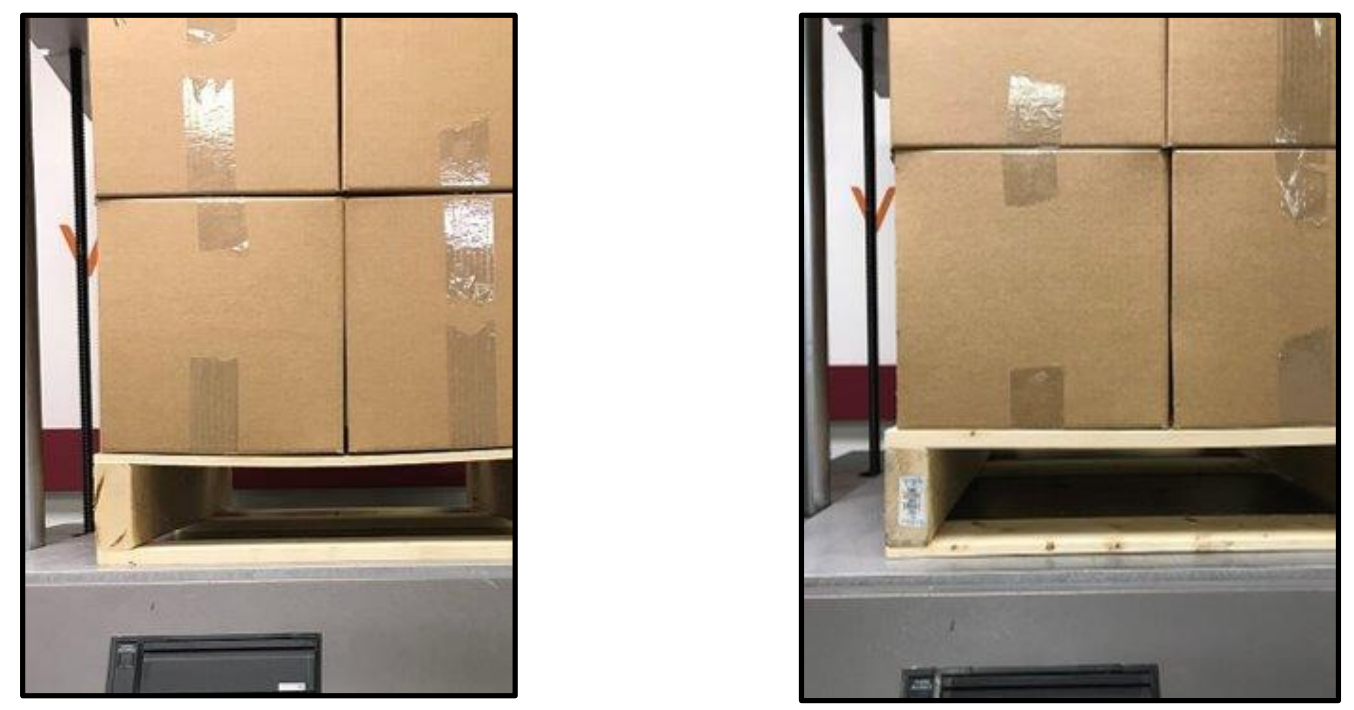

Figure 33 Low stiffness pallet deflection at box failure (left), medium-high stiffness pallet deflection at box failure (right).

\subsection{Pressure measurement results between pallet top deck and C-flute boxes}

Since the corners of a box structure support majority of the compression forces (Frank, 2014), investigating the pressure found at the corners can give insight into why there is a pallet top deck stiffness effect on box compression strength. The results of the percentage of total pressure found at the sidewalls supported above the two stringers and at the midspan of the deckboard are presented in Table $\mathbf{1 2}$. 
Table 12 Results of average total pressure above the pallet stringers and the midspan of deckboards.

\begin{tabular}{c|c|c|c|c|c|c}
\hline & \multicolumn{6}{|c}{ Percent of total pressure } \\
\hline $\begin{array}{c}\text { Pallet top } \\
\text { deck stiffness }\end{array}$ & \multicolumn{2}{|c|}{ Small Box C-Flute } & \multicolumn{3}{c}{ Large Box C-Flute } \\
\cline { 2 - 7 } & $\begin{array}{c}\text { Left } \\
\text { stringer }\end{array}$ & Midspan & $\begin{array}{c}\text { Right } \\
\text { stringer }\end{array}$ & $\begin{array}{c}\text { Left } \\
\text { stringer }\end{array}$ & Midspan & $\begin{array}{c}\text { Right } \\
\text { stringer }\end{array}$ \\
\hline Low & 26 & 18 & 25 & 24 & 23 & 26 \\
Medium & 24 & 24 & 19 & 22 & 26 & 21 \\
Medium-High & 24 & 27 & 14 & 20 & 27 & 18 \\
High & 21 & 26 & 17 & 19 & 29 & 18
\end{tabular}

There was an uneven compression stress distribution moving across the pallets' top decks for each pallet top deck stiffness scenario. (Figure 34). When the pressure on the pallets' top decks was investigated as a function of the pallet top deck stiffness, it was found that more pressure is shifted from the midspan to the stringers of low stiffness pallets' top decks. The same phenomenon was observed for both investigated C-flute box sizes. Also, a higher percentage of pressure was observed above the midspan location of the high stiffness pallets in comparison to low stiffness. The pressure distribution for the small and large boxes on pallets with low and high top deck stiffnesses are presented in Figure 35 and Figure 36. The results correlate with the finding of Yoo and Baker (Yoo, 2011; Baker, 2016) who found that reducing the pallet top deck stiffness results in increased pressure concentration around the stringers. Further, Yoo reported that there were higher compression stresses observed on low stiffness pallets in comparison to high stiffness pallets. The higher percentage of total pressure located above the stringers of the low stiffness pallets, and higher intensity (Yoo, 2011), cause the two corners of the box to experience more stress than if that same box would be carried by a stiffer pallet. Therefore, the two corners above the stringers have to disproportionately carry the load on a low stiffness pallet resulting in the box failing at a lower overall load. In contrast, the stiffer pallets deflect less and resemble more of a rigid surface, ultimately creating more even loading of all box corners.

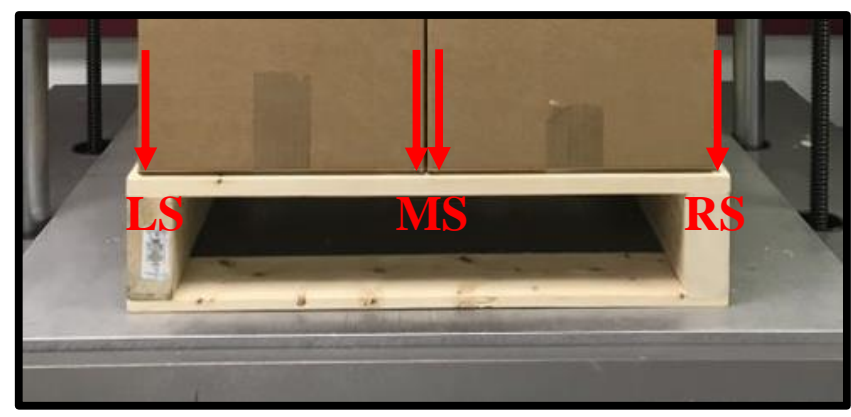

Figure 34 Locations of box sidewalls and resulting load transfer (LS - Left Stringer, MSMidspan, RS - Right Stringer). 


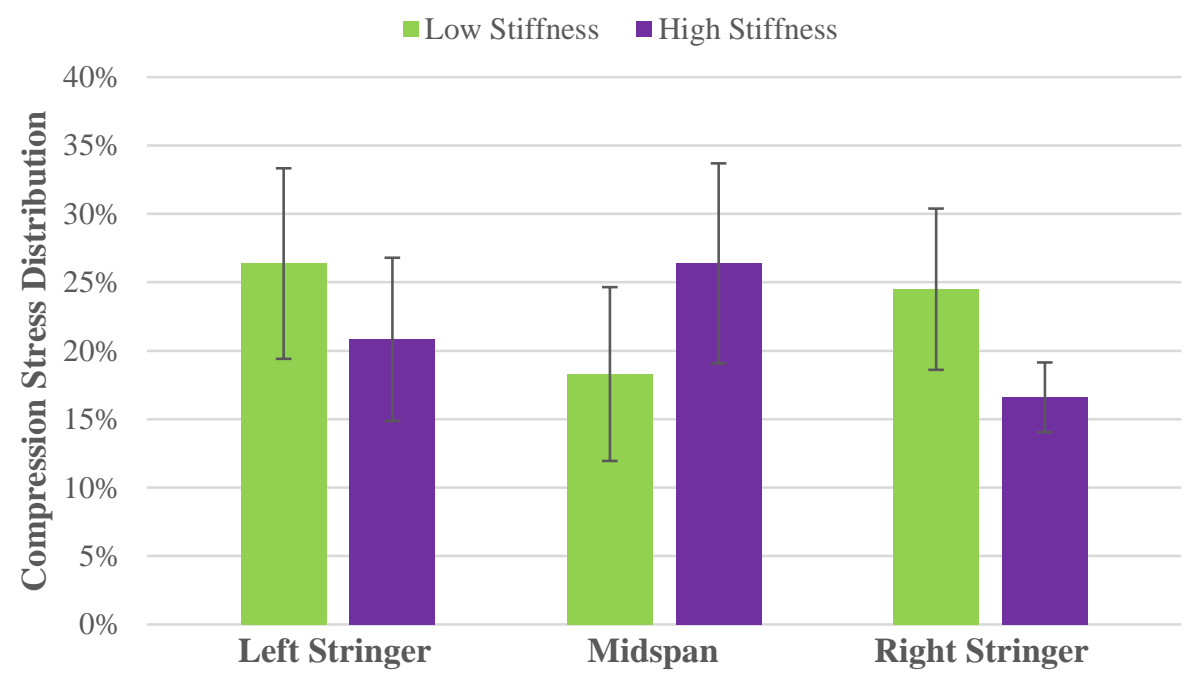

Figure 35 Pressure distribution for the small size C-flute corrugated boxes on pallets with low and high stiffness top decks.

Low Stiffness $\quad$ High Stiffness

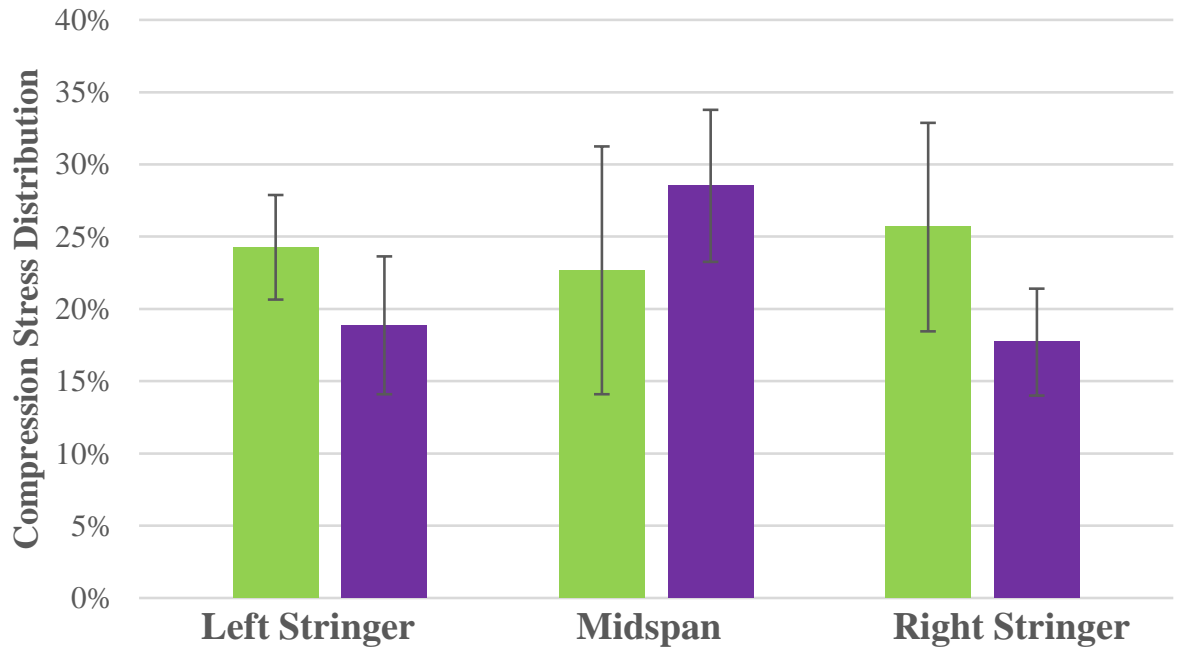

Figure 36 Pressure distribution for the large size C-flute corrugated boxes on pallets with low and high stiffness top decks.

\subsection{Cost analysis of designing unit loads with pallet stiffness in mind}

Three box suppliers and three pallet suppliers were surveyed to determine the total costs of hypothetical unit loads. The reasoning behind a cost analysis was to investigate potential cost savings from altering pallet top deck stiffness as an option for box designers to adjust box compression strength performance. 
The total cost of a unit load was calculated from the cost of boxes in the unit load summed with the cost of the pallet. Since a simulated $4 \times 4 \times 4$ box array in the unit load was tested, 48 boxes were assumed to be in the quoted unit load. Survey responses are in Table 13. According to suppliers, the average pallet cost is higher when deckboards are thicker and the average box cost is higher when the box has a higher ECT value. Additionally, switching box flute size from $\mathrm{B}$ to $\mathrm{C}$ at a similar ECT value results in a similar cost.

Table 13 Average quoted costs for unit load components

\begin{tabular}{c|c|c|c}
\hline \multicolumn{1}{c|}{16 in. $\mathbf{x} 10$ in. $\mathbf{x ~ 1 0}$ in. RSC box } & \multicolumn{2}{|c}{$\mathbf{4 8}$ in. $\mathbf{x} 40$ in. SPF stringer pallet } \\
\hline Box specification & Average cost & $\begin{array}{c}\text { Deckboard } \\
\text { thickness (in.) }\end{array}$ & Average cost \\
\hline 32 ECT B & $\$ 0.640$ & 0.375 & $\$ 9.82$ \\
40 ECT B & $\$ 0.713$ & 0.625 & $\$ 12.11$ \\
32 ECT C & $\$ 0.653$ & 0.750 & $\$ 13.04$ \\
40 ECT C & $\$ 0.739$ & &
\end{tabular}

A certain box compression strength of a palletized box can be attained by designing the unit load in multiple ways. Conventionally, the means of changing the compression strength of boxes is by adjusting board grade and flute type. Using a systems-based design methodology (White \& Hamner, 2005) by utilizing the pallet top deck stiffness effect on box compression performance, it is possible to deliver similar changes to compression strength without changing the boxes' cost. Using the McKee equation for predicting box compression strength, if the designer would increase the board grade from nominal $32 \mathrm{lb} / \mathrm{in}$. ECT to nominal $40 \mathrm{lb} / \mathrm{in}$. ECT Cflute on a low stiffness pallet, it would result in a $25 \%$ increase in box compression strength. However, based on the results presented in this study, the same increase in compression strength could be obtained for a nominal $32 \mathrm{lb} / \mathrm{in}$. ECT C-flute box if the thickness of the pallets' top deckboards is increased from 0.375 in. (low stiffness) to 0.625 in. (medium-high stiffness) which was a measured $175 \%$ increase in stiffness. Both approaches result in a $25 \%$ compression strength gain, but one design changes the box cost and the other design changes the pallet cost.

Changing the pallet cost instead of the box cost will result in a $\$ 1.84$ savings per unit load which could add up to $\$ 1,840,000$ in savings per year for companies who use a million pallets in their supply chain. Furthermore, when the top deck thickness was increased to 0.75 in. (high stiffness), a $36 \%$ increase in compression strength was measured in this study. Switching the deckboard thickness to 0.75 in. increased compression performance by more than what a switch to nominal $40 \mathrm{lb} / \mathrm{in}$. ECT C on a low stiffness pallet would provide, and there would still be savings of $\$ 0.91$ per unit load. 
The same scenario was also investigated using B-flute boxes. If a box designer increased board grade from nominal $32 \mathrm{lb} / \mathrm{in}$. ECT B-flute to $40 \mathrm{lb} / \mathrm{in}$. ECT B-flute on a low stiffness pallet, then a $25 \%$ increase in box compression strength would be expected based on the McKee equation. However, increasing the top deckboard thickness from 0.375 in. (low stiffness) to 0.75 in. (high stiffness) resulted in a $37 \%$ increase in box compression strength during the study. A higher box compression strength was achieved by using thicker pallet deckboards in comparison to switching the board grade of the box, and similar to the C-flute scenario, changing the pallet was the cheaper option to adjust box compression strength; $\$ 0.28$ per unit load could be saved. The financial information for each unit load design can be found in Table 14.

Table 14 Average unit load costs of multiple unit load designs.

\begin{tabular}{|c|c|c|c|c|c|c|}
\hline $\begin{array}{c}\text { Box } \\
\text { Specification }\end{array}$ & $\begin{array}{c}\text { Pallet } \\
\text { Top } \\
\text { Deck }\end{array}$ & $\begin{array}{c}\text { Average } \\
\text { Corrugated } \\
\text { Box Cost } \\
\mathbf{4 8} \text { Boxes) }\end{array}$ & $\begin{array}{c}\text { Average } \\
\text { Pallet } \\
\text { Cost }(\mathbf{1} \\
\text { pallet) }\end{array}$ & $\begin{array}{c}\text { Unit } \\
\text { Load } \\
\text { Cost }\end{array}$ & $\begin{array}{c}\text { Savings } \\
\text { per unit } \\
\text { load }\end{array}$ & $\begin{array}{c}\text { Savings } \\
\text { per million } \\
\text { unit loads }\end{array}$ \\
\hline $\begin{array}{c}40 \text { ECT C- } \\
\text { flute }\end{array}$ & 0.375 in. & $\$ 35.47$ & $\$ 9.82$ & $\$ 45.29$ & - & - \\
\hline $\begin{array}{c}32 \text { ECT C- } \\
\text { flute }\end{array}$ & 0.675 in. & $\$ 31.34$ & $\$ 12.11$ & $\$ 43.45$ & $-\$ 1.84$ & $\$ 1,840,000$ \\
\hline $\begin{array}{c}32 \text { ECT C- } \\
\text { flute }\end{array}$ & 0.750 in. & $\$ 31.34$ & $\$ 13.04$ & $\$ 44.38$ & $-\$ 0.91$ & $\$ 910,000$ \\
\hline $\begin{array}{c}40 \text { ECT B- } \\
\text { flute }\end{array}$ & 0.375 in. & $\$ 34.22$ & $\$ 9.82$ & $\$ 44.04$ & - & - \\
\hline $\begin{array}{c}32 \text { ECT B- } \\
\text { flute }\end{array}$ & 0.750 in. & $\$ 30.72$ & $\$ 13.04$ & $\$ 43.76$ & $-\$ 0.28$ & $\$ 280,000$ \\
\hline
\end{tabular}

When boxes are supported by a stiffer pallet, the boxes in both scenarios have compression performance similar to, or greater than, if a box's board grade was changed. Furthermore, the overall cost of the unit loads with stiffer deckboards are similar or even less expensive, according to this study. For the presented scenario, box designers have the option to upgrade compression performance, reduce total cost, or both when designing boxes by keeping pallet stiffness in mind.

When a corrugated box is designed specifically for unitized handling, changing the pallet top deck stiffness becomes an option to increase the box performance while possibly decreasing the overall cost. There are unit load cost savings because changing the pallet top deck stiffness (changing one unit load component) to affect box compression performance is, in some cases, cheaper than changing the board grade of the box (changing multiple components). The cost of 
changing the boxes' board grade is a multiplied effect based on how many boxes comprise the unit load. Using a stiffer pallet becomes the more cost-effective option when a unit load has a higher number of boxes, either by having many layers or by using smaller box sizes.

Additionally, the average pallet price reported was the initial purchase price of the pallet. The initial price doesn't account for the lifespan of the pallet. If a company has control over their supply chain, and they can reuse their purchased pallets for future unit loads, the initial price accounted for in the overall unit load cost decreases by the number of life cycles of the pallet. A stiffer pallet, utilizing thicker deckboards, is more durable during handling compared to the same design with thinner deckboards and this results in a longer lifespan (Weigel, 1998). Companies that are more likely to recycle rather than reuse their pallets could still experience cost savings by using stiffer pallets because more durable pallets will have less deckboard damages that would result in a higher recycling price. Using more durable pallets also could create an added benefit for the company by reducing the chance that the pallet gets broken during shipping and handling which could potentially reduce down time and also reduce the chance for product damage.

However, in some cases, a corrugated box is designed for other distribution hazards besides vertical compression forces from stacking. For example, using a higher board is an effective measure to protect against damages from manual handling. In these situations, changing the pallet design to manipulate box compression strength might not be the right approach because the design of the box is not driven by its compression strength on the pallet.

Overall, the study revealed that box designers should be aware of the variability of pallet top deck stiffnesses and how it can impact the compression performance of boxes shipped on pallets. A box could be shipped on many different pallets throughout the distribution process, but ultimately, the lowest pallet top deck stiffness will have the largest impact on compression performance of asymmetrically supported boxes. Designers could use pallet top deck stiffnesses to their advantage as an option for cost cutting or redesigning unit loads to achieve better performance. 


\section{Chapter 5 - Conclusion}

After analyzing the results of box compression strength for four different box types carried by four pallet deck stiffnesses, the following conclusions were made:

1) There was a significant effect of pallet top deck stiffness on box compression strength for asymmetrically supported boxes; a box carried by a stiffer pallet has a higher compression strength. The effect of pallet top deck stiffness on box compression strength was significant regardless of flute and box size used.

2) The pallet stiffness had slightly smaller effect on the box compression strength of a Bflute corrugated box $(0.017 x)$ compared to the C-flute corrugated box $(0.0247 x)$. Meanwhile, the correlation was stronger for the B-flute corrugated box $\left(\mathrm{R}^{2}=0.6078\right)$ compared to the C-flute corrugated box $\left(\mathrm{R}^{2}=0.4217\right)$

3) The box compression strength was not significantly different between medium and medium-high stiffness pallets (0.5 in. and 0.625 in. deckboards).

4) When the pressure distribution on the top deck of the pallet was investigated for low stiffness pallets, it was observed that the pressure was greater on the box sidewall that was supported by the stringer compared to the sidewall that was just on the deckboard. This increase in pressure indicated an asymmetrical loading of the box sidewalls which could have been responsible for the reduction in box compression strength for boxes supported on lower stiffness pallets.

5) It was found that for some cases increasing the compression strength of the box by changing the top deck stiffness of the pallet instead of changing the board grade of the box can reduce the overall unit load packaging cost. For example, increasing the pallet top deck stiffness by $175 \%$ (using $0.625 \mathrm{in}$. instead of $0.375 \mathrm{in}$. deckboards) for a nominal $32 \mathrm{lb} /$ in. ECT C-flute corrugated box for a unit load composed of 48 corrugated boxes, resulted in a $\$ 1.84$ savings per unit load compared to increasing the board grade to nominal $40 \mathrm{lb} / \mathrm{in}$. ECT C-flute without changing the pallet top deck thickness. 
The study revealed that the level of pallet top deck stiffness should be addressed during the box design process. Designers could use pallet top deck stiffness to their advantage as an option for cost cutting or redesigning corrugated boxes if they can control what pallets are being used for unit load shipment. The pallet top deck stiffness should be included as an adjustment factor for current design methodologies similar to other box-pallet factors such as pallet gaps, overhang, pallet pattern, and stacking alignment. 


\section{Chapter 6 - Recommendations for Future Research}

There is more to understand about pallet and unit load factors influencing corrugated box compression strength. In order to investigate pallet related factors further, the following recommendations for future studies have been made:

- An investigation using block class pallets would be valuable because block class pallets have an additional bending direction of the top deck during floor stacking which results in asymmetrical support along two axes, not just one.

- To further this study, box sizes that vary in width should be studied to understand at what point this effect goes away as box width increases. At some point, the box will be wide enough to bridge the deflecting top deckboards and will resemble more symmetrical support of the corners as the box width increases across the pallets' top deck.

- Most box compression tests are normally completed with single empty boxes, what happens if multiple boxes stretch-wrapped together are tested? They are commonly found in this form outside of testing. It would be interesting to observe if there is a strength effect from testing a stiffer unit. Do stretch-wrapped boxes have higher, lower, or the same compression strength than a single box during compression tests?

- Another variable to keep in mind is the effect of the bottom deck's stiffness of the top pallet in a double stacked unit load. Does the bottom deck stiffness change the load distribution during compression of double stacked unit loads?

- Additionally, an investigation into the pressure distribution of high stiffness pallets would be recommended. A higher percentage of pressure was observed at the midspan location in comparison to the location above the pallet stringers while a uniform pressure distribution was expected. 


\section{References}

AIAG. (2015). AIAG RC-9 Container Performance Test Guidelines. Automotive Industry Action Group, Southfield, Michigan.

ANSI MH1. (2016). Pallets, Slipsheets, and Other Bases for Unit Loads. Charlotte, NC: MH1 Secreteriat.

ASTM. (2009). D1185 - Standard test methods for pallets and related structures emplyed in materials handling and shipping. American Society for Testing and Materials, West Conshohocken, PA. doi:10.1520/D1185-98AR09

ASTM. (2015). D642 - Standard Test Method for Determining Compressive Resistance of Shipping Containers, Components, and Unit Loads. American Society for Testing andMaterials, West Conshohoken, PA. Retrieved 10 20, 2019

Baker, M. (2016). Effect of Pallet Stiffness and Unit Load Factors on Corrugated Box Compression Strength. Dissertation, Virginia Tech, Blacksburg, VA.

Campbell, A. (2010). THE USE OF A-FLUTE, B-FLUTE, AC-FLUTE, AND BC-FLUTE CORRUGATED PAPERBOARD AS A CUSHIONING MATERIAL. Thesis, Clemson University, Clemson, SC.

Carrano, A., Thorn, B., \& Woltag, H. (2014). Characterizing the Carbon Footprint of Wood Pallet Logistics. Forest Products Journal, 64(7/8), 232-241. doi:10.13073/FPJ-D-14-00011

Coles, M., McDowll, D., \& Kirwan, M. (2003). Food Packaging Technology. Boca Raton, FL: CRC Press LLC.

Collie, S. (1984). Laboratory verification of pallet design procedures. Thesis, Virginia Tech, Blacksburg, VA.

DiSalvo, M. (1999). Interaction effects of palletizing factors on fiberboard packaging strength. Thesis, San Jose State University, San Jose, CA.

Fagan, B. (1982). Load-support conditions and computerized test apparatus for wood pallets. Thesis, Virginia Tech, Blacksburg, VA.

Fibre Box Association. (2015). Fibre Box Handbook.

Fibre Box Association. (2016). Fibre Box Association Inudstry Annual Report. Fibre Box Association, Itasca, IL. Retrieved from www.fibrebox.org/upload/AnnualRpt/2016/AnnualReportNM.pdf

Forest Products Laboratory. (2010). Wood Handbook: Wood as an Engineering Material. Madison, Wisconson: U.S. Department of Agricutulture.

Forest Service. (1971). Wood Pallet Manufacturing. Forest Service, U.S. Department of Agriculture, Madison, WI. Retrieved 10 19, 2019

Frank, B. (2014). Corrugated Box Compression - A Literature Survey. Packaging Technology and Science, 27, 105-128. doi:10.1002/pts.2019

Frank, B., Gilgenbach, M., \& Maltenfort, M. (2010). Compression Testing to Simulate RealWorld Stresses. Packaging Technology and Science, 23(5), 275-282. doi:10.1002/pts

Gerber, N. (2018). Investigation of New and Recovered Wood Shipping Platforms in the United States. Thesis, Virginia Tech, Blacksburg, VA.

Glass, S., \& Zelinka, S. (2010). Moisture Relations and Physical Properties of Wood. In Wood Handbook: Wood as an Engineering Material (pp. 4-1). Madison, WI.

Heebrink, T. (1959). Load-Carrying Capacity of Deck Boards for General-Purpose Pallets. USDA Forest Products, Madison, WI.

Ievans, U. (1975). The effect of warehouse mishandling and stacking patterns on the compression strength of corrugated boxes. TAPPI, Vol: 58 (8) pp: 108-111.

ISO. (2011). 8611 - Pallets for materials handling - Flat pallets. International Standards Organization, Geneva, Switzerland. Retrieved 10 20, 2019

ISO. (2014). 6780 - Flat pallets for intercontiental materials handling - Principal dimensions and tolerances. Geneva, Switzerland. Retrieved 10 19, 2019 
Kaushal, M., Sirohiya, V., \& Rathore, R. (2015). Corrugated Board Structure: A Review. International Journal of Application of Engineering and Technology, 2(3), 228-234.

Kellicut, K. (1963). Load bearing surface on compressive strength and stacking life. TAPPI, Vol: 46 (1) $151-$.

Kellicut, K., \& Landt, E. (1958). Basic design data for use of fiberboard in shipping containers. Fibre Containers, 36(12), 62-80.

Kim, Y., Min, B., \& Won Kim, K. (2013). General Characteristics of Packaging Materials for Food System. In Innovations in Food Packaging: Second Edition (pp. 13-35). Elsevier Ltd. doi:10.1016/B978-0-12-394601-0.00002-3

Kretschmann, D. E. (2010). Mechanical Properties of Wood. In F. P. Laboratory, Wood Handbook: Wood as an Engineering Material (pp. 5-1 - 5-44). Madison, Wisconson: U.S. Department of Agriculture.

Landt, E., \& Kellicut, K. (1951). Safe stacking life of corrugated boxes. Fibre Containers, 36(9).

Laundrie, J. (1986). Unitized Goods on Pallets and Slipsheets. U.S. Department of Agriculture, Madison, WI. Retrieved 10 19, 2019

Leblanc, R., \& Richardson, S. (2003). Pallets: A north American Perspective. Ontario, Canada: Pacts Management Inc.

Maltenfort, G. (1988). Corrugated Shipping Containers. An Engineering Approach. Plainview, NY: Jelmar Publishing Co.

McCrea, B. (2017, September 5). The Pallet Report: Pallets help optimize operations, protect products and organize space. Retrieved from Modern Materials Handling: https://www.mmh.com/article/the_pallet_report_pallets_help_optimize_operations_prote ct_products_and_org

McKee, R., Gander, J., \& Wachuta, J. (1961). Edgewise compression strength of corrugated board. Institute of Paper Chemistry, Appleton, WI. Retrieved 10 20, 2019

Monaghan, J., \& Marcondes, J. (1992). Overhang and pallet gap effects on the performance of corrugated fiberboard boxes. Transactions of ASAE, Vol: 35 (6) 1945 -1947.

Montoya, E. (2017). Investigation of Pallet Stacking Pattern on Unit Load Bridging. Thesis, Virginia Tech, Blacksburg, VA.

Navaranjan, N., Dickson, A., Paltakari, J., \& Ilmonen, K. (2013). Humiditiy effect on compressive deformation and failure of recycled and virgin layered corrugated paperboard structures. Composites Part B: Engineering, 45(1), 965-971.

NWPCA. (1984). The Pallet Design System (PDS). Alexandria, Virginia, United States.

NWPCA. (2014). Uniform Wood Standard for Wood Pallets. National Wooden Pallet and Container Association Standards Committee, Alexandria, VA. Retrieved 10 19, 2019

Park, J. (2015). Investigation of Fundamental Relationships to Improve Sustainability of Unit Loads. Dissertation, Virginia Tech, Blacksburg, VA.

Phanthanousy, S. (2017). The effect of the stiffness of unit load components on pallet deflection and box compression strength. Thesis, Virginia Tech, Blacksburg, VA.

Raballand, G., \& Aldaz-Carroll, E. (2007). How Do Differing Standards Increase Trade Costs? The Case of Pallets. The World Economy, 30(4), 685-702. doi:10.1111/j.14679701.2007.01009.x

Rammer, D. (2010). Structural Analysis Equations. In Wood handbook: wood as an engineering material (pp. 9-1 - 9-11). Madison, WI.

Singh, J., Cernokus, E., Saha, K., \& Roy, S. (2014). The Effect of Stretch Wrap Prestretch on Unitized Load Containment. Packaging Technology and Science, 27(12), 944-961. doi:10.1002/pts.2083

Singh, J., Singh, P., \& Saha, K. (2011a). Effect of Horizontal Offset on Vertical Compression Strength of Stacked Corrugated Fiberboard Boxes. Journal of Applied Packaging Research, 5(3), 131-143. 
Singh, P., Singh, J., \& Saha, K. (2011b). Effect of Palletized Box Offset on Compression Strength of Unitized and Stacked Empty Corrugated Fiberboard Boxes. Journal of Applied Packaging Research, 5(3), 157-167. Retrieved 10 25, 2019, from https://digitalcommons.calpoly.edu/it_fac/67

Stott, R. (1959). Compression and stacking strength of corrugated fiberboard containers. APPITA, 13(2), 84-89.

TAPPI. (1985). Flexural Stiffness of Corrugated Board. Technical Association of Pulp and Paper Industry, Peachtree Corners, GA. Retrieved 10 20, 2019

TAPPI. (1997). T-808 Flat Crush Test. Technical Association of Pulp and Paper Industry, Peachtree Corners, GA. Retrieved 10 20, 2019

TAPPI. (2009). T-810 Bursting Strength of Corrugated Board. Technical Association of Pulp and Paper Industry, Peachtree Corners, GA. Retrieved 10 20, 2019

TAPPI. (2012a). T-804 Compression test of fiberboard shipping containers. Technical Association of Pulp and Paper Industry, Peachtree Corners, GA. Retrieved 10 20, 2019

TAPPI. (2012b). T-811 Edgewise compressive strength of corrugated fiberboard using the Morris method (short column test). Technical Association of Pulp and Paper Industry, Peachtree Corners, GA. Retrieved 10 20, 2019

TAPPI. (2012c). T-838 ECT Neckdown. Technical Association of Pulp and Paper Industry, Peachtree Corners, GA. Retrieved 10 20, 2019

TAPPI. (2012d). T-839 ECT Clamping Method. Technical Association of Pulp and Paper Industry, Peachtree Corners, GA. Retrieved 10 20, 2019

Twede, D., Selke, S., Kamdem, D., \& Shires, D. (2015). Cartons, Crates and Corrugated Board. Lancaster, Pennsylvania: DEStech Publications, Inc.

Weigel, T. G. (1998). Pep Study Summary: Data Applicable to The Development of an Updated Durability Analysis for PDS. Retrieved 12 18, 2019

White and Company. (2011). Best Pallet. Blacksburg, Virginia, United States.

White, M., \& Hamner, P. (2005). Pallets move the world: the case for developing system-based designs for unit loads. Forest Products Journal, Vol: 55 (3) pp: 8-16.

Whitsitt, W., \& McKee, R. (1972). Effect of relative humidity and temperature on stacking performance. Institute of Paper Chemistry, Appleton, WI.

Whittsitt, W., Gander, J., \& McKee, R. (1967). Stacking behavior of boxes and corrugated board. Appleton, WI.

Yoo, J. (2011). Modeling Compressive Stress Distributions at hte Interface between a Pallet Deck and Distribution Packaging. Dissertation, Blacksburg, VA. 


\section{Appendix A: Statistical Analysis}

Table 15 ANOVA results for the effect of pallet top deck stiffness on box compression strength of asymmetrically supported boxes

\begin{tabular}{|l|c|c|c|c|c|}
\hline Source & DF & $\begin{array}{c}\text { Sum of } \\
\text { Squares }\end{array}$ & Mean Square & F Ratio & Prob > F \\
\hline Pallet top deck stiffness & 3 & 5646.176 & 1882.059 & 54.0517 & $<.0001$ \\
\hline Error & 154 & 5362.22 & 34.8196 & & \\
\hline C. Total & 157 & 11008.40 & & & \\
\hline
\end{tabular}

\section{Appendix B: Experimental Data}

Table 16 Raw Compression Data

\begin{tabular}{|c|c|c|c|c|}
\hline $\begin{array}{l}\text { Flute } \\
\text { Size }\end{array}$ & $\begin{array}{l}\text { Box } \\
\text { Size }\end{array}$ & $\begin{array}{c}\text { Pallet } \\
\text { Stiffness }\end{array}$ & $\begin{array}{c}\text { Adjusted Compression } \\
\text { Strength (divide fail } \\
\text { value by } 2 \text { and add top } \\
\text { box weight) }\end{array}$ & Fail Value \\
\hline B & $16 "$ & $3 / 8^{\prime \prime}$ & 281.35 & 442.7 \\
\hline B & $16 "$ & $3 / 8^{\prime \prime}$ & 304.75 & 489.5 \\
\hline B & $16 "$ & $3 / 8^{\prime \prime}$ & 278.55 & 437.1 \\
\hline B & $16 "$ & $3 / 8 "$ & 262.7 & 405.4 \\
\hline B & $16 "$ & $3 / 8 "$ & 269.75 & 419.5 \\
\hline B & $16 "$ & $3 / 8 "$ & 264.45 & 408.9 \\
\hline $\mathrm{B}$ & $16 "$ & $3 / 8^{\prime \prime}$ & 248.75 & 377.5 \\
\hline $\mathrm{B}$ & $16^{\prime \prime}$ & $3 / 8^{\prime \prime}$ & 260.15 & 400.3 \\
\hline $\mathrm{B}$ & $16 "$ & $3 / 8^{\prime \prime}$ & 223.5 & 327 \\
\hline B & $16 "$ & $3 / 8 "$ & 236 & 352 \\
\hline B & $16 "$ & $4 / 8 "$ & 291.2 & 462.4 \\
\hline $\mathrm{B}$ & $16^{\prime \prime}$ & $4 / 8 "$ & 298.65 & 477.3 \\
\hline B & $16 "$ & $4 / 8 "$ & 304 & 488 \\
\hline B & $16 "$ & $4 / 8 "$ & 275.5 & 431 \\
\hline B & $16 "$ & $4 / 8 "$ & 317.35 & 514.7 \\
\hline B & $16^{\prime \prime}$ & $4 / 8^{\prime \prime}$ & 304.1 & 488.2 \\
\hline B & $16^{\prime \prime}$ & $4 / 8^{\prime \prime}$ & 289.85 & 459.7 \\
\hline $\mathrm{B}$ & $16^{\prime \prime}$ & $4 / 8 "$ & 303.6 & 487.2 \\
\hline B & $16^{\prime \prime}$ & $4 / 8 "$ & 310.4 & 500.8 \\
\hline B & $16 "$ & $4 / 8 "$ & 319.8 & 519.6 \\
\hline B & $16^{\prime \prime}$ & $5 / 8 "$ & 261.5 & 403 \\
\hline $\mathrm{B}$ & $16^{\prime \prime}$ & $5 / 8 "$ & 333.85 & 547.7 \\
\hline $\mathrm{B}$ & $16^{\prime \prime}$ & $5 / 8^{\prime \prime}$ & 351.75 & 583.5 \\
\hline B & $16 "$ & $5 / 8 "$ & 327 & 534 \\
\hline B & $16 "$ & $5 / 8 "$ & 278.55 & 437.1 \\
\hline B & $16^{\prime \prime}$ & $5 / 8 "$ & 299.15 & 478.3 \\
\hline B & $16 "$ & $5 / 8 "$ & 291.5 & 463 \\
\hline
\end{tabular}




\begin{tabular}{|c|c|c|c|c|}
\hline B & $16 "$ & $5 / 8 "$ & 373.5 & 627 \\
\hline B & $16 "$ & $5 / 8 "$ & 286.2 & 452.4 \\
\hline B & $16 "$ & $5 / 8 "$ & 262.6 & 405.2 \\
\hline B & $16 "$ & $6 / 8 "$ & 306.4 & 492.8 \\
\hline B & $16^{\prime \prime}$ & $6 / 8 "$ & 378.25 & 636.5 \\
\hline B & $16 "$ & $6 / 8 "$ & 332.25 & 544.5 \\
\hline B & $16 "$ & $6 / 8 "$ & 350.2 & 580.4 \\
\hline B & $16 "$ & 6/8" & 329.05 & 538.1 \\
\hline B & $16 "$ & 6/8" & 347.45 & 574.9 \\
\hline B & $16 "$ & $6 / 8 "$ & 430.7 & 741.4 \\
\hline B & $16 "$ & $6 / 8 "$ & 364.75 & 609.5 \\
\hline B & $16 "$ & $6 / 8 "$ & 392.25 & 664.5 \\
\hline B & $16 "$ & $6 / 8 "$ & 369.2 & 618.4 \\
\hline B & $24 "$ & $3 / 8 "$ & 270.8 & 391.6 \\
\hline B & $24 "$ & $3 / 8 "$ & 310 & 470 \\
\hline B & 24" & $3 / 8 "$ & 267.5 & 385 \\
\hline B & 24" & $3 / 8 "$ & 268.1 & 386.2 \\
\hline B & 24" & $3 / 8 "$ & 243.5 & 337 \\
\hline B & 24" & $3 / 8 "$ & 276.9 & 403.8 \\
\hline B & 24" & $3 / 8 "$ & 264.65 & 379.3 \\
\hline B & $24 "$ & $3 / 8 "$ & 277.85 & 405.7 \\
\hline B & $24 "$ & $3 / 8 "$ & 284.65 & 419.3 \\
\hline B & $24 "$ & $3 / 8 "$ & 294.15 & 438.3 \\
\hline B & $24 "$ & $4 / 8 "$ & 319.45 & 488.9 \\
\hline B & $24 "$ & $4 / 8 "$ & 318.65 & 487.3 \\
\hline B & $24 "$ & $4 / 8 "$ & 319.7 & 489.4 \\
\hline B & $24 "$ & $4 / 8^{\prime \prime}$ & 308.65 & 467.3 \\
\hline B & $24 "$ & $4 / 8 "$ & 304.75 & 459.5 \\
\hline B & $24 "$ & $4 / 8 "$ & 306.6 & 463.2 \\
\hline B & $24 "$ & $4 / 8 "$ & 312.4 & 474.8 \\
\hline B & $24 "$ & $4 / 8 "$ & 312.35 & 474.7 \\
\hline B & $24 "$ & $4 / 8 "$ & 326.1 & 502.2 \\
\hline B & $24 "$ & $4 / 8 "$ & 312.2 & 474.4 \\
\hline B & $24 "$ & $5 / 8 "$ & 366 & 582 \\
\hline B & $24 "$ & $5 / 8 "$ & 304 & 458 \\
\hline B & $24 "$ & $5 / 8 "$ & 317.8 & 485.6 \\
\hline B & $24 "$ & $5 / 8 "$ & 322.95 & 495.9 \\
\hline B & $24 "$ & $5 / 8 "$ & 319 & 488 \\
\hline B & 24" & $5 / 8 "$ & 319.45 & 488.9 \\
\hline B & $24 "$ & $5 / 8 "$ & 299.15 & 448.3 \\
\hline B & $24 "$ & $5 / 8 "$ & 369.45 & 588.9 \\
\hline B & $24 "$ & $5 / 8 "$ & 336.15 & 522.3 \\
\hline B & $24 "$ & $5 / 8 "$ & 341.9 & 533.8 \\
\hline
\end{tabular}




\begin{tabular}{|c|c|c|c|c|}
\hline B & $24 "$ & 6/8" & 353.25 & 556.5 \\
\hline B & 24" & $6 / 8 "$ & 372.25 & 594.5 \\
\hline B & 24" & $6 / 8 "$ & 344 & 538 \\
\hline B & 24" & $6 / 8 "$ & 350.1 & 550.2 \\
\hline B & $24 "$ & $6 / 8 "$ & 341.3 & 532.6 \\
\hline B & $24 "$ & $6 / 8 "$ & 359.6 & 569.2 \\
\hline B & $24 "$ & $6 / 8 "$ & 373.9 & 597.8 \\
\hline B & 24" & 6/8" & 364.8 & 579.6 \\
\hline B & 24" & 6/8" & 364.75 & 579.5 \\
\hline B & 24" & $6 / 8 "$ & 376.25 & 602.5 \\
\hline $\mathrm{C}$ & $16 "$ & $3 / 8 "$ & 285.6 & 421.2 \\
\hline $\mathrm{C}$ & $16 "$ & $3 / 8 "$ & 285.35 & 420.7 \\
\hline C & $16 "$ & $3 / 8 "$ & 322.6 & 495.2 \\
\hline C & $16 "$ & $3 / 8 "$ & 299.25 & 448.5 \\
\hline C & $16 "$ & $3 / 8 "$ & 358.25 & 566.5 \\
\hline C & $16 "$ & $3 / 8 "$ & 418.3 & 686.6 \\
\hline C & 16" & $3 / 8 "$ & 349.25 & 548.5 \\
\hline C & 16" & $3 / 8 "$ & 325.55 & 501.1 \\
\hline C & $16 "$ & $3 / 8 "$ & 337.25 & 524.5 \\
\hline C & $16 "$ & $3 / 8 "$ & 338.3 & 526.6 \\
\hline C & $16 "$ & $4 / 8 "$ & 375.95 & 601.9 \\
\hline C & $16 "$ & $4 / 8 "$ & 502.05 & 854.1 \\
\hline C & $16 "$ & $4 / 8 "$ & 379.35 & 608.7 \\
\hline C & $16 "$ & $4 / 8 "$ & 536.35 & 922.7 \\
\hline C & $16 "$ & $4 / 8 "$ & 368.7 & 587.4 \\
\hline $\mathrm{C}$ & $16^{\prime \prime}$ & $4 / 8 "$ & 370.6 & 591.2 \\
\hline $\mathrm{C}$ & $16 "$ & $4 / 8^{\prime \prime}$ & 369.4 & 588.8 \\
\hline $\mathrm{C}$ & $16 "$ & $4 / 8 "$ & 368.15 & 586.3 \\
\hline $\mathrm{C}$ & $16 "$ & $4 / 8 "$ & 352.6 & 555.2 \\
\hline C & $16 "$ & $4 / 8 "$ & 324.65 & 499.3 \\
\hline $\mathrm{C}$ & $16 "$ & $5 / 8 "$ & 360.75 & 571.5 \\
\hline $\mathrm{C}$ & 16" & $5 / 8 "$ & 377.65 & 605.3 \\
\hline $\mathrm{C}$ & 16" & $5 / 8 "$ & 452.25 & 754.5 \\
\hline $\mathrm{C}$ & 16" & $5 / 8 "$ & 427.9 & 705.8 \\
\hline $\mathrm{C}$ & 16" & $5 / 8 "$ & 514.7 & 879.4 \\
\hline $\mathrm{C}$ & 16" & $5 / 8 "$ & 432 & 714 \\
\hline $\mathrm{C}$ & $16 "$ & $5 / 8 "$ & 419.75 & 689.5 \\
\hline $\mathrm{C}$ & 16" & $5 / 8 "$ & 411.05 & 672.1 \\
\hline C & $16 "$ & $5 / 8 "$ & 384.75 & 619.5 \\
\hline C & $16 "$ & $5 / 8 "$ & 367 & 584 \\
\hline C & $16 "$ & 6/8" & 509.9 & 869.8 \\
\hline C & $16 "$ & $6 / 8 "$ & 532.2 & 914.4 \\
\hline $\mathrm{C}$ & $16^{\prime \prime}$ & $6 / 8 "$ & 508.1 & 866.2 \\
\hline
\end{tabular}




\begin{tabular}{|c|c|c|c|c|}
\hline $\mathrm{C}$ & $16 "$ & 6/8" & 472.95 & 795.9 \\
\hline C & $16 "$ & $6 / 8 "$ & 351.05 & 552.1 \\
\hline C & $16 "$ & $6 / 8 "$ & 480.45 & 810.9 \\
\hline C & $16 "$ & $6 / 8 "$ & 439.1 & 728.2 \\
\hline $\mathrm{C}$ & $16^{\prime \prime}$ & $6 / 8 "$ & 426.3 & 702.6 \\
\hline $\mathrm{C}$ & $16 "$ & $6 / 8 "$ & 380.75 & 611.5 \\
\hline C & $16 "$ & 6/8" & 396.5 & 643 \\
\hline C & 24" & $3 / 8 "$ & 302.05 & 434.1 \\
\hline C & 24" & $3 / 8 "$ & 330.6 & 491.2 \\
\hline $\mathrm{C}$ & 24" & $3 / 8 "$ & 345.1 & 520.2 \\
\hline $\mathrm{C}$ & 24" & $3 / 8 "$ & 338.6 & 507.2 \\
\hline $\mathrm{C}$ & 24" & $3 / 8 "$ & 317.4 & 464.8 \\
\hline C & $24 "$ & $3 / 8 "$ & 341.3 & 512.6 \\
\hline C & $24 "$ & $3 / 8 "$ & 344.8 & 519.6 \\
\hline C & $24 "$ & $3 / 8 "$ & 352.8 & 535.6 \\
\hline C & 24" & $3 / 8 "$ & 316.1 & 462.2 \\
\hline C & 24" & $3 / 8 "$ & 407.1 & 644.2 \\
\hline C & 24" & 4/8" & 386 & 602 \\
\hline C & 24" & $4 / 8 "$ & 373.55 & 577.1 \\
\hline C & 24" & $4 / 8 "$ & 398.9 & 627.8 \\
\hline C & $24 "$ & $4 / 8 "$ & 386.5 & 603 \\
\hline C & $24 "$ & $4 / 8 "$ & 410.35 & 650.7 \\
\hline C & $24 "$ & $4 / 8 "$ & 395.2 & 620.4 \\
\hline C & $24 "$ & $4 / 8 "$ & 433.7 & 697.4 \\
\hline C & $24 "$ & $4 / 8 "$ & 366.65 & 563.3 \\
\hline $\mathrm{C}$ & $24 "$ & $4 / 8 "$ & 442.45 & 714.9 \\
\hline $\mathrm{C}$ & $24 "$ & $4 / 8^{\prime \prime}$ & 424.8 & 679.6 \\
\hline $\mathrm{C}$ & $24 "$ & $5 / 8 "$ & 389.35 & 608.7 \\
\hline $\mathrm{C}$ & $24 "$ & $5 / 8 "$ & 404 & 638 \\
\hline $\mathrm{C}$ & $24 "$ & $5 / 8 "$ & 425.1 & 680.2 \\
\hline $\mathrm{C}$ & $24 "$ & $5 / 8 "$ & 412.75 & 655.5 \\
\hline $\mathrm{C}$ & $24 "$ & $5 / 8 "$ & 364.35 & 558.7 \\
\hline $\mathrm{C}$ & $24 "$ & $5 / 8 "$ & 391.9 & 613.8 \\
\hline $\mathrm{C}$ & $24 "$ & $5 / 8 "$ & 414.7 & 659.4 \\
\hline $\mathrm{C}$ & $24 "$ & $5 / 8 "$ & 410.6 & 651.2 \\
\hline $\mathrm{C}$ & $24 "$ & $5 / 8 "$ & 442.55 & 715.1 \\
\hline $\mathrm{C}$ & $24 "$ & $5 / 8 "$ & 494.45 & 818.9 \\
\hline $\mathrm{C}$ & $24 "$ & $6 / 8 "$ & 446.85 & 723.7 \\
\hline C & 24" & 6/8" & 423.4 & 676.8 \\
\hline $\mathrm{C}$ & $24 "$ & $6 / 8 "$ & 399.1 & 628.2 \\
\hline C & $24 "$ & $6 / 8 "$ & 427.35 & 684.7 \\
\hline C & 24" & $6 / 8 "$ & 417.85 & 665.7 \\
\hline $\mathrm{C}$ & $24 "$ & $6 / 8 "$ & 421.25 & 672.5 \\
\hline
\end{tabular}




\begin{tabular}{|c|c|c|c|c|}
\hline $\mathrm{C}$ & $24 "$ & $6 / 8 "$ & 456.75 & 743.5 \\
\hline $\mathrm{C}$ & $24 "$ & $6 / 8 "$ & 453.65 & 737.3 \\
\hline $\mathrm{C}$ & $24 "$ & $6 / 8 "$ & 433.5 & 697 \\
\hline $\mathrm{C}$ & $24 "$ & $6 / 8 "$ & 426.2 & 682.4 \\
\hline
\end{tabular}

Table 17 Raw Pressure Data

\begin{tabular}{|l|l|l|l|l|l|}
\hline $\begin{array}{l}\text { Box } \\
\text { Size }\end{array}$ & $\begin{array}{l}\text { Pallet } \\
\text { thickness }\end{array}$ & $\begin{array}{l}\text { Load } \\
\text { (lb) }\end{array}$ & $\begin{array}{l}\text { Left } \\
\text { Stringer }\end{array}$ & Center & $\begin{array}{l}\text { Right } \\
\text { Stringer }\end{array}$ \\
\hline $16 "$ & $3 / 8 "$ & 415 & $22 \%$ & $40 \%$ & $16 \%$ \\
\hline $16 "$ & $3 / 8 "$ & 415 & $23 \%$ & $36 \%$ & $29 \%$ \\
\hline $16 "$ & $3 / 8 "$ & 415 & $18 \%$ & $49 \%$ & $15 \%$ \\
\hline $16 "$ & $3 / 8 "$ & 415 & $39 \%$ & $39 \%$ & $19 \%$ \\
\hline $16 "$ & $3 / 8 "$ & 415 & $29 \%$ & $30 \%$ & $27 \%$ \\
\hline $16 "$ & $3 / 8 "$ & 415 & $29 \%$ & $27 \%$ & $31 \%$ \\
\hline $16 "$ & $3 / 8 "$ & 415 & $18 \%$ & $42 \%$ & $28 \%$ \\
\hline $16 "$ & $3 / 8 "$ & 415 & $23 \%$ & $38 \%$ & $30 \%$ \\
\hline $16 "$ & $3 / 8 "$ & 415 & $35 \%$ & $34 \%$ & $22 \%$ \\
\hline $16 "$ & $3 / 8 "$ & 415 & $28 \%$ & $31 \%$ & $26 \%$ \\
\hline $16 "$ & $4 / 8 "$ & 415 & $29 \%$ & $48 \%$ & $16 \%$ \\
\hline $16 "$ & $4 / 8 "$ & 415 & $26 \%$ & $50 \%$ & $16 \%$ \\
\hline $16 "$ & $4 / 8 "$ & 415 & $19 \%$ & $41 \%$ & $29 \%$ \\
\hline $16 "$ & $4 / 8 "$ & 415 & $20 \%$ & $57 \%$ & $18 \%$ \\
\hline $16 "$ & $4 / 8 "$ & 415 & $20 \%$ & $54 \%$ & $18 \%$ \\
\hline $16 "$ & $4 / 8 "$ & 415 & $21 \%$ & $48 \%$ & $24 \%$ \\
\hline $16 "$ & $4 / 8 "$ & 415 & $31 \%$ & $50 \%$ & $16 \%$ \\
\hline $16 "$ & $4 / 8 "$ & 415 & $17 \%$ & $45 \%$ & $25 \%$ \\
\hline $16 "$ & $4 / 8 "$ & 415 & $29 \%$ & $41 \%$ & $14 \%$ \\
\hline $16 "$ & $4 / 8 "$ & 415 & $24 \%$ & $46 \%$ & $17 \%$ \\
\hline $16 "$ & $5 / 8 "$ & 415 & $30 \%$ & $49 \%$ & $15 \%$ \\
\hline $16 "$ & $5 / 8 "$ & 415 & $23 \%$ & $56 \%$ & $12 \%$ \\
\hline $16 "$ & $5 / 8 "$ & 415 & $24 \%$ & $59 \%$ & $12 \%$ \\
\hline $16 "$ & $5 / 8 "$ & 415 & $25 \%$ & $48 \%$ & $13 \%$ \\
\hline $16 "$ & $5 / 8 "$ & 415 & $21 \%$ & $54 \%$ & $13 \%$ \\
\hline $16 "$ & $5 / 8 "$ & 415 & $21 \%$ & $55 \%$ & $12 \%$ \\
\hline $16 "$ & $5 / 8 "$ & 415 & $31 \%$ & $49 \%$ & $10 \%$ \\
\hline $16 "$ & $5 / 8 "$ & 415 & $22 \%$ & $48 \%$ & $18 \%$ \\
\hline $16 "$ & $5 / 8 "$ & 415 & $21 \%$ & $56 \%$ & $16 \%$ \\
\hline $16 "$ & $5 / 8 "$ & 415 & $23 \%$ & $58 \%$ & $16 \%$ \\
\hline $16 "$ & $6 / 8 "$ & 415 & $35 \%$ & $34 \%$ & $22 \%$ \\
\hline $16 "$ & $6 / 8 "$ & 415 & $19 \%$ & $54 \%$ & $16 \%$ \\
\hline $16 "$ & $6 / 8 "$ & 415 & $15 \%$ & $55 \%$ & $18 \%$ \\
\hline $16 "$ & $6 / 8 "$ & 415 & & $52 \%$ & $15 \%$ \\
\hline
\end{tabular}




\begin{tabular}{|c|c|c|c|c|c|}
\hline $16^{\prime \prime}$ & $6 / 8^{\prime \prime}$ & 415 & $21 \%$ & $61 \%$ & $15 \%$ \\
\hline 16" & $6 / 8 "$ & 415 & $18 \%$ & $54 \%$ & $16 \%$ \\
\hline $16^{\prime \prime}$ & $6 / 8^{\prime \prime}$ & 415 & $26 \%$ & $54 \%$ & $14 \%$ \\
\hline $16^{\prime \prime}$ & 6/8" & 415 & $19 \%$ & $52 \%$ & $17 \%$ \\
\hline 16" & $6 / 8 "$ & 415 & $14 \%$ & $52 \%$ & $19 \%$ \\
\hline 16" & $6 / 8 "$ & 415 & $21 \%$ & $59 \%$ & $13 \%$ \\
\hline $24 "$ & $3 / 8^{\prime \prime}$ & 430 & $28 \%$ & $34 \%$ & $32 \%$ \\
\hline $24^{\prime \prime}$ & $3 / 8^{\prime \prime}$ & 430 & $23 \%$ & $48 \%$ & $24 \%$ \\
\hline $24 "$ & $3 / 8^{\prime \prime}$ & 430 & $25 \%$ & $33 \%$ & $38 \%$ \\
\hline $24 "$ & 3/8" & 430 & $24 \%$ & $38 \%$ & $34 \%$ \\
\hline $24 "$ & $3 / 8^{\prime \prime}$ & 430 & $26 \%$ & $47 \%$ & $22 \%$ \\
\hline $24 "$ & $3 / 8^{\prime \prime}$ & 430 & $26 \%$ & $48 \%$ & $21 \%$ \\
\hline $24 "$ & $3 / 8^{\prime \prime}$ & 430 & $23 \%$ & $45 \%$ & $29 \%$ \\
\hline $24^{\prime \prime}$ & $3 / 8^{\prime \prime}$ & 430 & $30 \%$ & $50 \%$ & $18 \%$ \\
\hline $24 "$ & $3 / 8^{\prime \prime}$ & 430 & $24 \%$ & $62 \%$ & $17 \%$ \\
\hline $24^{\prime \prime}$ & $3 / 8^{\prime \prime}$ & 430 & $23 \%$ & $50 \%$ & $22 \%$ \\
\hline $24 "$ & $4 / 8^{\prime \prime}$ & 430 & $30 \%$ & $50 \%$ & $24 \%$ \\
\hline $24 "$ & $4 / 8^{\prime \prime}$ & 430 & $21 \%$ & $44 \%$ & $26 \%$ \\
\hline $24 "$ & $4 / 8 "$ & 430 & $19 \%$ & $54 \%$ & $20 \%$ \\
\hline $24^{\prime \prime}$ & $4 / 8^{\prime \prime}$ & 430 & $18 \%$ & $57 \%$ & $19 \%$ \\
\hline $24 "$ & $4 / 8 "$ & 430 & $27 \%$ & $48 \%$ & $19 \%$ \\
\hline $24^{\prime \prime}$ & $4 / 8 "$ & 430 & $26 \%$ & $42 \%$ & $27 \%$ \\
\hline $24 "$ & $4 / 8^{\prime \prime}$ & 430 & $24 \%$ & $62 \%$ & $15 \%$ \\
\hline $24 "$ & $4 / 8 "$ & 430 & $24 \%$ & $65 \%$ & $17 \%$ \\
\hline $24^{\prime \prime}$ & $4 / 8 "$ & 430 & $24 \%$ & $49 \%$ & $21 \%$ \\
\hline $24 "$ & $4 / 8^{\prime \prime}$ & 430 & $24 \%$ & $41 \%$ & $31 \%$ \\
\hline $24^{\prime \prime}$ & $5 / 8 "$ & 430 & $13 \%$ & $63 \%$ & $24 \%$ \\
\hline $24 "$ & $5 / 8 "$ & 430 & $27 \%$ & $43 \%$ & $25 \%$ \\
\hline $24 "$ & $5 / 8^{\prime \prime}$ & 430 & $23 \%$ & $43 \%$ & $26 \%$ \\
\hline $24 "$ & $5 / 8 "$ & 430 & $27 \%$ & $54 \%$ & $14 \%$ \\
\hline $24^{\prime \prime}$ & $5 / 8 "$ & 430 & $13 \%$ & $68 \%$ & $12 \%$ \\
\hline $24 "$ & $5 / 8^{\prime \prime}$ & 430 & $15 \%$ & $68 \%$ & $9 \%$ \\
\hline $24 "$ & $5 / 8 "$ & 430 & $25 \%$ & $39 \%$ & $29 \%$ \\
\hline $24 "$ & $5 / 8 "$ & 430 & $29 \%$ & $52 \%$ & $24 \%$ \\
\hline $24 "$ & $5 / 8^{\prime \prime}$ & 430 & $17 \%$ & $57 \%$ & $18 \%$ \\
\hline $24^{\prime \prime}$ & $5 / 8 "$ & 430 & $15 \%$ & $61 \%$ & $15 \%$ \\
\hline $24 "$ & $6 / 8^{\prime \prime}$ & 430 & $20 \%$ & $52 \%$ & $22 \%$ \\
\hline $24 "$ & $6 / 8 "$ & 430 & $13 \%$ & $62 \%$ & $24 \%$ \\
\hline $24 "$ & $6 / 8^{\prime \prime}$ & 430 & $24 \%$ & $58 \%$ & $21 \%$ \\
\hline $24 "$ & 6/8" & 430 & $19 \%$ & $64 \%$ & $13 \%$ \\
\hline $24 "$ & $6 / 8 "$ & 430 & $27 \%$ & $46 \%$ & $22 \%$ \\
\hline
\end{tabular}




\begin{tabular}{|l|l|l|l|l|l|}
\hline $24 "$ & $6 / 8 "$ & 430 & $25 \%$ & $58 \%$ & $13 \%$ \\
\hline $24 "$ & $6 / 8 "$ & 430 & $14 \%$ & $59 \%$ & $21 \%$ \\
\hline $24 "$ & $6 / 8 "$ & 430 & $15 \%$ & $56 \%$ & $19 \%$ \\
\hline $24 "$ & $6 / 8 "$ & 430 & $17 \%$ & $59 \%$ & $14 \%$ \\
\hline $24 "$ & $6 / 8 "$ & 430 & $23 \%$ & $54 \%$ & $17 \%$ \\
\hline
\end{tabular}

Table 18 Raw Deflection Results

\begin{tabular}{|c|c|c|c|c|}
\hline \multicolumn{5}{|c|}{ Deflection at 160lb top load } \\
\hline Rep & 3/8" & 4/8" & $5 / 8^{\prime \prime}$ & 6/8" \\
\hline 1 & 0.058 & 0.045 & 0.037 & 0.025 \\
\hline 2 & 0.064 & 0.046 & 0.03 & 0.029 \\
\hline 3 & 0.06 & 0.043 & 0.035 & 0.027 \\
\hline 4 & 0.044 & 0.049 & 0.028 & 0.025 \\
\hline 5 & 0.042 & 0.045 & 0.03 & 0.029 \\
\hline 6 & 0.062 & 0.039 & 0.026 & 0.027 \\
\hline 7 & 0.055 & 0.048 & 0.03 & 0.029 \\
\hline 8 & 0.065 & 0.044 & 0.03 & 0.026 \\
\hline 9 & Missed & Missed & 0.026 & 0.028 \\
\hline 10 & Missed & Missed & 0.028 & 0.025 \\
\hline \multicolumn{5}{|c|}{ Deflection at Box failure } \\
\hline Rep & 3/8" & 4/8" & $5 / 89$ & 6/8" \\
\hline 1 & 0.198 & 0.189 & 0.178 & 0.149 \\
\hline 2 & 0.252 & 0.212 & 0.147 & 0.155 \\
\hline 3 & 0.214 & 0.208 & 0.178 & 0.144 \\
\hline 4 & 0.187 & 0.175 & 0.167 & 0.13 \\
\hline 5 & 0.211 & 0.167 & 0.186 & 0.106 \\
\hline 6 & 0.209 & 0.152 & 0.148 & 0.106 \\
\hline 7 & 0.205 & 0.175 & 0.148 & 0.109 \\
\hline 8 & 0.186 & Missed & 0.128 & 0.102 \\
\hline 9 & Missed & Missed & 0.137 & 0.111 \\
\hline 10 & Missed & Missed & 0.138 & 0.111 \\
\hline
\end{tabular}

